Title:

\title{
Energy status-promoted growth and development of Arabidopsis require copper deficiency response transcriptional regulator SPL7
}

\begin{abstract}
Authors:
Anna Schulten ${ }^{1, \S}$, Björn Pietzenuk ${ }^{1}$, Julia Quintana ${ }^{1, \#}$, Marcus Krause ${ }^{1}$, Regina Feil ${ }^{2}$, Maida Romera-Branchat ${ }^{3, \$}$, Vanessa Wahl ${ }^{2}$, Edouard Severing ${ }^{3}$, George Coupland ${ }^{3}$, Ute Krämer ${ }^{1, *}$
\end{abstract}

${ }^{1}$ Department of Molecular Genetics and Physiology of Plants, Ruhr University Bochum, 44801 Bochum, Germany

${ }^{2}$ Max Planck Institute of Molecular Plant Physiology, 14476 Potsdam-Golm, Germany

${ }^{3}$ Max Planck Institute for Plant Breeding Research, 50829 Cologne, Germany

Present addresses: §John Innes Centre, Norwich NR4 7UH, UK; ${ }^{\#}$ Centro de

Biotecnología y Genómica de Plantas (UPM-INIA), Universidad Politécnica de Madrid, 28223 Pozuelo de Alarcón, Spain; ${ }^{\$}$ Faculty of Biology, University of Münster, 48149

Münster, Germany

*Address correspondence to Ute.Kraemer@ruhr-uni-bochum.de 


\section{Abstract}

2 Copper $(\mathrm{Cu})$ is a cofactor of around 300 Arabidopsis proteins including photosynthetic and mitochondrial electron transfer chain enzymes critical for ATP production and carbon fixation. Plant acclimation to $\mathrm{Cu}$ deficiency requires the transcription factor SQUAMOSA PROMOTER-BINDING PROTEIN-LIKE7 (SPL7). We report that in the wild type and in the spl7-1 mutant, respiratory electron flux via Cu-dependent cytochrome $c$ oxidase remained unaffected under both normal and low-Cu cultivation conditions. Contrary to the wild type, supplementing $\mathrm{Cu}$-deficient media with exogenous sugar failed to stimulate growth of sp/7-1. The sp/7-1 mutant accumulated carbohydrates including the signaling sugar trehalose 6-phosphate, as well as ATP and $\mathrm{NADH}$, also under normal Cu supply and without sugar supplementation. Late flowering of sp/7-1 was in agreement with its attenuated sugar responsiveness. Functional TOR and SnRK1 kinase signaling in spl7-1 suggested against fundamental defects in these energy-signaling hubs. Sequencing of chromatin immunoprecipitates combined with transcriptomics identified direct targets of SPL7-mediated positive regulation, including FE SUPEROXIDE DISMUTASE1 (FSD1),

COPPER-DEFICIENCY-INDUCED TRANSCRIPTION FACTOR1 (CITF1) and uncharacterized bHLH23 (CITF2), as well as an enriched upstream GTACTRC motif. In summary, transducing energy availability into growth and reproductive development requires the function of SPL7. Our results could help to increase crop yields, especially on Cu-deficient soils.

\section{Introduction}

As sessile organisms, plants depend on acquiring mineral nutrients from the soil solution through their roots. Several class B and borderline elements, which are often addressed as "transition metals" or simply "metals", for example iron (Fe), zinc (Zn), and copper $(\mathrm{Cu})$, are micronutrients required for the functions of numerous metalloproteins.

27 The plant metal homeostasis network operates to fulfill the demands of the metalloproteomes of different organs, tissues and cell types, as well as to counteract local accumulation of a toxic excess of any essential or chemically similar non-essential metal (Clemens, 2001; Krämer and Clemens, 2005). Many of the network components mediating metal acquisition, distribution, utilization and storage in plants were 
32 functionally characterized. We know less about regulatory components, for example 33 metal sensors, signal transduction pathways and proteins activating acclimation responses. Among the latter, several identified transcription factors mediate transcriptional responses to $\mathrm{Fe}, \mathrm{Zn}$ or $\mathrm{Cu}$ deficiencies in Arabidopsis (Colangelo and Guerinot, 2004; Wang et al., 2007; Yamasaki et al., 2009; Assunção et al., 2010; Bernal et al., 2012; Li et al., 2016; Liang et al., 2017; Yan et al., 2017).

Of all essential metals, Cu cations possess the highest ligand-binding affinities (Fraústo da Silva and Williams, 2001). As a result, Cu cofactors carry out challenging ligandbinding tasks, for example the interaction with gas molecules. In addition, Cu readily catalyzes single-electron transfer reactions involving the $\mathrm{Cu}^{2+} / \mathrm{Cu}^{+}$redox couple. Probably as a result of these potent chemical properties, cellular $\mathrm{Cu}$ homeostasis is exceptionally tight (Rae et al., 1999; Robinson and Winge, 2010; Foster et al., 2014). In plants, the largest $\mathrm{Cu}$ quota are required in chloroplasts where $\mathrm{Cu}$ acts as a cofactor in PLASTOCYANIN (PC), the soluble electron carrier between the cytochrome $b_{6} f$ complex and photosystem I in photosynthetic electron transfer and one of the most abundant proteins in the thylakoid lumen (Redinbo et al., 1994; Schubert et al., 2002). The association of PC with its $\mathrm{Cu}$ cofactor occurs post-translationally in the thylakoid lumen and involves the delivery of $\mathrm{Cu}$ by PLASTID CHAPERONE1 (PCH1) to the Cutransporting P-TYPE ATPASE OF ARABIDOPSIS1 (PAA1) of the inner chloroplast envelope membrane, and subsequently $\mathrm{Cu}$ transport by PAA2 across the thylakoid membrane (Shikanai et al., 2003; Abdel-Ghany et al., 2005; Blaby-Haas et al., 2014). $\mathrm{Cu}$ is also a cofactor in cytochrome coxidase (COX or mitochondrial complex IV), which transfers electrons to oxygen as the terminal electron acceptor of the respiratory electron transport chain in the mitochondria (mETC) (Kadenbach et al., 2000). Cu delivery to its binding sites in the COX1 and COX2 subunits involves the Cu chaperone COX17 and HOMOLOG OF CU CHAPERONE SCO1 (HCC1), which were identified based on their homology to yeast proteins (Attallah et al., 2011; Garcia et al., 2016). The presence of Cu-dependent enzymes at the two key cellular sites of ATP production emphasizes the central relevance of $\mathrm{Cu}$ in plant energy metabolism. Whether plants integrate Cu homeostasis and energy metabolism, however, remains unknown. 

operates as a regulator of $\mathrm{Cu}$ deficiency-responsive gene expression in Arabidopsis thaliana (Yamasaki et al., 2009; Bernal et al., 2012). SPL7 is a member of a transcription factor family characterized by the Squamosa promoter Binding Protein (SBP) domain containing both the nuclear localization signal and the recognition domain for the binding of a GTAC core DNA motif (Cardon et al., 1999; Birkenbihl et al., 2005). The Arabidopsis SPL family comprises 16 proteins constituting subfamily I (SPL1, 7, 12, 14 and 16) and subfamily II, based on size and sequence similarity (Xing et al., 2010). Subfamily II SPL proteins (SPL2 to $-6,-8$ to $-11,-13$ and SPL15) have regulatory roles in diverse aspects of plant development including leaf and trichome formation, developmental phase transitions, floral meristem identity and fertility (Unte et al., 2003; Wu and Poethig, 2006; Wang et al., 2008; Yamaguchi et al., 2009; Xing et al., 2010; Yu et al., 2010; Xing et al., 2013; Xu et al., 2016; He et al., 2018). With plant age, a gradual decrease in the abundance of miRNA156, which targets transcripts encoding all subfamily II SPL proteins except SPL8, contributes to increasing levels and cellular activities of these SPL proteins (Wu et al., 2009; Yang et al., 2013; Yu et al., 2013). With the exception of SPL7, the biological functions of subfamily I SPL proteins are less well understood (Stone et al., 2005; Chao et al., 2017; Schulten et al., 2019). SPL7 is required to enhance the transcription of genes encoding proteins with roles in $\mathrm{Cu}$ acquisition, such as root surface $\mathrm{Cu}$ (II) chelate reductases (annotated as FERRIC REDUCTASE OXIDASE, FRO) FRO4/FRO5 and transporters of $\mathrm{Cu}^{+}$into the cytosol of the COPT membrane protein family (Bernal et al., 2012). Additionally, SPL7 mediates the microRNA-dependent post-transcriptional downregulation of the levels of transcripts encoding several abundant but non-essential $\mathrm{Cu}$ metalloproteins. This aspect of the Arabidopsis $\mathrm{Cu}$ deficiency response is thought to reflect an economization strategy that prioritizes the allocation of $\mathrm{Cu}$ to essential cuproproteins like PC (Abdel-Ghany and Pilon, 2008; Yamasaki et al., 2009). For example, under Cu deficiency the abundant CuZn superoxide dismutase-encoding CSD2 and CSD1 transcripts are targeted by miR398 to replace these CSDs by Fe SUPEROXIDE DISMUTASE1 (FSD1) in an SPL7-dependent manner (Yamasaki et al., 2007; Abdel-Ghany and Pilon, 2008; 
green alga Chlamydomonas reinhardtii involving SBP domain-containing CU 94 RESPONSE REGULATOR1 (CRR1) (Quinn and Merchant, 1995; Kropat et al., 2005). ChIP-seq using transgenic $A$. thaliana expressing FLAG-tagged SPL7 under the control of the CaMV 35S promoter identified 1,266 genes associated with SPL7 binding sites under Cu deficiency (Zhang et al., 2014), far more than the 188 transcripts identified as up- or downregulated in an SPL7-dependent manner (Bernal et al., 2012). Here we examine the hypothesis of an integration between $\mathrm{Cu}$ homeostasis and plant energy metabolism through SPL7. The Arabidopsis sp/7-1 mutant, which lacks a broad range of $\mathrm{Cu}$ deficiency responses, was unresponsive to growth stimulation by sucrose under $\mathrm{Cu}$ deficiency, different from the wild type. An accumulation of sugars in spl7-1, including also the signaling sugar trehalose 6-phosphate (T6P), suggested that the mutant is impaired in sugar utilization. Indicating against simple biochemical defects in spl7-1, respiratory electron flux, NADH and ATP levels were normal or even elevated in the mutant. Activities of TOR and SnRK1 kinases were sugar-responsive and in agreement with elevated sugar levels in sp/7-1, suggesting that these major energy signaling pathways are generally functional in the mutant. The sp/7-1 mutant bolted substantially later than the wild type. We sequenced chromatin immunoprecipitates from A. thaliana spl7-1 producing HA-tagged SPL7 under the control of the native promoter and terminator, and we conducted comparative transcriptomics in spl7-1 and the wild

112 type. In combination, these data suggest a direct activation of transcription of bHLH 113 transcription factor-encoding genes by SPL7 and delineate candidate processes and 114 genes for roles in SPL7-dependent sugar signaling. We report a predominantly 115 promoter-localized GTACTRC motif as enriched among SPL7-bound genes showing 116 SPL7-dependent increase in transcript levels under Cu deficiency, while other enriched 117 motifs are likely to reflect additional and complex roles of SPL7. In summary, 118 maintaining a balance between energy availability, growth and development requires 119 SPL7 function, especially under Cu-deficient growth conditions.

\section{Results}

122 The spl7-1 mutant is impaired in directing sugars into growth processes and 
124 To test for interactions between $\mathrm{Cu}$ homeostasis and sugar metabolism, we transferred

125 7-d-old wild-type and spl7-1 mutant seedlings onto agar-solidified media differing in $\mathrm{Cu}$ 126 and sucrose contents (Supplemental Figure 1A and E, compare B-D and F)(Bernal et 127 al., 2012; Marschner and Marschner, 2012). In the wild type, we observed a sucrose128 dependent stimulation of biomass production by up to $60 \%$ irrespective of Cu supply, 129 but this sugar response was absent in spl7-1 cultivated in low Cu (Figure 1A-B). Also on 130 moderate sucrose concentrations between 0.1 and $3 \%$ in low-Cu medium, biomass of 131 spl7-1 did not increase significantly, in contrast to the wild type (Supplemental Figure 2). 132 Anthocyanin production is a well-known response of plants to high internal levels of 133 sucrose (Larronde et al., 1998; Weiss, 2000; Teng et al., 2005; Solfanelli et al., 2006). 134 The spl7-1 and the spl7-2 mutants both accumulated higher anthocyanin levels than the wild type and a complemented line (Bernal et al., 2012), with the highest anthocyanin 136 levels in sp/7 mutants cultivated under low $\mathrm{Cu}$ conditions (Figure $1 \mathrm{~A}$ and $\mathrm{C}$, 137 Supplemental Figure 3A). The maintenance of wild type-like anthocyanin levels in ran11381 (Woeste and Kieber, 2000) indicated against an ethylene-signaling defect as a cause 139 of this sp/7 mutant phenotype. Shoots of spl7-1 cultivated in low Cu accumulated about 1402 -fold higher sugar levels than wild-type shoots without exogenous sucrose supply and 141 17- and 20-fold higher sucrose and glucose levels under high-sucrose cultivation 142 conditions (Figure 1D-E, Supplemental Figure 3B-C for an independent experiment). 143 Sugar levels were elevated in the spl7-1 mutant even under Cu-sufficient control 144 conditions, despite a fresh biomass comparable to the wild type (Figure $1 A-B$ and D-E, 145 Supplemental Figure 3B-C).

146 We also observed SPL7-independent ionomic alterations in high-sucrose grown 147 seedlings, namely generally decreased shoot Fe concentrations and decreased shoot 148 Cu levels only under low-Cu conditions (Supplemental Figure 1A and B, compare with 149 C-F). We confirmed sucrose responses of transcript levels of known SPL7-dependently 150 regulated genes in the wild type, which were reported previously on media containing 151 identical sucrose concentrations (Ren and Tang, 2012)(Supplemental Figure 4). These 152 sucrose responses of transcript levels were generally of low magnitude, and they 153 remained detectable in the sp/7-1 mutant. 
Pursuing our focus on SPL7-dependent phenotypes in this present study, we sought to identify the causes of the defects in sugar utilization in sp/7-1. In plants, part of the fixed carbon accumulates as starch during the day and is remobilized during the night to avoid carbon depletion and allow continued growth, which is why several mutants with defects in starch synthesis or degradation (e.g. pgm) were reported to have reduced growth rates in short days (Caspar et al., 1985; Gibon et al., 2004). At the end of the day, starch concentrations in the sp/7-1 mutant paralleled sugar levels, and they were similar or higher ( $0 \%$ sucrose), or far higher ( $6 \%$ sucrose), than in the wild type, demonstrating that the starch biosynthesis pathways are generally functional in the mutant (Supplemental Figure 5A). At the end of the night, starch was depleted or strongly reduced throughout, except in sp/7-1 cultivated under low-Cu-high-sucrose conditions (Supplemental Figure 5B). We view this as a consequence of the very high availability of soluble sugars (see Figure 1D and E, Supplemental Figure 3B and C) and starch in the mutant under this condition. We conclude that both the synthesis and mobilization of starch are generally functional in sp/7-1.

Taken together, these results suggest that $s p / 7-1$ is generally impaired in the utilization of sugars and that low-Cu growth conditions exacerbate this further. This could reflect a direct function of SPL7, or it could result indirectly as a symptom from the loss in sp/7-1 of $\mathrm{Cu}$-dependent biochemical functions required for sugar utilization, given the $\mathrm{Cu}$ homeostasis defects in this mutant and its apparent susceptibility to physiological $\mathrm{Cu}$ limitation.

\section{Increased respiration rates and altered profile of respiration-related metabolites} in sp/7-1

Mitochondrial respiration connects the breakdown of carbohydrates with the production of ATP and of carbon skeletons as biosynthetic precursors (O'Leary et al., 2019). We tested whether defective $\mathrm{Cu}$ homeostasis in the sp/7-1 mutant results in respiratory restrictions, which could occur through a decrease in Cu-dependent COX activity and feed back to cause insufficient sugar catabolism (Dahan et al., 2014). Notably, total respiration rate was not decreased in sp/7-1 and even significantly higher than in the wild type under low $\mathrm{Cu}$ (Figure 2A). In the presence of the inhibitor of mitochondrial 
alternative oxidase (AOX) salicylhydroxamic acid (SHAM) respiration rates did not differ between the sp/7-1 mutant and the wild type (Figure 2A). When AOX activity is inhibited by SHAM, electrons are not redirected into the COX pathway (Bahr and Bonner, 1973; Møller et al., 1988). Consequently, our results suggest that COX (mitochondrial complex IV) was fully functional in sp/7-1 even in low-Cu medium.

In the presence of $\mathrm{KCN}$, electron flux in the cytochrome $c$ pathway is inhibited and consequently redirected to the alternative pathway according to the maximum AOX capacity (Møller et al., 1988). Respiration rates of low-Cu-grown sp/7-1 remained more than twice as high compared to the wild type under KCN treatment, indicating a much higher capacity for KCN-insensitive respiration in sp/7-1 (Figure 2A). Accordingly, elevated levels of total respiration in sp/7-1 cultivated under low-Cu conditions can likely be attributed to a higher AOX activity, in agreement with increased transcript levels of all four genes encoding AOX isoforms in shoots of the spl7-2 mutant, particularly of the isoform AOX1D (Bernal et al., 2012).

The sp/7-1 mutant contained elevated levels of ATP under control conditions, and more pronouncedly under low-Cu conditions, by comparison to the wild type (Figure 2B, Supplemental Figure $6 \mathrm{~A}$ ). The $\mathrm{NADH} / \mathrm{NAD}^{+}$ratio of sp/7-1 was between about 1.5-fold (control $\mathrm{Cu}$ ) and 9-fold (low $\mathrm{Cu}$ ) higher than that of the wild type (Figure 2C, Supplemental Figure 6B). These ratios are generally consistent with previous findings that NADH contributes less than about $1 \%$ of the cytosolic NAD pool in wild-type plants (Heineke et al., 1991; Shen et al., 2006). Compared to the wild type, the sp/7-1 mutant contained higher levels of both $\mathrm{NAD}^{+}$and NADH under low $\mathrm{Cu}$ (Figure 2C, Supplemental Figure 6B). Taken together, our observations are consistent with a simple model in which the high availability of sugars in sp/7-1 feeds into the production of reductant in the form of NADH. The high levels of NADH in turn fuel respiratory electron flow and ATP production, with normal levels of COX activity and increased AOX activity. AOX partially uncouples NADH oxidation in the mETC from ATP production and can thus function in redox balancing (Vanlerberghe, 2013), but its increased activity in sp/71 may be insufficient to prevent the excess of NADH and ATP. This model does not yet provide an explanation for the accumulation of sugars in the sp/7-1 mutant. 
215 We analyzed the levels of metabolites associated with respiratory and sugar

216 metabolism in shoots of 21-d-old seedlings grown in low-Cu and control agar-solidified 217 media lacking added sucrose. In addition to wild-type and sp/7-1 seedlings, we included 218 two previously characterized Cu-deficient Arabidopsis lines, the paa1-3 mutant 219 (Shikanai et al., 2003; Abdel-Ghany et al., 2005) and a transgenic 35S:amiR-FRO4/5 220 line (Bernal et al., 2012). In paa1-3, severe photosynthetic defects resulting from 221 impaired chloroplastic $\mathrm{Cu}$ import and compromised plastocyanin function can be 222 rescued by high levels of exogenous $\mathrm{Cu}$. 35S:amiRFRO4/5 lines are partially impaired 223 in the reduction of $\mathrm{Cu}(\mathrm{II})$ to $\mathrm{Cu}(\mathrm{I})$ at the cell surface, which is required for high-affinity 224 cellular Cu uptake in low-Cu medium (Bernal et al., 2012).

225 We observed few and quantitatively minor changes in metabolite concentrations in the wild type under $\mathrm{Cu}$ deficiency compared to control conditions, none of which were consistent across independent experiments (Figure 2D, Supplemental Figures 6C-D, Supplemental Table 1). The majority of metabolites were present at higher levels in spl7-1 than in the wild type under both low-Cu and Cu-sufficient cultivation conditions. Compared to the wild type, we observed the consistently largest alterations in sp/7-1 for the levels of glycerol-3-phosphate (Gly3P), 2-oxoglutarate (2-OG), shikimate, sucrose6-phosphate (Suc6P) and succinate, especially under low $\mathrm{Cu}$. The profiles of these metabolites in sp/7-1 differed from 35S:amiR-FRO4/5, whereas other sugar- and glycolysis-related metabolites showed similar alterations in both sp/7-1 and 35S:amiRFRO4/5 compared to the wild type (e.g. glucose-1-phosphate [Glc1P] and glucose-1,6bisphosphate [GBP]). Different from spl7-1, the concentrations of nearly all of the analyzed metabolites were markedly lower in paa1-3 cultivated in low-Cu media.

238 Chloroplasts of sp/7-1 contain about 20\% less Cu than those of the wild type (Zhang et al., 2014), whereas a 58\% reduction in chloroplast $\mathrm{Cu}$ levels was reported for paa1-3 (Abdel-Ghany et al., 2005), suggesting a more severe lack of $\mathrm{Cu}$ in chloroplasts of paa1-3. The opposing trends in metabolite profiles between sp/7-1 and paa1-3, together with specific alterations in sp/7-1 when compared to 35S:amiR-FRO4/5, suggested that

243 the contributions of chloroplast and general physiological $\mathrm{Cu}$ deficiency to the 244 metabolite profiles of sp/7-1 were minor. 
Notably, both of the most strongly altered metabolites, Gly3P (57\% increase in sp/7-1 compared to wild type in low $\mathrm{Cu})$ and $2-\mathrm{OG}(60 \%$ decrease in sp/7-1), have roles in the shuttling of reducing agents, for example $\mathrm{NADH}$, across the inner mitochondrial membrane as part of the glycerol phosphate shuttle (Shen et al., 2006) and the malate/aspartate shuttle (Journet et al., 1981). The alterations in the levels of Gly3P and 2-OG in sp/7-1 are consistent with the mutant being locked in an overall more reduced state.

In accordance with elevated sugar concentrations in sp/7-1 (see Figure 1D, E), the levels of all monitored sugar metabolism intermediates were higher in sp/7-1 under low Cu compared to the wild type in at least two out of three independent experiments, with Suc6P levels increased by 76\%, for example (Figure 2D, Supplemental Figures 6C-D, Supplemental Table 1). Relative to the wild-type, we observed increased levels of the signaling sugar trehalose 6-phosphate in spl7-1 (T6P; 56\% increase compared to wild type) independent of Cu supply in two out of three independent experiments, and T6P levels broadly followed sugar levels, as is known (Lunn et al., 2006). Consequently, growth defects in spl7-1 cannot be attributed to a depletion in the signaling sugar T6P (Schluepmann et al., 2003; Figueroa and Lunn, 2016). Together, these results suggest that the primary metabolite profile of $s p / 7-1$ is rather different from that of other $\mathrm{Cu}$ deficient mutants and thus implicate SPL7-dependent processes, rather than pleiotropic defects common to Cu-limited plants, in reduced growth despite a high energy status of spl7-1.

\section{Major energy signaling pathways are generally functional in the sp/7-1 mutant}

Next, we examined sugar-dependent signaling that is known to connect energy status with growth and development (Baena-Gonzalez and Hanson, 2017). Two central regulators in plant energy signaling are the antagonistically operating kinases Target of Rapamycin (TOR) and Sucrose non-fermenting-Related Kinase (SnRK1). SnRK1 is activated in response to a low energy status, acting to repress energy-consuming processes and growth, and it is inhibited by sugars, likely in the form of sugar phosphates such as T6P (Baena-González et al., 2007; Zhang et al., 2009; Nunes et al., 2013a; Zhai et al., 2018). Transcriptional markers for SnRK1 activity were reported 
276 for protoplasts transiently expressing SnRK1 subunits as well as for seedlings after 277 short-term sugar starvation treatments (Baena-González et al., 2007; Nunes et al., 278 2013a). To test for the functionality of the SnRK1-activating pathway in sp/7-1, we 279 employed a submerged liquid cultivation system in flasks as described, which allows the 280 rapid exchange of media for 3-h sucrose starvation treatments (Nunes et al., 2013a). In response to sucrose starvation, transcript levels of the SnRK1 marker Dark Inducible 6 (DIN6) were strongly upregulated as expected in both the wild type and spl7-1, irrespective of $\mathrm{Cu}$ supply (Figure $3 \mathrm{~A}-\mathrm{B}$ ). This indicated an ability to activate SnRK1 throughout. However, transcript abundance of DIN6 was clearly lower in sp/7-1 compared to wild type under low-Cu conditions. Transcript levels of Expansin 10 (EXP10), which are downregulated by increased SnRK1 activity, decreased in response to sucrose starvation in all samples except for spl7-1 under low Cu (Figure 3C). Together, these observations suggest that SnRK1 activity reflected sugar levels in spl71, congruent with our interpretation that the SnRK1 pathway is sugar-responsive and thus generally functional in the mutant.

TOR kinase activity is stimulated by sugars, and this promotes growth and development via the regulation of processes such as cell proliferation and growth, ribosome biogenesis and protein synthesis (Deprost et al., 2007; Xiong et al., 2013). To assess TOR activity, we analyzed the phosphorylation state of its downstream target S6 kinase (S6K) as a marker in seedlings cultivated in our combined $\mathrm{Cu}$ (low $\mathrm{Cu}$ and control) and sucrose $(0 \%$ and $6 \%)$ growth conditions, using modification-specific anti-S6K antibodies (Dong et al., 2017). In seedlings grown in 6\% sucrose, compared to $0 \%$ sucrose, the ratio of phosphorylated relative to non-phosphorylated S6K protein responded no less in sp/7-1 than it responded in wild-type seedlings, independent of Cu supply (Figure 4, Supplemental Figure 7). This observation is consistent with the known activation of TOR by glucose and sucrose and indicated that TOR-mediated sugar signaling is generally functional in spl7-1 (Xiong and Sheen, 2012; Xiong et al., 2013; Dobrenel et al., 2016). 303 Following internal sugar levels (see Figure 1D-E), the relative abundance of 304 phosphorylated S6K protein was higher in spl7-1 than in the wild type upon cultivation in $3056 \%$ sucrose, and the difference between genotypes was more pronounced and more 306 consistently observed when seedlings were grown in low-Cu medium (Figure 4, 
307 Supplemental Figure 7). Taken together, our data implicate a process that acts either

308 independently, or downstream, of the TOR and SnRK1 kinases, in SPL7-dependent energy metabolism.

\section{Flowering time of sp/7-1}

312 Sugar signals such as T6P promote growth as well as developmental phase transitions,

313 for example flowering (Schluepmann et al., 2003; Wahl et al., 2013; Yang et al., 2013;

314 Yu et al., 2013; Ponnu et al., 2020). We thus tested for phenotypic changes in sp/7-1 at

315 later developmental stages. For comparison, we included the transgenic

316 35S:amiRTPS1 line in which T6P levels are reduced as a consequence of the post-

317 transcriptional downregulation of TREHALOSE 6-PHOSPHATE SYNTHASE1 gene

318 expression, resulting in a strongly delayed flowering time in long days (Wahl et al., 319 2013). Under our growth conditions, T6P levels were reduced by about $34 \%$ in 320 35S:amiRTPS1 compared to wild type independent of $\mathrm{Cu}$ supply (Figure 5A), in 321 agreement with published data (Wahl et al., 2013). In sp/7-1 mutant plants cultivated 322 alongside, T6P levels were increased to about $178 \%$ of the wild type on low-Cu medium 323 and to $140 \%$ of the wild type on control medium.

324 Our standard greenhouse soil is $\mathrm{Cu}$-deficient (low $\mathrm{Cu}$ ), and the defects in reproduction 325 of spl7-1 are rescued by watering with $2 \mathrm{mM} \mathrm{CuSO}_{4}$ (control) once per week (Schulten 326 et al., 2019). With this supplementation, $\mathrm{Cu}$ concentrations in rosette leaf and aerial 327 tissues of spl7-1 were significantly higher than in unamended low-Cu soil (Figure 5B), 328 and the stunted growth of spl7-1 was partially rescued (Figure 5C), as was reported 329 earlier (Yamasaki et al., 2009; Bernal et al., 2012; Garcia-Molina et al., 2014a; Yan et 330 al., 2017). Cu supplementation led to a significant increase in rosette Cu levels to about $3315 \mu \mathrm{g} \mathrm{g}^{-1}$ dry biomass in the wild type and 35S:amiRTPS1. Cu concentrations in aerial 332 tissues of wild type and 35S:amiRTPS1 were around $8 \mu^{-1} \mathrm{DW}$, clearly above those 333 in rosette tissues and unaffected by $\mathrm{Cu}$ supplementation. By contrast, $\mathrm{Cu}$ 334 concentrations in aerial tissues of sp/7-1 were only a little higher than in rosette tissues. 335 This suggested that during the reproductive phase of the life cycle, wild-type plants 336 preferentially allocate $\mathrm{Cu}$ into aerial tissues and that this is largely SPL7-dependent. 
As expected, 35S:amiRTPS1 plants flowered later than the wild type according to both plant age and the number of rosette leaves at bolting (Figure 5D-E, Supplemental Figure 8) (Wahl et al., 2013). Based on the number of leaves at bolting, the spl7-1 mutant flowered at a similar time or slightly earlier than the wild type (Figure 5D, Supplemental Figure $8 \mathrm{~A}$ and $\mathrm{C}$ ). In relation to plant age, bolting time was clearly delayed in sp/7-1 by about 7 days compared to wild type irrespective of Cu supply (Figure 5E, Supplemental Figure 8B and D), and comparable to 35S:amiRTPS1. Taken together, these results suggest that, in addition to growth, the transition to flowering is partially uncoupled from sugar levels in sp/7-1. Consistent with a known repression of miR156 by metabolizeable sugars and T6P (Wahl et al., 2013; Yang et al., 2013; Yu et al., 2013; Ponnu et al., 2020), miR156 levels were lower in shoots of $6 \%$ sucrose- than in $0 \%$ sucrose-grown seedlings of both the wild type and spl7-1 (Figure 5F). This confirmed that miR156 levels remained responsive to internal sugar levels in sp/7-1 (Yang et al., 2013; Yu et al., 2013). However, despite elevated sugar levels in sp/7-1 compared to the wild type (see Figures 2 and 5A), miR156 levels were higher in sp/7-1 than in the wild type when cultivated under low-Cu conditions (Figure 5F). Thus, the known sugar-dependent decrease in miR156 levels with plant age was attenuated in the mutant in low $\mathrm{Cu}$.

Flowering requires a developmental switch in the apical meristem. Therefore, we investigated whether SPL7 might be capable of influencing this switch also locally. RNA in situ hybridization revealed the presence of SPL7 transcript in the shoot apical meristem and young leaf primordia of vegetative plants cultivated in both short and long days as well as in reproductive shoot apices (Figure 5G). Several miR156-targets, for example SPL9, SPL13 and SPL15, are also expressed in the shoot apical meristem (Wang et al., 2009; Yamaguchi et al., 2014b; Hyun et al., 2016; Xu et al., 2016). The function of SPL7 in the shoot apical meristem warrants further investigation.

\section{Genome-wide identification of SPL7 binding sites}

We reasoned that expanding our knowledge on direct target genes of SPL7-dependent transcriptional regulation could provide mechanistic insights into how SPL7 affects energy metabolism. For the genome-wide identification of SPL7 DNA binding sites 
using ChIP-seq, we generated sp/7-1 transformants with a genomic construct encoding an SPL7 protein flanked by HA-tags at both the $\mathrm{N}$ - and the C-terminus, under control of the native promoter in the spl7-1 background (promSPL7::HA-SPL7-HA:termSPL7; short HA-SPL7-HA). Of three homozygous lines complementing the sp/7 phenotype under low $\mathrm{Cu}$ cultivation conditions, we chose a line in which SPL7 transcript levels were similar to the wild type (Figure 6A-B, Supplemental Figure 9). SPL7 transcript levels were unaffected by $\mathrm{Cu}$ levels in the medium, as reported previously (Yamasaki et al., 2009; Bernal et al., 2012). Likewise, immunoblots detected the HA-SPL7-HA fusion protein under both low $\mathrm{Cu}$ and control conditions (Figure 6C, Supplemental Figure 10), in line with a proposed post-translational mechanism for the regulation of the activity of SPL7 as a transcriptional enhancer, similar to CrCRR1 (Kropat et al., 2005; Sommer et al., 2010). The HA-SPL7-HA protein was visible as a single band running at a size of around $100 \mathrm{kDa}$, which is slightly higher than the calculated protein size including the HA-tags of $\sim 92 \mathrm{kDa}$ (Figure $6 \mathrm{C}$, Supplemental Figure 10). Chromatin Immunoprecipitation (ChIP) was conducted on rosette tissues of 21-d-old HA-SPL7-HA seedlings cultivated in low- $\mathrm{Cu}$ and control conditions. ChIP-qPCR confirmed an enrichment relative to chromatin input for positive control SPL7 target gene MIR408 (Zhang and Li, 2013) and the expected SPL7 target gene FSD1 (Zhang et al., 2014) in HA-SPL7-HA samples relative to the wild type, in contrast to the negative control gene ACTIN7 (ACT7) (Figure 6D). Next, we identified putative SPL7 binding sites genomewide based on sequencing of input and ChIP sample pairs. In low-Cu conditions and control $\mathrm{Cu}$ conditions, respectively, we identified 758 peaks/2,026 genes and 713 peaks/1,901 genes as SPL7 binding sites/in the vicinity of SPL7 binding sites, supported by a minimum of 2 (of 4) independent experiments (Figure 7A and B, Supplemental Data Sets 1 and 2). About $85 \%$ of the genomic segments we identified by ChIP-seq were common to both cultivation conditions (Figure 7B). Around $9 \%$ of the genes associated with these genomic segments were among 1,266 genes previously identified based on a single SPL7-ChIP-seq experiment (Zhang et al., 2014)(more than expected by chance; $P<10^{-15}$, hypergeometric test; Supplemental Table 2). Different from the earlier study by Zhang et al. (2014), by far the most frequently observed localization of peaks was 200 to $20 \mathrm{bp}$ upstream of the predicted transcriptional start 
site (Supplemental Figure 11). Possible explanations for findings differing between the earlier publication and this present study may lie in differing plant cultivation conditions, the earlier expression of FLAG-SPL7 under the control of the CaMV 35S promoter, or the fact that these FLAG-SPL7-ChIP-seq data were apparently based on a single replicate (Zhang et al., 2014).

404 In order to evaluate genomic SPL7 binding sites based on SPL7-dependence of 405 transcript levels, we conducted RNA-seq on rosette tissues of wild-type and sp/7 406 seedlings cultivated as for ChIP-seq. Out of the top eight candidate genes for SPL7407 dependent transcriptional activation identified through the largest SPL7 dependence at 408 the transcript level under low Cu conditions (Supplemental Data Set 3), five genes were 409 also identified in our ChIP-seq under low $\mathrm{Cu}$ conditions: FSD1, bHLH transcription factor-encoding bHLH160 (COPPER-DEFICIENCY INDUCED TRANSCRIPTION FACTOR1, CITF1; (Yan et al., 2017)), bHLH23 (addressed here as CITF2), YELLOW STRIPE-LIKE2 (YSL2) and ZINC-REGULATED TRANSPORTER, IRON-REGULATED

413 TRANSPORTER-RELATED PROTEIN2 (ZIP2) (Table 1, Supplemental Figure 12A-I, 414 Supplemental Data Set 2). Of these, we tested three genes, FSD1, CITF1 and CITF2, in 415 independent ChIP-qPCR experiments and were able to confirm all three (Figure 7C, 416 Supplemental Figure $12 \mathrm{~J}$ and $\mathrm{K}$ ). This supported a role of SPL7 in transcriptional 417 activation under low-Cu conditions (Kropat et al., 2005).

418 All SPL family transcription factor proteins are thought to share the core GTAC motif of 419 their DNA binding sites (Birkenbihl et al., 2005). Either individually or in common among genes previously identified by DAP-seq for SPL1, -5, -9, -13, -14 and -15 (O'Malley et

421 al., 2016), the numbers of genes shared with our SPL7 ChIP-seq data were not 422 significantly above expectations based on random picking (Supplemental Table 2, 423 Supplemental Data Set 2). Notably, however, all of the top five genes highlighted above 424 also contained binding sites for between three and five SPL proteins according to DAP425 seq data (Table 1). This was also the case for the miRNA loci previously identified to be 426 direct targets of SPL7 binding and SPL7-mediated transcriptional activation, miR408 427 and miR398B and C (Yamasaki et al., 2009; Zhang and Li, 2013).

428 Examining the sequences of all peaks identified by SPL7 ChIP-seq together, we could 429 not identify any enriched sequence motif (Supplemental Data Set 4). Restricting our 
430 analysis to ChIP-seq peaks unique to low $\mathrm{Cu}$, we identified the significantly enriched 431 GTACTA/GC motif that is partially identical to the previously reported A/TGTACT/A, as 432 well as significantly enriched AGGAAGC/T (reverse complement: A/GCTTCCT) that is 433 reminiscent of TCTTCTTCTCCTTCCTC (Zhang et al., 2014)(Supplemental Figure 13). 434 The subfamily II SPL protein IPA1 (SPL14) of Oryza sativa binds to differing core motifs, either GTAC or TGGGCC/T, dependent on environmental conditions (Wang et al., 2018). To further accommodate possible alternative SPL7 binding preferences dependent on $\mathrm{Cu}$ supply, we generated differing sets of peaks based on the transcriptional regulation of the associated genes for subsequent motif identification (Supplemental Data Sets 5 and 6). In this manner, we obtained 51 and 52 candidate genes for the direct activation and repression by SPL7 under low Cu conditions, respectively (Supplemental Data Set 5). Note that binding site positions predominantly upstream of transcriptional start sites were equally consistent with SPL7-dependent activation and repression in low-Cu conditions (compare Supplemental Figure 11D and F). Under control cultivation conditions, a clearly smaller number of 16 and 24 genes were candidates for undergoing direct SPL7-mediated activation and repression, respectively (Supplemental Data Set 5). SPL7 binding sites were positioned upstream or within the gene body at similar frequencies, suggesting either a lesser or a more complex role of SPL7 in transcriptional regulation under Cu-sufficient conditions (compare Supplemental Figure 11C and E).

450 We identified enriched motifs GTACTA/GC and AC/GAGAAGA (TCTTCTC/GT) among 451 peaks identified by ChIP-seq associated with genes undergoing SPL7-dependent 452 transcriptional activation, under low-Cu conditions (Figure 7D-I). Overall motif 453 positioning, density and abundance supported the GTACRC motif more strongly than 454 the TCTTCTST motif. Applying progressively relaxed filtering criteria for assembling 455 sets of ChIP-seq peak-associated and SPL7-dependently regulated genes, identified 456 multiple sequence motifs, part of which contain previously reported binding sites of 457 other transcription factors (Supplemental Figure 14, Supplemental Data Sets 4 and 6). 458 Four motifs newly identified here were predominantly positioned within gene bodies 459 (Supplemental Figure 14A, D, G, I), similar to the other non-GTAC-containing motifs 460 (see Figure 7G, Supplemental Figure 13D). Taken together, these results are consistent 
461 with a possible direct transcriptional activation by SPL7 under low Cu of FSD1, CITF1 462 and CITF2, alongside a small set of other genes. Beyond this, our data are consistent with complex roles and interactions of SPL7 (Garcia-Molina et al., 2014a; Zhang et al., 2014; Yan et al., 2017).

465 Despite strong support for both positive and direct regulation of FSD1 transcript levels by SPL7 (Table 1, Figures 6D and 7C, Supplemental Figures 4D and 12J and K), MEME did not identify FSD1 to contain any of the enriched sequence motifs (Supplemental Data Sets 4 and 6). Manual inspection identified a total of 8 GTAC core motifs in the region corresponding to the FSD1-associated peak, with a minimum of a total of 4 copies of the GTAC core motif upstream of all annotated transcriptional start sites of FSD1 (Supplemental Figure 15). Two of these copies correspond to GTACTRC,

472 the motif identified here (see Figure 7D, Supplemental Figure 13A). There are two 473 copies of AGTACA/TGTACT which was previously concluded to have the highest in 474 vitro binding affinity for SPL7 out of several variants tested using electrophoretic mobility shift assays (Zhang et al., 2014).

\section{Discussion}

\section{How do altered sugar responses arise in the sp/7 mutant?}

479 In plant leaves, the largest cellular quota of both Fe ( 70\% to 80\%) and Cu ( 30\%) are 480 localized in chloroplasts (Shikanai et al., 2003; Yruela, 2013). The primary requirement 481 for $\mathrm{Cu}$ in chloroplasts is in plastocyanin (Schubert et al., 2002). Cultivation of Populus 482 trichocarpa in a Cu-limiting hydroponic solution caused a reduced abundance of PC 483 protein and a strong decrease in photosynthetic electron transport rates, with plant 484 biomass reduced by one half (Ravet et al., 2011). Arabidopsis plants lacking both plastocyanin isoforms are incapable of photoautotrophic growth and require exogenous sucrose to survive (Weigel et al., 2003). Biomass production was severely reduced in 487 the sp/7-1 mutant cultivated under low-Cu conditions (Figure 1). It was plausible to attribute this growth defect to $\mathrm{Cu}$ limitation of photosynthesis in this mutant, given the known requirement for SPL7 in the transcriptional activation of $\mathrm{Cu}$ acquisition and $\mathrm{Cu}$ economization processes (Yamasaki et al., 2009; Bernal et al., 2012). However, the 
492 enhanced accumulation of sugars in sp/7-1 implicated processes other than 493 photosynthetic assimilate production in its growth defect (Figure 1, Supplemental 494 Figures 2 to 4 ).

495 The second most relevant cellular site of $\mathrm{Cu}$ use in Arabidopsis is in the mitochondrial 496 ETC, where Cu acts as a cofactor of cytochrome $c$ oxidase (COX, complex IV). Total 497 respiration was reduced by about $60 \%$ in Cu-deficient compared to Cu-replete cells of 498 the green alga Chlamydomonas reinhardtii (Kropat et al., 2015). In wild-type 499 Arabidopsis thaliana, electron flow via the COX-dependent cytochrome $c$ pathway was 500 not affected by Cu deficiency in the wild type (Figure 2), consistent with unaltered COX2 501 protein levels in $A$. thaliana and $P$. trichocarpa cultivated in low-Cu media (Yamasaki et 502 al., 2007; Ravet et al., 2011). Interestingly, also in low-Cu grown sp/7-1, there was no 503 reduction in electron flux via the cytochrome $c$ pathway. A slight SPL7-independent 504 increase in transcript levels of HCC1, a chaperone involved in Cu delivery to COX 505 (Attallah et al., 2011), under Cu deficiency may contribute to COX functionality in Cu506 deficient Arabidopsis (Bernal et al., 2012). It is possible that sp/7-1 seedlings can only 507 maintain adequate Cu supply to COX because of their attenuated growth (Bernal et al., 508 2012). An elevated total respiration rate in the spl7-1 mutant under low Cu resulted from 509 the activation of AOX-dependent respiration and may have a compensatory role in the 510 presence of elevated ATP levels and NADH/NAD+ ratios in spl7-1 (Figure 2, 511 Supplemental Figure 6). An increased engagement of the alternative electron pathway 512 in response to sugar stimuli is thought to constitute a balancing mechanism for an 513 excess of reducing equivalents (Lambers, 1982; Azcón-Bieto et al., 1983). Dissimilar 514 from the properties of COX-defective (Dahan et al., 2014) and other Cu-deficient 515 genotypes (Figure 2D), we interpret enhanced respiration, increased NADH/NAD ${ }^{+}$ratio, 516 accumulation of ATP and an altered metabolite profile of spl7-1 as consequences of an 517 elevated sugar status, and not as its causes.

518 Given that we excluded major contributions from defects in the two most prominent Cu519 dependent metabolic pathways, the attenuation of growth of sp/7-1 under low Cu 520 despite high internal sugar levels might result from defective sugar/energy sensing or 521 signaling. SnRK1 kinase activity is directly inhibited by T6P (Zhang et al., 2009; Zhai et 522 al., 2018), a signaling metabolite of which we found elevated levels in sp/7-1 (Figures 2 
523 and 5, Supplemental Figure 6). The responsiveness of downstream marker transcripts

524 of the SnRK1 signaling pathway were consistent with its general functionality in sp/7-1

525 (Figure 3). The phosphorylation state of the TOR kinase target S6K was in accordance

526 with sugar levels also in sp/7-1, indicating that the TOR pathway is also generally

527 functional in spl7-1 under low Cu (Figures 1 and 4, Supplemental Figure 3 and 7).

528 Different from these observations in spl7-1, TOR activity is decreased under nitrogen

529 starvation (Liu et al., 2021). While TOR is involved in the phosphorylation of a variety of

530 targets in several downstream signaling pathways, phosphorylation of S6K is

531 responsive to sucrose and glucose (Xiong and Sheen, 2012; Dobrenel et al., 2016) and

532 thus a suitable marker for TOR activity in our conditions. To summarize, TOR and

533 SnRK1 activity responded to sugar signals irrespective of $\mathrm{Cu}$ availability and in both wild

534 type and spl7-1, indicating against an involvement of these kinases in the SPL7-

535 dependent integration of $\mathrm{Cu}$ deficiency responses with energy-dependent regulation of

536 growth in Arabidopsis. Yet, we cannot exclude a possible partial attenuation of SnRK1

537 or TOR signaling in spl7.

538 Different from spl7-1, failure to grow as a consequence of impaired sulfur assimilation in 539 the $A$. thaliana sir1-1 mutant lacking the enzyme sulfite reductase was linked to reduced 540 TOR activity (Dong et al., 2017). In agreement with sugar signals governing TOR 541 activity, the sir1-1 mutant contained reduced carbohydrate levels. Finally, transcript 542 levels of published targets of nuclear Hexokinase1 (HXK1) signaling function CAA 543 (CA2) and CAB (LHCB1.1) (Cho et al., 2006), as well as of the proposed downstream 544 target of (HXK1)-dependent metabolic regulation, NRT2.1 (Lejay et al., 2003; Lejay et 545 al., 2008), were regulated as expected based on higher sugar contents in sp/7-1 546 (Supplemental Data Set 3; CA2, LHCB1.1 four-fold down, NRT1.2 eight-fold up in spl75471 vs. WT under - Cu). The combination of Cu deficiency and the lack of SPL7 might 548 generate sink-limited conditions by affecting unknown processes downstream of the $549 \mathrm{~T} 6 \mathrm{P} / \mathrm{SnRK} 1$ module. It was proposed that under sink-limited environmental conditions, 550 namely low nitrogen supply or low temperature, the strongly inter-related levels of 551 sucrose, T6P and SnRK1 activity are disconnected from the growth outcome (Nunes et 552 al., 2013b). Regulator of G-protein Signaling 1 (RGS1) was proposed to operate as a 553 plasma membrane-localized sensor of extracellular glucose (Urano et al., 2012). The 
activation of RGS1-dependent signaling was noted to require unexpectedly high extracellular glucose concentrations (Li and Sheen, 2016). A possible defect in RGS1dependent signaling in sp/7 deserves attention in future work.

\section{SPL7 and Cu deficiency in plant development}

The levels of miR156, which post-transcriptionally represses subfamily II SPLs except $S P L 8$, are progressively down-regulated with plant age in response to increasing sugar levels in leaves, thereby promoting vegetative phase change (Yang et al., 2011; Yang et al., 2013; Yu et al., 2013). The miR156/subfamily II SPL module was also implicated in the regulation of flowering time (Wu and Poethig, 2006; Schwarz et al., 2008; Wang et al., 2009). Transgenic plants containing reduced levels of the signaling sugar T6P contained reduced levels of FLOWERING LOCUS T transcript in whole rosettes, as well as elevated levels of miR156 in the shoot apex, and they flowered late (Wahl et al., 2013).

Our results are consistent with an attenuated response of developmental transitions to internal sugar levels in sp/7-1. Compared to the wild type, flowering of sp/7-1 was delayed and unaltered by $\mathrm{Cu}$ supplementation, although at a given plant age the levels of the metabolizeable sugars sucrose and glucose as well as of T6P were increased (Figures 1 and 5, Supplemental Figures 3 and 8). Although remaining sugar-responsive in the sp/7-1 mutant, miR156 levels were strongly elevated in the mutant upon cultivation in low-sucrose-low-Cu conditions despite comparably high internal sugar levels, and miR156 could thus contribute to a condition-specific developmental delay (Figure 1 and Figure 5F). It is unlikely, however, that elevated levels of miR156 are causal in sugar accumulation of sp/7-1, because sugar levels including T6P are not elevated in miR156-overexpressing plants (Ponnu et al., 2020). In A. thaliana, eight genetic loci encode miR156 precursors, and not all precursor transcripts decrease in abundance in response to sugars (Yang et al., 2013). Moreover, various abiotic stresses, such as heat stress, phosphate starvation, salt stress and drought, lead to increased miR156 levels (Hsieh et al., 2009; Cui et al., 2014; Stief et al., 2014).

Elevated $\mathrm{Cu}$ levels in aerial tissues compared to rosette leaves in the wild type indicated that $\mathrm{Cu}$ allocation to the inflorescence is prioritized, in agreement with the previously 
585

586

587

588

589

590

591

592

593

594

595

596

597

598

599

600

601

602

603

604

605

606

607

608

609

610

611

612

613

614

615

established role of $\mathrm{Cu}$ in plant fertility, for example in the Cu-binding protein plantacyanin involved in pollen tube guidance (Kim et al., 2003; Dong et al., 2005; Yan et al., 2017; Rahmati Ishka and Vatamaniuk, 2020). This prioritization was to a large extent dependent on SPL7 (Figure 5B). Employing in situ RNA hybridization, we detected a signal for SPL7 mRNA in the vasculature of the shoot apical meristem (Figure 5G). Future work will be required to analyze possible functions of SPL7 in the shoot apical meristem and during the reproductive phase of development.

\section{Genomic targets of SPL7 binding and transcriptional regulation}

All SPL family proteins are characterized by a highly conserved recognition domain for the binding of a GTAC core DNA motif, and there is functional overlap among subfamily II SPLs in the regulation of plant development (Birkenbihl et al., 2005; Xing et al., 2010; Xing et al., 2013; Xu et al., 2016). Our phenotypic analysis of spl7-1 mutants did not support a predominant functional antagonism between SPL7 and mir156-regulated subfamily II SPLs (Figure 5). Alternatively, direct or indirect target genes of regulation by the transcription factor SPL7 could include critical functions in sugar sensing, signaling or utilization. The combined analysis of genomic SPL7 binding sites and SPL7dependent regulation of transcript levels did not reveal any evident well-characterized genes directly targeted by SPL7 and likely to cause the altered energy metabolism in spl7-1 (Supplemental Data Set 5). Consequently, it is possible that SPL7 is required for the expression of a yet uncharacterized gene critical for sugar utilization.

The putative direct SPL7 target genes CITF1 (bHLH160) and CITF2 (bHLH23) identified here were reported as differentially regulated between the wild type and spl7-2 in previous studies (Bernal et al., 2012; Yan et al., 2017). Additionally, our data support FSD1 as a direct target of SPL7 (Table 1, Supplemental Figures 12 and 15). FSD1 undergoes the most pronounced SPL7-dependent transcriptional regulation (Table 1, Supplemental Figure 4D). FSD1 was also detected in the earlier ChIP-seq study of SPL7 (Zhang et al., 2014), together with the well-established direct targets of SPL7dependent transcription under $\mathrm{Cu}$ deficiency, MIR398B, MIR398C and MIR408 (Yamasaki et al., 2009; Zhang and Li, 2013). For all these genes, the positions of ChIPseq peaks were consistent with SPL7 binding directly to the promoters under $\mathrm{Cu}$ 
deficiency (Table 1, Supplemental Figures 12 and 15). CITF1 was identified through its physical interaction with SPL7 and subsequently shown to be important in Cu deficiency responses of roots and reproductive organs, as well as for pollen fertility and jasmonate responses in flowers (Yan et al., 2017). It groups among bHLH transcription factors lb, alongside the central $\mathrm{Fe}$ deficiency response regulatory transcription factors bHLH38/39/100 and 101 (Heim et al., 2003). Group VIla of the bHLH transcription factors comprises CITF2 as well as the well-studied PHYTOCHROME INTERACTING FACOR and -LIKE bHLH proteins. Future work will address the functions of these transcription factors, as well as of superoxide dismutases, in particular of FSD1, in sugar responses and sugar utilization. An example of sugar signalling via reactive oxygen species was recently published (Roman et al., 2021).

Our ChIP-qPCR data suggested highly effective binding of SPL7 to FSD1 in Cudeficient conditions, associated with very high FSD1 transcript levels, and exceptionally - notable SPL7 binding even in Cu-sufficient seedlings, as well as both consensus and unusual GTAC-containing sequence elements in the promoter region (Figures 6 and 7, Table 1, Supplemental Figures 12,13 and 15). Our observations support some residual SPL7 activity even when sufficient $\mathrm{Cu}$ is available, implying that small amounts of SPL7 are located inside the nucleus and active on a subset of target sites. Based on the transient expression of GFP-tagged SPL7 in leaves of Nicotiana benthamiana, it was proposed that SPL7 is anchored to the ER membrane by a transmembrane helix in its $\mathrm{C}$-terminus and released into the cytoplasm only under $\mathrm{Cu}$ deficiency upon proteolytic cleavage at a site in the center of the protein. Accordingly, entry of the N-terminal half of SPL7, which includes the SBP domain, into the nucleus would then allow the transcriptional activation of $\mathrm{Cu}$ deficiency-responsive genes (Garcia-Molina et al., 2014b). Different from this proposed mechanism, immunoblots revealed only a single band corresponding approximately to the full protein size, irrespective of plant physiological Cu status, in a stably transformed HA-SPL7-HA line (Figure 6, Supplemental Figure 10).

Although we identified several motifs here, our data supported in a manner corresponding to simple expectations only the consensus GTACTRC motif in promoter regions for SPL7-mediated transcriptional enhancement primarily under low-Cu 
647 conditions (Table 1, Figure 7, Supplemental Figures 12 to 15). A shift in the SPL7 648 regulon under control $\mathrm{Cu}$ conditions, as exemplified by FSD1, could involve differing cisregulatory DNA sequence elements that exhibit a higher binding affinity for SPL7, or alternatively as yet unidentified conditional protein interaction partners of SPL7. For example, KIN17 interacts with SPL7 specifically in aerial tissues and is involved in promoting $\mathrm{Cu}$ deficiency responses (Garcia-Molina et al., 2014a). SPL7 interacts with ELONGATED HYPOCOTYL (HY5) to enhance the levels of miR408 (Zhang et al., 2014). Physical interactions of SPL7 with other transcription factors may contribute to explaining the identification of multiple overrepresented motifs among SPL7 ChIP-seq peaks, the apparent binding of SPL7 within gene bodies under Cu-sufficient cultivation conditions, or the predominant localization of peaks in promoter regions also of genes repressed at the transcript level dependent on SPL7 (Figure 7G-I, Supplemental Figure 11C-F, 13D-F and 14, Supplemental Data Sets 4 and 6). Alternatively, SPL7 could act alone as a repressor of some of its direct target genes. To date, SPL7-dependent negative regulation was exclusively reported to occur indirectly via SPL7-dependent transcriptional activation of miRNA loci (Abdel-Ghany and Pilon, 2008; Yamasaki et al., 2009).

664 Another mechanism that can modulate the activity of SPL proteins was described for SPL14 in Oryza sativa, a homolog of AtSPL9/15 (Wang et al., 2018). The phosphorylation of a conserved serine residue in the SBP domain caused an altered DNA-binding specificity of OSSPL14, i.e. a change in preference for binding to a nonGTAC TGGGCC motif. OsSPL14 was thus found to have a dual role in alternatively 669 promoting either yield or disease resistance. If a similar mechanism operated in SPL7, it 670 could explain the additional identification of a non-GTAC SPL7-binding motif (Figure 671 7G-I, 13D-F and 14, Supplemental Data Set 6). Among genes associated with SPL7 672 ChIP-seq peaks, "response to hypoxia" was strongly overrepresented, but far less so 673 among SPL7-dependently regulated transcripts (Supplemental Figure 16). CrCRR1 674 mediates transcriptional responses to both $\mathrm{Cu}$ deficiency and hypoxia (Hemschemeier 675 et al., 2013). It now appears relevant to examine whether SPL7 and its orthologues 676 regulate a subset of hypoxia responses in land plants, as well. 
677 Future work will address the complex functions of SPL7 including the molecular

678 mechanisms underlying growth and developmental impairment despite sugar

679 accumulation in sp/7 mutants. Understanding the coordination of plant metal

680 homeostasis with energy metabolism, growth and reproduction can help to increase

681 crop yield and quality, especially on soils deficient in bioavailable $\mathrm{Cu}$, which comprise

682 more than $10 \%$ of the agricultural land in Europe (Reimann et al., 2014).

683

684

\section{Methods}

685

Plant material

686

Arabidopsis thaliana wild-type seeds (Col-0) were obtained from Lehle seeds (Round

Rock, TX, USA). The spl7-1 (SALK_093849) and spl7-2 (SALK_125385) mutants are a

T-DNA insertion lines from the Nottingham Arabidopsis Stock Centre and were

characterized earlier (Yamasaki et al., 2009; Bernal et al., 2012). The generation of the spl7-2 SPL7 (spl7-2_C) complemented line and transgenic 35S:amiRFRO4/FRO5 plants (line 27) was described in Bernal et al. (2012). The paa1-3 loss-of-function mutant was a kind gift from Prof. Marinus Pilon (Shikanai et al., 2003), and ran1-1 (N3808) was from the Nottingham Arabidopsis Stock Centre. Transgenic line 35S:amiRTPS1 was kindly provided by Dr. Vanessa Wahl (Wahl et al., 2013). All mutants and transgenic lines are in the Col-0 genetic background. Primers used for genotyping are listed in Supplemental Table 3.

HA-SPL7-HA (promSPL7::HA-SPL7-HA:termSPL7) constructs were generated as follows (Lampropoulos et al., 2013). The promSPL7 upstream region (-2506 to -5 from beginning of translational start codon) was PCR-amplified from genomic DNA of $A$. thaliana (Col-0) and cloned into the Greengate entry module pGGA000 via Bsal restriction. The genomic SPL7 (AT5G18830.1) coding region (translational start to stop 702 codon) was PCR-amplified and cloned into the pBluescript SK+ vector 703 (Stratagene/Agilent Technologies, Waldbronn, Germany) which was used a PCR 704 template for site-directed mutagenesis (A279T) to remove the internal Bsal recognition 705 site in SPL7 through a silent mutation. A Kozak consensus sequence and N- \& C706 terminal HA-tags were added to the genomic SPL7 sequence with primer overhangs 707 during the PCR amplification for the cloning into the Greengate entry module pGGI000 
708

709

710

711

712

713

714

715

716

717

718

719

720

721

722

723

724

725

726

727

728

729

730

731

732

733

734

735

736

737

738

via Bsal restriction. The downstream termSPL7 segment $(+1$ to +438 from end of translational stop codon) was PCR-amplified and cloned into the Greengate entry module pGGE000 via Bsal restriction. Using all entry modules and pGGF005 (Lampropoulos et al., 2013), the construct promSPL7::HA-SPL7-HA:termSPL7:HygR was assembled into the Greengate destination vector pGGZ003. The resulting binary plasmid was used to transform Agrobacterium tumefaciens (GV3130 [pSoup]), and the sp/7-1 mutant was transformed using the floral dip method (Clough and Bent, 1998). All primer sequences used for cloning are listed in Supplemental Table 3.

\section{Plant growth}

Soil cultivation was in $16-\mathrm{h}$ long days $\left(145 \mu \mathrm{mol} \mathrm{m} \mathrm{m}^{-2} \mathrm{~s}^{-1}, 22^{\circ} \mathrm{C}\right) / 8$-h night $\left(18^{\circ} \mathrm{C}\right)$, with $\mathrm{Cu}$ conditions as described (Schulten et al., 2019). Glass petri dishes were soaked in $0.2 \mathrm{~N}$ $\mathrm{HCl}$ overnight and rinsed with deionized water to remove possible contaminant $\mathrm{Cu}$ before autoclaving. For plant cultivation in sterile culture on glass petri dishes, wild-type or mutant seeds were surface-sterilized, stratified in the dark at $4^{\circ} \mathrm{C}$ for $2 \mathrm{~d}$ and sown on a modified Hoagland solution $\left(0.28 \mathrm{mM} \mathrm{KH}_{2} \mathrm{PO}_{4}, 1.25 \mathrm{mM} \mathrm{KNO}_{3}, 1.5 \mathrm{mM} \mathrm{Ca}\left(\mathrm{NO}_{3}\right)_{2}\right.$, $0.75 \mathrm{mM} \mathrm{MgSO}_{4}, 5 \mu \mathrm{M}$ of a complex of $\mathrm{Fe}(\mathrm{III})$ and N,N'-di-(2-hydroxybenzoyl)ethylenediamine- $N, N^{\prime}$-diacetate (HBED), $25 \mu \mathrm{M} \mathrm{H}_{3} \mathrm{BO}_{3}, 5 \mu \mathrm{M} \mathrm{MnSO}_{4}, 5 \mu \mathrm{M} \mathrm{ZnSO}_{4}, 0.5$ $\mu \mathrm{M} \mathrm{CuSO}_{4}, 50 \mu \mathrm{M} \mathrm{KCl}$, and $0.1 \mu \mathrm{M} \mathrm{Na}_{2} \mathrm{MoO}_{4}$, buffered at $\mathrm{pH} 5.7$ with $3 \mathrm{mM} 2-(N-$ morpholino)ethanesulfonate) in ultrapure water (Becher et al., 2004, with modifications), containing $1 \%(\mathrm{w} / \mathrm{v})$ sucrose unless indicated otherwise and solidified with $1 \%(\mathrm{w} / \mathrm{v})$ EDTA-washed Agar Type M (Sigma-Aldrich, Steinheim, Germany), as described (Schulten et al., 2019). Generally, 20 (or 40 for spl7-1 under conditions without added $\mathrm{CuSO}_{4}$ ) seedlings were cultivated on each vertically orientated round glass petri dish (diameter of $150 \mathrm{~mm}$ ) in 8-h short-day $\left(145 \mu \mathrm{mol} \mathrm{m} \mathrm{m}^{-2} \mathrm{~s}^{-1}, 22^{\circ} \mathrm{C}\right) / 16$-h night $\left(18^{\circ} \mathrm{C}\right)$ cycles in a growth chamber (CFL Plant Climatics, Wertingen, Germany) for $21 \mathrm{~d}$ and pooled during harvest. For ChIP and RNA-seq, seedlings were grown for $21 \mathrm{~d}$ as described for Cu deficiency experiments in sterile culture, on glass petri dishes in 11-h short days (Schulten et al., 2019).

336 For experiments with combined $\mathrm{Cu}$ and sugar treatments, seedlings were pre37 germinated on modified Hoagland's medium without added $\mathrm{CuSO}_{4}$, containing $0.5 \%$ (w/v) sucrose and solidified with 1\% (w/v) Agar Type M (Sigma-Aldrich, Steinheim, 
Germany), on square polypropylene petri dishes (120 mm x $120 \mathrm{~mm}$ ) for $7 \mathrm{~d}$. Seedlings were then transferred to controlled $\mathrm{Cu}$ growth conditions as described above for further cultivation for $14 \mathrm{~d}$, with addition of either $0.05 \mu \mathrm{M} \mathrm{CuSO}_{4}$ (low Cu) or $0.5 \mu \mathrm{M} \mathrm{CuSO}_{4}$ (control conditions) and $0 \%$ or $6 \%(\mathrm{w} / \mathrm{v})$ sucrose, respectively. All plants cultivated on soil and in agar-solidified media were harvested at Zeitgeber time (ZT) $3 \mathrm{~h}$ (3 h after lights on), or transferred darkness for $30 \mathrm{~min}$ at ZT $3 \mathrm{~h}$ for the quantification of ATP and $\mathrm{NADH} / \mathrm{NAD+}$, unless indicated otherwise.

For liquid cultures, $3.5 \mathrm{mg}$ of surface-sterilized and stratified seeds of wild type and sp/7-1 were grown in $50 \mathrm{ml}$ liquid 2x modified Hoagland solution with $0.5 \%(\mathrm{w} / \mathrm{v})$ sucrose in $300 \mathrm{ml}$ Erlenmeyer flasks placed on a rotation shaker $(80 \mathrm{rpm})$ in an 8-h day $\left(145 \mu \mathrm{mol} \mathrm{m} \mathrm{m}^{-2} \mathrm{~s}^{-1}, 22^{\circ} \mathrm{C}\right) / 16$-h night $\left(18^{\circ} \mathrm{C}\right)$ cycle in a growth chamber (CFL Plant Climatics, Wertingen, Germany) for $14 \mathrm{~d}$. Note that all liquid cultures were germinated without added $\mathrm{CuSO}_{4}$ for one week, after which the medium was exchanged and half of the cultures of each genotype were cultivated with $1 \mu \mathrm{M} \mathrm{CuSO}_{4}$ for the remainder of the growth period. Two days before the sugar starvation treatment (d 13), the medium was exchanged again. The 3-h sugar starvation treatment was started at ZT $1 \mathrm{~h}$ (on d 15: Cultures were washed twice with sterile ultrapure water and fresh solutions as before without or with $0.5 \%(\mathrm{w} / \mathrm{v})$ sucrose. For harvest $(\mathrm{ZT} 4 \mathrm{~h})$, seedlings were washed in ultrapure water, shoots were separated from roots with a scalpel and blotted dry before snap-freezing in liquid nitrogen.

\section{Quantification of plant biomass and elemental concentrations}

Quantification of plant biomass and elemental concentrations in plant tissues was conducted as described (Sinclair et al., 2017; Schulten et al., 2019). Aerial tissue samples were homogenized by grinding with a pestle in a mortar, which had been incubated in $0.2 \mathrm{~N} \mathrm{HCl}$ overnight, rinsed in ultrapure water and dried at $60^{\circ} \mathrm{C}$ for $>1 \mathrm{~h}$ beforehand.

\section{RNA extraction and quantitative real time RT-PCR}

RNA extraction, cDNA synthesis using oligo(dT) ${ }_{18}$ primers and reverse transcription quantitative real-time PCR (RT-qPCR) were performed as described (Schulten et al., 2019). Stem-loop pulsed reverse transcription of mature miRNAs was performed following a published protocol (Varkonyi-Gasic et al., 2007). Relative transcript levels 
770 (RTL) were calculated as follows: $R T L=R E_{m}{ }^{-\Delta C T}$, with $R E_{m}$ as the mean of reaction

771 efficiencies per primer pair and $\Delta \mathrm{C}_{\mathrm{T}}=\mathrm{C}_{\mathrm{T}}$ (target gene) $-\mathrm{C}_{\mathrm{T}}$ (constitutively expressed 772 reference genes: EIF4, HEL or TUB3), as described (Bernal et al., 2012). Primer 773 sequences are listed in Supplemental Table 3.

774 RNA in situ hybridization

775 Vegetative-stage shoot apical meristems were harvested from soil-grown plants at $8 \mathrm{~d}$ 776 (cultivation in $16 \mathrm{~h}$ long days) and $30 \mathrm{~d}$ (cultivation in $8 \mathrm{~h}$ short days) of age, 777 inflorescences from long-day grown plants at 15 to $20 \mathrm{~cm}$ height; tissues were 778 processed to conduct RNA in situ hybridization, with probe synthesis from the cds of 779 SPL7 amplified and cloned into pGEMTeasy (Promega) according to manufacturer 780 instructions, as described (Wahl et al., 2013).

\section{Metabolite extraction and measurement}

782

783

784

785

786

787

788

789

790

791

792

793

794

795

796

797

798

799

800

Anthocyanins were extracted from aliquots (50 to $100 \mathrm{mg}$ ) of frozen ground shoot tissue powder in $2 \mathrm{ml}$ methanol containing 1\%(w/v) $\mathrm{HCl}$ by shaking overnight on a rotational shaker $(150 \mathrm{rpm})$ at $4^{\circ} \mathrm{C}$ in the dark. Spectrophotometry was conducted on supernatants in 96-well plates and relative anthocyanin concentrations calculated as $\left(A_{530}-0.25^{\star} A_{657}\right) g^{-1}$ fresh biomass (Rabino and Mancinelli, 1986).

Soluble sugars were extracted from aliquots $(20 \mathrm{mg})$ of frozen ground shoot tissue powder in $250 \mu \mathrm{l}$ of $80 \%(\mathrm{v} / \mathrm{v})$ ethanol containing $10 \mathrm{mM} \mathrm{HEPES} / \mathrm{NaOH}\left(\mathrm{pH}\right.$ 7) at $80^{\circ} \mathrm{C}$ for $30 \mathrm{~min}$. After $10 \mathrm{~min}$ centrifugation at 3,500 rpm, the supernatant was collected and stored on ice. The extraction was repeated in $150 \mu$ of the same solution and in $250 \mu l$ of $50 \%(\mathrm{v} / \mathrm{v})$ ethanol containing $10 \mathrm{mM} \mathrm{HEPES} / \mathrm{NaOH}(\mathrm{pH} 7)$. Supernatants were combined and evaporated to dryness using a centrifugal vacuum dryer, followed by resuspension in $250 \mu \mathrm{l}$ sterile ultrapure water. Aliquots (10 to $50 \mu \mathrm{l}$ ) were analyzed for sucrose and glucose contents with the K-SUFRG Kit (Megazyme, Bray, Ireland) in triplicate measurements in 96-well plates using a Synergy HTX microplate reader (BioTek, Bad Friedrichshall, Germany). For the quantification of starch, dried residues from the ethanolic extractions were washed in $1 \mathrm{ml}$ ultrapure water, then resuspended in $400 \mu \mathrm{l}$ of $0.1 \mathrm{M} \mathrm{NaOH}$ and heated at $98^{\circ} \mathrm{C}$ for $30 \mathrm{~min}$. After $\mathrm{pH}$ neutralization, $100 \mu \mathrm{l}$ starch degradation mix (16.8 units $\mathrm{ml}^{-1}$ amyloglucosidase [\#10102857001; Roche, Mannheim, Germany] and 12 units $\mathrm{ml}^{-1}$ a-amylase [\#10102814001; Roche, Mannheim, 
801 Germany] in $50 \mathrm{mM} \mathrm{Na-acetate} \mathrm{pH}$ 4.9) was added per sample, followed by constant 802 shaking at $37^{\circ} \mathrm{C}$ overnight. After centrifugation as described above, aliquots (50 $\left.\mu \mathrm{l}\right)$ were 803 used for the quantification of glucose levels as described above.

804 Trehalose 6-phosphate (T6P), phosphorylated intermediates and organic acids were 805 extracted from aliquots (15 to $20 \mathrm{mg}$ ) of frozen ground shoot tissue powder in 806 chloroform/methanol (3:7, v/v) and evaporated to dryness using a centrifugal vacuum 807 dryer. The dried extracts were dissolved in $350 \mu$ purified water and filtered through 808 MultiScreen PCR-96 Filter Plate membranes (Merck Millipore, Darmstadt, Germany) to 809 remove high-molecular-mass compounds. The metabolite extracts were subjected to 810 high-performance anion-exchange chromatography coupled to tandem mass spectrometry (LC-MS/MS) as described (Lunn et al., 2006), with modifications (Figueroa 812 et al., 2016).

813 For the quantification of adenosine triphosphate (ATP) levels, frozen ground shoot 814 tissue $(50 \mathrm{mg}$ ) was homogenized in $1 \mathrm{ml}$ phenol (equilibrated with $10 \mathrm{mM} \mathrm{TRIS} / \mathrm{HCl}, 1$ $\mathrm{mM}$ EDTA, $\mathrm{pH}$ 8) and extracted into $0.5 \mathrm{ml}$ of $10 \mathrm{mM} \mathrm{TRIS} / \mathrm{HCl}(\mathrm{pH}$ 8).a protocol for maize endosperm (Lappe et al., 2018). After centrifugation for $10 \mathrm{~min}$ at 10,000×g, the aqueous phase was extracted in an equal volume of chloroform. The supernatant was diluted 200-fold in $10 \mathrm{mM}$ Tris/ $\mathrm{HCl}(\mathrm{pH} 8)$, and $100 \mu \mathrm{l}$ sample volumes were assayed in triplicate for ATP content using the BacTiter-Glo bioluminescence kit (Promega, Mannheim, Germany). After 5 min incubation in the dark to allow for the decay of plate autofluorescence, photon emissions were recorded in white 96-well plates with an integration time of $0.5 \mathrm{~s}$ using a Synergy HTX microplate reader. ATP concentrations were quantified based on a standard curve (50 pM to $1 \mu \mathrm{M})$ and normalized to fresh biomass. For the quantification of $\mathrm{NAD}^{+}$and $\mathrm{NADH}$ levels, 25-mg aliquots of frozen ground shoot tissues were extracted with $250 \mu \mathrm{l}$ of either $0.2 \mathrm{M} \mathrm{NaOH}$ (NADH) or $0.2 \mathrm{M}$ $\mathrm{HCl}\left(\mathrm{NAD}^{+}\right)$. The homogenates were centrifuged at $10,000 \times \mathrm{xg}$ and $4^{\circ} \mathrm{C}$ for $10 \mathrm{~min}$. The supernatant $(200 \mu \mathrm{l})$ was neutralized with $175 \mu \mathrm{l}$ of either $0.2 \mathrm{M} \mathrm{HCl}$ or $0.2 \mathrm{M} \mathrm{NaOH}$ and 828 the neutralization to $\mathrm{pH} 7$ to 8 was confirmed with $\mathrm{pH}$ indicator paper. Aliquots of $50 \mu \mathrm{l}$ 829 were analyzed in triplicate for $\mathrm{NAD}^{+}$and NADH with the NAD/NADH-Glo Kit (Promega, 830 Mannheim, Germany) in white 96-well plates using a Synergy HTX microplate reader, with normalization to fresh biomass. 
832

833

834

835

836

837

838

839

840

841

842

843

844

845

846

847

848

849

850

851

852

853

854

855

856

857

858

859

860

861

862

\section{Respiration measurements}

The uptake of $\mathrm{O}_{2}$ by whole rosettes was quantified using a CG867 $\mathrm{O}_{2}$-meter (Schott Instruments, Weilheim, Germany) and the Clark-type oxygen electrode OX1100 (Schott Instruments, Weilheim, Germany), calibrated with saturated sodium dithionite solution and air-saturated water. Measurements were performed in darkness under constant stirring in a cuvette surrounded by a water-flow cooling system. Seedlings were kept in the dark for $30 \mathrm{~min}$ prior to the start of measurements to prevent photosynthesis. A total of $100 \mathrm{mg}$ fresh biomass of rosette tissue was submerged in $3 \mathrm{~mL}$ of air-saturated 20 $\mathrm{mM}$ potassium phosphate buffer $(\mathrm{pH} \mathrm{6.8)}$ in the measuring cuvette. After 5 min of equilibration time, total respiration was monitored for 10 min during which $\mathrm{O}_{2}$ concentration was recorded every $30 \mathrm{sec}$. Then, potassium cyanide (KCN, $1 \mathrm{mM}$ final concentration) or salicylhydroxamic acid (SHAM, $20 \mathrm{mM}$ final concentration) were added to the cuvette for the measurement of cyanide (CN)- or SHAM-resistant respiration, respectively. Following the addition of an inhibitor and stabilization of the rate of $\mathrm{O}_{2}$ uptake during an equilibration time, respiration was monitored for another 7 to $10 \mathrm{~min}$.

\section{Immunoblots}

Immunological detection of S6K-1/2 and S6K-p and was performed as described with some modifications (Dong et al., 2017). In brief, total soluble protein was extracted from $50 \mathrm{mg}$ of ground frozen shoot material in $250 \mu \mathrm{l} 2 \times$ Laemmli buffer supplemented with $1 \%(v / v)$ phosphatase inhibitor cocktail 2 (Sigma-Aldrich, Steinheim, Germany). Proteins were denatured for $10 \mathrm{~min}$ at $90^{\circ} \mathrm{C}$ and separated using $10 \%(\mathrm{w} / \mathrm{v})$ SDS-PAGE (22 mA, $2 \mathrm{~h}$ ), followed by wet tank transfer to nitrocellulose membranes $\left(100 \mathrm{~V}, 1 \mathrm{~h}, 4^{\circ} \mathrm{C}\right)$ (Towbin et al., 1979). After Ponceau staining (0.2\% [w/v] Ponceau-S in $1 \%[\mathrm{v} / \mathrm{v}]$ acetic acid) to confirm equal loading per lane and blocking with $5 \%(\mathrm{w} / \mathrm{v})$ BSA in TRIS-buffered saline containing $0.05 \%(\mathrm{v} / \mathrm{v})$ Tween-20 (TBST) for $1 \mathrm{~h}$, membranes were incubated with the primary antibody Phospho-p70 S6 Kinase (\#9205; Cell Signaling, Frankfurt am Main, Germany) or anti-S6K1/2 (\#AS12-1855; Agrisera, Vännas, Sweden) diluted $1: 5,000$ in TBST additionally containing $1 \%(\mathrm{w} / \mathrm{v})$ BSA (TBSTB) at $4^{\circ} \mathrm{C}$ overnight. Membranes were washed 3 times 10 min in TBST and then incubated with an HRPconjugated secondary antibody diluted 1:15,000 in TBSTB at RT for $1 \mathrm{~h}$. After repeating 
863 the washes with TBST, detection was carried out with Pierce ECL Western Blotting 864 Substrate (ThermoFisher, Schwerte, Germany) using a Fusion Fx7 GelDoc (Vilber 865 Lourmat, Eberhardzell, Germany).

866 For the immunological detection of HA epitope-tagged SPL7, total soluble proteins were 867 extracted from $50 \mathrm{mg}$ of ground frozen shoot material with $100 \mu \mathrm{l} 2 \times$ Laemmli buffer 868 (\#S3401, Sigma-Aldrich, Steinheim, Germany). Proteins were denatured and separated 869 as described above, with wet/tank transfer overnight (60 mA, 4 $\mathrm{C}$ ) (Towbin et al., 1979). 870 After Ponceau staining of the membrane as described above and blocking with $5 \%(\mathrm{w} / \mathrm{v})$ 871 blotting-grade milk powder in TBST for $1 \mathrm{~h}$, membranes were incubated with the primary 872 anti-HA antibody (\#26183; ThermoFisher, Schwerte, Germany) diluted 1:5,000 in TBST 873 containing 1\% (w/v) milk powder (TBSTM) or anti-Actin antibody diluted 1:2,500 in 874 TBSTM (\#AS132640; Agrisera, Vännas, Sweden) at RT for 2 h. Membranes were 875 washed as described above and then incubated with HRP-conjugated secondary 876 antibodies (ThermoFisher, Schwerte, Germany) diluted 1:250 (\#32430 following anti$877 \mathrm{HA}$ ) in TBSTM or 1:2,500 (\#31466, following anti-Actin) in TBSTM at RT for $1 \mathrm{~h}$, 878 followed by washing as described above and detection with ECL Select Western 879 Blotting Reagent (GE Healthcare, Little Chalfont, England) as described above.

880 Flowering time parameters

881 The number of days to flowering was counted from the day the seeds were placed in 882 the growth chamber after stratification until the bolting shoot reached $\sim 0.5 \mathrm{~cm}$ in length. 883 Rosette leaves were counted alongside plant growth until the bolting shoot had reached 884 $\sim 0.5 \mathrm{~cm}$ in length. Plants were photographed $10 \mathrm{~d}$ after bolting to record the flowering phenotype. Rosette leaves and aerial tissues above the rosette were then harvested for analysis of elemental contents.

888 For samples of pooled rosette leaves of 80 spl7-1 HA-SPL7-HA or wild-type seedlings 889 grown on petri plates, chromatin was crosslinked by vacuum-infiltrating seedlings in a 890 solution of $1 \%(\mathrm{w} / \mathrm{v})$ formaldehyde in PBS buffer for $5 \mathrm{~min}$, briefly releasing the vacuum, 891 followed by vacuum-infiltration for another $10 \mathrm{~min}$ (Gendrel et al., 2002). The cross892 linking reaction was stopped by adding glycine to a final concentration of $0.125 \mathrm{M}$ and 893 vacuum-infiltrating for $5 \mathrm{~min}$. The rosettes were rinsed twice with sterile ultrapure water 
894 (Purelab Flex 2; ELGA LabWater, Celle, Germany), blotted dry and snap-frozen in liquid 895 nitrogen. After grinding the plant material to a fine powder with a mortar and pestle in 896 liquid nitrogen, nuclei were isolated as described (Moehs et al., 1988), with all extraction 897 buffers additionally containing $1 \mathrm{mM}$ phenylmethylsulfonyl fluoride (PMSF) and protease 898 inhibitor cocktail (PIC) in a 1:1000 dilution (P9599, Sigma-Aldrich, Steinheim, Germany). 899 Chromatin was extracted with nuclei lysis buffer $(50 \mathrm{mM}$ TRIS/HCI pH 8, $10 \mathrm{mM}$ EDTA, $9001 \%[\mathrm{w} / \mathrm{v}]$ SDS, $1 \mathrm{mM}$ PMSF, PIC) and sonicated using the Bioruptor Pico (Diagenode, 901 Seraing, Belgium) for 5 cycles (30 s on/ $30 \mathrm{~s}$ off) to achieve an average fragment size of 902200 bp. After removing cellular debris by centrifugation (twice for 10 min at $10.000 \times g$ ), 903 the chromatin was diluted 10-fold with ChIP dilution buffer (1.1\% [v/v] Triton x-100, 1.2 $904 \mathrm{mM}$ EDTA, $16.7 \mathrm{mM}$ TRIS/HCl pH 8, $167 \mathrm{mM} \mathrm{NaCl}$ ) and pre-cleared at $4^{\circ} \mathrm{C}$ for $1 \mathrm{~h}$ by 905 incubating with $80 \mu$ l of protein A beads (\#17127901, GE Healthcare, Freiburg, Germany), pre-equilibrated with ChIP dilution buffer. After the pre-clear, an aliquot 908 corresponding to $1 \%(\mathrm{v} / \mathrm{v})$ of the starting chromatin volume was removed for use as the input DNA control. Monoclonal anti-HA antibody 12CA5 (ROAHA; Roche, Mannheim, Germany) was used to immunoprecipitate HA-SPL7-HA-bound chromatin (5 $\mu \mathrm{g}$ of antibody per IP) with $50 \mu$ of pre-equilibrated protein $A$ beads at $4^{\circ} \mathrm{C}$ overnight on a rotator (12 rpm). Washes of the immunocomplexes were performed as follows: one wash step with low salt wash buffer $(150 \mathrm{mM}, 0.1 \%$ (w/v) SDS, 1\% (v/v) Triton X-100, 2 $\mathrm{mM}$ EDTA, $20 \mathrm{mM}$ TRIS/HCl pH 8), two wash steps with high salt wash buffer $(500 \mathrm{mM}$, 0.1\% (w/v) SDS, 1\% (v/v) Triton X-100, 2 mM EDTA, 20 mM TRIS/HCl pH 8), three wash steps with $\mathrm{LiCl}$ wash buffer $(250 \mathrm{mM} \mathrm{LiCl,} \mathrm{0.5 \%} \mathrm{(w/v)} \mathrm{IGEPAL,} \mathrm{0.5 \%} \mathrm{(w/v)} \mathrm{sodium}$ deoxycholate, $1 \mathrm{mM}$ EDTA, $10 \mathrm{mM}$ TRIS/HCl pH 8) and two wash steps with TE buffer 917 (1 mM EDTA, 10 mM TRIS/HCl pH 8) (Yamaguchi et al., 2014a, with modifications). 918 The immunocomplexes were eluted twice from the protein $A$ beads with freshly 919 prepared elution buffer $\left(1 \%[\mathrm{w} / \mathrm{v}] \mathrm{SDS}, 0.1 \mathrm{M} \mathrm{NaHCO}_{3}\right)$ by incubating at $65^{\circ} \mathrm{C}$ for $15 \mathrm{~min}$ 920 at $1200 \mathrm{rpm}$ in a ThermoMixer Comfort (Eppendorf AG, Hamburg, Germany). NaCl was 921 added to the eluates and the input DNA aliquots to a final concentration of $0.2 \mathrm{M}$; 922 samples were then incubated overnight $\left(65^{\circ} \mathrm{C}, 600 \mathrm{rpm}\right)$ for de-crosslinking and treated 923 with proteinase $\mathrm{K}$ at $42^{\circ} \mathrm{C}$ for $1 \mathrm{~h}$. DNA was purified with the NucleoSpin PCR Cleanup 
924 kit (\#740609; Macherey-Nagel, Düren, Germany) with buffer NTB (\#740595.150;

925 Macherey-Nagel, Düren, Germany) and eluted in $15 \mu \mathrm{l}$ of $5 \mathrm{mM}$ TRIS/HCl pH 8.5.

926 ChIP samples were tested for enrichment by qPCR, performed as described, measuring

927 enrichment on the promoter regions of FSD1 and MIR408 as positive controls and

928 ACTIN7 as a negative control (Schulten et al., 2019). The sequences of the primers

929 used in ChIP-qPCR are listed in Supplemental Table 1. Libraries for ChIP-seq were

930 prepared and sequenced at the Max-Planck-Genome Center Cologne on an Illumina

931 HiSeq3000 instrument (Romera-Branchat et al., 2020).

932 Transcriptome sequencing

933 Wild-type and spl7-1 seedlings were grown and harvested as described above for ChIP.

934 Total RNA was extracted from 50-mg aliquots of frozen ground rosette tissues using the 935 RNeasy Plant Mini Kit (\#74904, Qiagen, Hilden, Germany) including on-column DNase 936 digestion to remove any contaminating genomic DNA (\#79254, Qiagen, Hilden, 937 Germany). RNA was quantified using the Qubit RNA Assay Kit in a Qubit 2.0 938 Fluorometer (Thermo Fisher, Schwerte, Germany). RNA integrity was assessed with the 939 RNA Nano 6000 Assay Kit of the Agilent Bioanalyzer 2100 system (Agilent 940 Technologies, Waldbronn, Germany) and the RNA integrity number (RIN) was between 9418 and 9 for all samples. Library construction and next-generation sequencing were 942 performed using Illumina technology by the Novogene Company (Wan Chai, Hong 943 Kong). In brief, $1 \mu \mathrm{g}$ of total RNA was used as input for library preparation, mRNA was 944 enriched with oligo(dT)-beads and cDNA was synthesized with random hexamer 945 primers with the NEB Next Ultra RNA Library Prep Kit (NEB, Ipswich, USA). All libraries

946 were sequenced using the Illumina NovaSeq6000 platform in paired-end mode with a 947 read length of $150 \mathrm{bp}$.

948 Chromatin immunoprecipitation sequence data analysis

949 Upon sequencing of chromatin immonoprecipitates and the corresponding input control 950 libraries of all samples from four independent experiments (addressed as four replicates 951 below), adapter sequences were removed and low-quality ends were trimmed from raw 952 reads using cutadapt (Martin, 2011) and Trimmomatic (Bolger et al., 2014), respectively. 953 Read length distribution was summarized using the density function available in $R$ ( $R$ 954 Core Team, 2019). Reads were mapped to the $A$. thaliana TAIR10 reference genome 
955

956

957

958

959

960

961

962

963

964

965

966

967

968

969

970

971

972

973

974

975

976

977

978

979

980

981

982

983

984

assembly using bowtie2 (Langmead et al., 2009; Langmead and Salzberg, 2012) with default settings and a minimum mapping quality of 30, obtaining between 9 and 11 mio. reads per sample (median 10.4 mio. reads). ChIP peaks were identified using MACS2 v2.1.3.3 (Zhang et al., 2008) on each IP together with the respective INPUT from each sample by adjusted manifold confidence of enrichment ratio (-m 2 20; FDR $\leq 0.05$ (Benjamini and Hochberg, 1995). The peaks of replicates were merged when at least $80 \%$ of the length of the shortest genomic segment covered by a peak overlapped with the segment covered by another peak (Romera-Branchat et al., 2020). A merged peak segment was thus at least as long as, or longer than, the broadest of the replicate peaks merged. A peak was considered as present in both low $\mathrm{Cu}$ and control $\mathrm{Cu}$ conditions when there was any overlap between the segments defined by peak center (mid-point of segment covered by the merged peak) $\pm 30 \%$ length of segment covered by the merged peak, respectively. Peaks were associated with $A$. thaliana genes (TAIR10) using Bioconductor $\mathrm{R}$ package chipPeakAnno and as previously described (Romera-Branchat et al., 2020).

\section{RNAseq data analysis}

Adapters and low-quality bases were removed in RNAseq data from three independent experiments using trimmomatic (Bolger et al., 2014), keeping reads of at least $120 \mathrm{bp}$ in length (19.6 to 27.3 million trimmed reads per sample). Reads were mapped to the $A$. thaliana TAIR10 genome assembly using hisat2 v2.1, excluding unaligned reads from the output BAM file (Lamesch et al., 2012; Berardini et al., 2015; Kim et al., 2019), followed by corrections of multiple mapping with identical start or end positions through COMEX 2.1 (Pietzenuk et al., 2016). Total numbers of counts per gene were retrieved non-strand specifically using Qualimap v.2.2.1 employing the proportional algorithm for multiply mapping reads and the $A$. thaliana Araport11 genome annotation (Okonechnikov et al., 2016; Cheng et al., 2017). Differentially expressed genes were identified using DESeq2 version 3.11 on the $\mathrm{R}$ 4.0.3 statistical computing platform with default settings using the local fit type (fitType = "local") (Love et al., 2014; R Core Team, 2019)(Supplemental Data Sets 3 and 5).

\section{Motif discovery}


985 For each set of ChIP peaks (Supplemental Data Set 1) passing a given set of filters

986 (Supplemental Data Sets 3 to 6), the corresponding genomic sequences were extracted 987 and analyzed for enriched motifs using MEME-ChIP (Bailey et al., 2009; Machanick and 988 Bailey, 2011), with the following parameters: maximum motif width (-meme-maxw) 10, 989 minimum motif width (-meme-minw) 4, motif occurrences mode (-meme-mod), anr (any 990 number of repetitions), and motif database (-db) ArabidopsisDAPv1.meme. The 991 predicted motifs were extracted from the corresponding FIMO output GFF file using a 992 custom-made shell script and subsequently collated with the corresponding set of genes 993 for calculation of motif distance to peak center, motif distance to TSS (gene 994 transcriptional start site) and motif incidence using custom-made scripts.

995 Quantification and statistical analyses

996 Each experiment was repeated independently two to three times. Poorly germinated seedlings or obvious phenotypic outlier individuals were excluded from harvest and measurements. Data are shown from one representative experiment, with $n$ as 999 indicated in the figure legends. Statistical analyses were performed with R v.3.5.0 (R 1000 Core Team, 2019). ANOVA followed by a Tukey's post hoc test $(p<0.05)$ was 1001 conducted for datasets with homoscedasticity and a normal distribution of residuals. For 1002 all other datasets, pairwise $t$-tests (Student's $t$-test or Welch $t$-test as applicable) with 1003 false discovery rate adjustment $(q$-value $<0.05)$ were performed instead (Storey et al., 1004 2019).

\section{Accession numbers}

1006 Sequence data from this article can be found at ENA, EMBL-EBI under accession 1007 number PRJEB47134 (ERR6548266 - ERR6548277 for RNA-seq, ERR6558497 1008 ERR6558513 for ChIP-seq).

\section{Acknowledgements}

1011 We thank Petra Düchting (Ruhr University Bochum, Germany) for multi-element 1012 analysis, John E. Lunn (Max Planck Institute of Molecular Plant Physiology, Golm, 1013 Germany) for discussions of metabolite data as well as Dr. Yihan Dong (Institute of 1014 Molecular Biology of Plants, Strasbourg, France) and Dr. Markus Wirtz (Centre for 1015 Organismal Studies, Heidelberg, Germany) for advice on S6K immunoblots. This work 
1016

1017

1018

1019

1020

1021

1022

1023

1024

1025

1026

1027

1028

1029

1030

1031

1032

1033

1034

1035

1036

1037

1038

1039

1040

1041

1042

1043

1044

1045

1046

was funded by the Deutsche Forschungsgemeinschaft (Kr1967/15-1) and Ruhr University Bochum, Germany.

\section{Author contributions}

A.S., J.Q., M. R.-B., R.F. and V.W. performed experiments, A.S., B.P., M.K., E.S., G.C. and U.K. conducted computational or other data analysis, A.S. and U.K. designed the research and wrote the manuscript, with contributions from J.Q. and B.P., all authors edited the manuscript.

\section{Supplemental Data}

Supplemental Table 1. Metabolite data related to Fig. 3D and Fig. S6C-D

Supplemental Table 2. Number of genes commonly identified in the present study and in earlier studies.

Supplemental Table 3. Oligonucleotides used in this study

Supplemental Figure 1. Effects of $\mathrm{Cu}$ deficiency and sucrose on nutrient metal concentrations in wild-type and sp/7-1 mutant seedlings.

Supplemental Figure 2. Sucrose does not stimulate shoot fresh biomass gain in the sp/7-1 mutant cultivated under low-Cu conditions.

Supplemental Figure 3. Independent experiment (repeat) related to Figure 1 (C-E). Supplemental Figure 4. Effects of $\mathrm{Cu}$ deficiency and sucrose on relative transcript levels of known SPL7-dependently expressed genes.

Supplemental Figure 5. Starch levels in wild-type and sp/7-1 mutant seedlings upon cultivation in agar-solidified media containing different combinations of $\mathrm{Cu}$ and sucrose.

Supplemental Figure 6. Independent experiments (repeats) related to Figure 2. Supplemental Figure 7. Two independent experiments (repeats) related to Figure 4. Supplemental Figure 8. Two independent experiments (repeats) related to Figure 5 (D, E).

Supplemental Figure 9. Complementation of the sp/7-1 mutant through the $P_{S P L 7}:$ HASPL7-HA:t ${ }_{S P L 7}$ transgene (two independent lines in addition to line 4-1 shown in Figure $6)$. 
1047 Supplemental Figure 10. Full image and independent replication of immunoblot shown 1048 in Figure 6C.

1049 Supplemental Figure 11. Distribution of genomic SPL7 binding sites relative to genes.

1050 Supplemental Figure 12. SPL7 binding profiles at chosen loci, and two independent 1051 repeats related to Figure 7C.

1052 Supplemental Figure 13. Enriched motifs identified by MEME motif analysis among 1053 SPL7 binding sites detected exclusively under low $\mathrm{Cu}$.

1054 Supplemental Figure 14. Enriched motifs identified by MEME motif analysis on 1055 subgroups of SPL7 binding sites delineated by including information on gene 1056 expression.

1057 Supplemental Figure 15. Putative SPL7-binding motifs at the FE SUPEROXIDE 1058 DISMUTASE1 (FSD1) locus identified by ChIP-seq.

1059

Supplemental Figure 16. GO and KEGG enrichment analyses.

1060

1061

Supplemental Data Set 1. Genomic binding sites of SPL7 detected by ChIP-seq.

1062

Supplemental Data Set 2. Genes associated with SPL7 binding sites detected by

1063 ChIP-seq, and comparison with published DAP-seq data for other Arabidopsis SPL 1064 proteins.

1065

Supplemental Data Set 3. Universal RNA-seq data.

1066

Supplemental Data Set 4. Motifs in genomic SPL7 binding sites identified by ChIP-seq.

1067

Supplemental Data Set 5. Genes exhibiting both SPL7-dependent regulation of transcript abundance and SPL7-binding peaks identified by ChIP-seq.

1069 Supplemental Data Set 6. Putative SPL7-binding sequence motifs within the SPL71070 binding region at the FE SUPEROXIDE DISMUTASE1 (FSD1) locus identified by ChIP1071 seq.

\section{References}

Abdel-Ghany, S.E., and Pilon, M. (2008). MicroRNA-mediated systemic down-regulation of copper protein expression in response to low copper availability in Arabidopsis. J Biol Chem 283, 1593215945. ATPases are required for copper delivery in Arabidopsis thaliana chloroplasts. Plant Cell 17, 1233-1251. 
Assunção, A.G.L., Herrero, E., Lin, Y.-F., Huettel, B., Talukdar, S., Smaczniak, C., Immink, R.G.H., van Eldik, M., Fiers, M., Schat, H., and Aarts, M.G.M. (2010). Arabidopsis thaliana transcription factors bZIP19 and bZIP23 regulate the adaptation to zinc deficiency. Proc Natl Acad Sci USA 107, 10296.

Attallah, C.V., Welchen, E., Martin, A.P., Spinelli, S.V., Bonnard, G., Palatnik, J.F., and Gonzalez, D.H. (2011). Plants contain two SCO proteins that are differentially involved in cytochrome $c$ oxidase function and copper and redox homeostasis. J Exp Bot 62, 4281-4294.

Azcón-Bieto, J., Lambers, H., and Day, D.A. (1983). Effect of photosynthesis and carbohydrate status on respiratory rates and the involvement of the alternative pathway in leaf respiration. Plant Physiol 72, 598-603.

Baena-Gonzalez, E., and Hanson, J. (2017). Shaping plant development through the SnRK1-TOR metabolic regulators. Curr Opin Plant Biol 35, 152-157.

Baena-González, E., Rolland, F., Thevelein, J.M., and Sheen, J. (2007). A central integrator of transcription networks in plant stress and energy signalling. Nature 448, 938.

Bahr, J.T., and Bonner, W.D., Jr. (1973). Cyanide-insensitive respiration. II. Control of the alternate pathway. J Biol Chem 248, 3446-3450.

Bailey, T.L., Boden, M., Buske, F.A., Frith, M., Grant, C.E., Clementi, L., Ren, J., Li, W.W., and Noble, W.S. (2009). MEME SUITE: tools for motif discovery and searching. Nucleic Acids Res 37, W202208.

Becher, M., Talke, I.N., Krall, L., and Krämer, U. (2004). Cross-species microarray transcript profiling reveals high constitutive expression of metal homeostasis genes in shoots of the zinc hyperaccumulator Arabidopsis halleri. Plant J 37, 251-268.

Benjamini, Y., and Hochberg, Y. (1995). Controlling the False Discovery Rate: A Practical and Powerful Approach to Multiple Testing. Journal of the Royal Statistical Society: Series B (Methodological) 57, 289-300.

Berardini, T.Z., Reiser, L., Li, D., Mezheritsky, Y., Muller, R., Strait, E., and Huala, E. (2015). The Arabidopsis information resource: Making and mining the "gold standard" annotated reference plant genome. Genesis 53, 474-485.

Bernal, M., Casero, D., Singh, V., Wilson, G.T., Grande, A., Yang, H., Dodani, S.C., Pellegrini, M., Huijser, P., Connolly, E.L., Merchant, S.S., and Krämer, U. (2012). Transcriptome sequencing identifies SPL7-regulated copper acquisition genes FRO4/FRO5 and the copper dependence of iron homeostasis in Arabidopsis. Plant Cell 24, 738-761.

Birkenbihl, R.P., Jach, G., Saedler, H., and Huijser, P. (2005). Functional dissection of the plant-specific SBP-domain: overlap of the DNA-binding and nuclear localization domains. J Mol Biol 352, 585596.

Blaby-Haas, C.E., Padilla-Benavides, T., Stube, R., Argüello, J.M., and Merchant, S.S. (2014). Evolution of a plant-specific copper chaperone family for chloroplast copper homeostasis. Proc Natl Acad Sci USA 111, E5480-5487.

Bolger, A.M., Lohse, M., and Usadel, B. (2014). Trimmomatic: a flexible trimmer for Illumina sequence data. Bioinformatics 30, 2114-2120.

Cardon, G., Hohmann, S., Klein, J., Nettesheim, K., Saedler, H., and Huijser, P. (1999). Molecular characterisation of the Arabidopsis SBP-box genes. Gene 237, 91-104.

Caspar, T., Huber, S.C., and Somerville, C. (1985). Alterations in Growth, Photosynthesis, and Respiration in a Starchless Mutant of Arabidopsis thaliana (L.) Deficient in Chloroplast Phosphoglucomutase Activity. Plant Physiol 79, 11-17.

Chao, L.M., Liu, Y.Q., Chen, D.Y., Xue, X.Y., Mao, Y.B., and Chen, X.Y. (2017). Arabidopsis Transcription Factors SPL1 and SPL12 Confer Plant Thermotolerance at Reproductive Stage. Mol Plant 10, 735748. 
Cheng, C.Y., Krishnakumar, V., Chan, A.P., Thibaud-Nissen, F., Schobel, S., and Town, C.D. (2017). Araport11: a complete reannotation of the Arabidopsis thaliana reference genome. Plant J 89, 789-804.

Cho, Y.H., Yoo, S.D., and Sheen, J. (2006). Regulatory functions of nuclear hexokinase1 complex in glucose signaling. Cell 127, 579-589.

Clemens, S. (2001). Molecular mechanisms of plant metal tolerance and homeostasis. Planta 212, 475486.

Clough, S.J., and Bent, A.F. (1998). Floral dip: a simplified method for Agrobacterium-mediated transformation of Arabidopsis thaliana. Plant J 16, 735-743.

Colangelo, E.P., and Guerinot, M.L. (2004). The Essential Basic Helix-Loop-Helix Protein FIT1 Is Required for the Iron Deficiency Response. Plant Cell 16, 3400.

Cui, L.-G., Shan, J.-X., Shi, M., Gao, J.-P., and Lin, H.-X. (2014). The miR156-SPL9-DFR pathway coordinates the relationship between development and abiotic stress tolerance in plants. Plant J 80, 1108-1117.

Dahan, J., Tcherkez, G., Macherel, D., Benamar, A., Belcram, K., Quadrado, M., Arnal, N., and Mireau, H. (2014). Disruption of the CYTOCHROME C OXIDASE DEFICIENT1 gene leads to cytochrome $c$ oxidase depletion and reorchestrated respiratory metabolism in Arabidopsis. Plant Physiol 166, 1788-1802.

Deprost, D., Yao, L., Sormani, R., Moreau, M., Leterreux, G., Nicolaï, M., Bedu, M., Robaglia, C., and Meyer, C. (2007). The Arabidopsis TOR kinase links plant growth, yield, stress resistance and mRNA translation. EMBO Rep 8, 864-870.

Dobrenel, T., Mancera-Martínez, E., Forzani, C., Azzopardi, M., Davanture, M., Moreau, M., Schepetilnikov, M., Chicher, J., Langella, O., Zivy, M., Robaglia, C., Ryabova, L.A., Hanson, J., and Meyer, C. (2016). The Arabidopsis TOR Kinase Specifically Regulates the Expression of Nuclear Genes Coding for Plastidic Ribosomal Proteins and the Phosphorylation of the Cytosolic Ribosomal Protein S6. Front Plant Sci 7, 1611-1611.

Dong, J., Kim, S.T., and Lord, E.M. (2005). Plantacyanin Plays a Role in Reproduction in Arabidopsis. Plant Physiol 138, 778.

Dong, Y., Silbermann, M., Speiser, A., Forieri, I., Linster, E., Poschet, G., Allboje Samami, A., Wanatabe, M., Sticht, C., Teleman, A.A., Deragon, J.M., Saito, K., Hell, R., and Wirtz, M. (2017). Sulfur availability regulates plant growth via glucose-TOR signaling. Nat Commun 8, 1174.

Figueroa, C.M., and Lunn, J.E. (2016). A Tale of Two Sugars: Trehalose 6-Phosphate and Sucrose. Plant Physiol 172, 7-27.

Figueroa, C.M., Feil, R., Ishihara, H., Watanabe, M., Kölling, K., Krause, U., Höhne, M., Encke, B., Plaxton, W.C., Zeeman, S.C., Li, Z., Schulze, W.X., Hoefgen, R., Stitt, M., and Lunn, J.E. (2016). Trehalose 6-phosphate coordinates organic and amino acid metabolism with carbon availability. Plant J 85, 410-423.

Foster, A.W., Osman, D., and Robinson, N.J. (2014). Metal Preferences and Metallation. J Biol Chem 289, 28095-28103.

Fraústo da Silva, J.J.R., and Williams, R.J.P. (2001). The Biological Chemistry of the Elements. (Oxford, UK: Oxford University Press).

Garcia-Molina, A., Xing, S., and Huijser, P. (2014a). A conserved KIN17 curved DNA-binding domain protein assembles with SQUAMOSA PROMOTER-BINDING PROTEIN-LIKE7 to adapt Arabidopsis growth and development to limiting copper availability. Plant Physiol 164, 828-840.

Garcia-Molina, A., Xing, S., and Huijser, P. (2014b). Functional characterisation of Arabidopsis SPL7 conserved protein domains suggests novel regulatory mechanisms in the $\mathrm{Cu}$ deficiency response. BMC Plant Biol 14, 231. 
Garcia, L., Welchen, E., Gey, U., Arce, A.L., Steinebrunner, I., and Gonzalez, D.H. (2016). The cytochrome $\underline{\mathrm{c}}$ oxidase biogenesis factor AtCOX17 modulates stress responses in Arabidopsis. Plant Cell Environ 39, 628-644.

Gendrel, A.-V., Lippman, Z., Yordan, C., Colot, V., and Martienssen, R.A. (2002). Dependence of Heterochromatic Histone H3 Methylation Patterns on the Arabidopsis Gene DDM1. Science 297, 1871-1873.

Gibon, Y., Bläsing, O.E., Palacios-Rojas, N., Pankovic, D., Hendriks, J.H., Fisahn, J., Hohne, M., Gunther, M., and Stitt, M. (2004). Adjustment of diurnal starch turnover to short days: depletion of sugar during the night leads to a temporary inhibition of carbohydrate utilization, accumulation of sugars and post-translational activation of ADP-glucose pyrophosphorylase in the following light period. Plant J 39, 847-862.

He, J., Xu, M., Willmann, M.R., McCormick, K., Hu, T., Yang, L., Starker, C.G., Voytas, D.F., Meyers, B.C., and Poethig, R.S. (2018). Threshold-dependent repression of SPL gene expression by miR156/miR157 controls vegetative phase change in Arabidopsis thaliana. PLOS Genet 14, e1007337.

Heim, M.A., Jakoby, M., Werber, M., Martin, C., Weisshaar, B., and Bailey, P.C. (2003). The basic helixloop-helix transcription factor family in plants: a genome-wide study of protein structure and functional diversity. Mol Biol Evol 20, 735-747.

Heineke, D., Riens, B., Grosse, H., Hoferichter, P., Peter, U., Flügge, U.I., and Heldt, H.W. (1991). Redox Transfer across the Inner Chloroplast Envelope Membrane. Plant Physiol 95, 1131-1137.

Hemschemeier, A., Casero, D., Liu, B., Benning, C., Pellegrini, M., Happe, T., and Merchant, S.S. (2013). Copper response regulator1-dependent and -independent responses of the Chlamydomonas reinhardtii transcriptome to dark anoxia. Plant Cell 25, 3186-3211.

Hsieh, L.-C., Lin, S.-I., Shih, A.C.-C., Chen, J.-W., Lin, W.-Y., Tseng, C.-Y., Li, W.-H., and Chiou, T.-J. (2009). Uncovering Small RNA-Mediated Responses to Phosphate Deficiency in Arabidopsis by Deep Sequencing. Plant Physiol 151, 2120.

Hyun, Y., Richter, R., Vincent, C., Martinez-Gallegos, R., Porri, A., and Coupland, G. (2016). Multilayered Regulation of SPL15 and Cooperation with SOC1 Integrate Endogenous Flowering Pathways at the Arabidopsis Shoot Meristem. Dev Cell 37, 254-266.

Journet, E.-P., Neuburger, M., and Douce, R. (1981). Role of Glutamate-oxaloacetate Transaminase and Malate Dehydrogenase in the Regeneration of $\mathrm{NAD}^{+}$for Glycine Oxidation by Spinach leaf Mitochondria. Plant Physiol 67, 467-469.

Kadenbach, B., Huttemann, M., Arnold, S., Lee, I., and Bender, E. (2000). Mitochondrial energy metabolism is regulated via nuclear-coded subunits of cytochrome c oxidase. Free Radic Biol Med 29, 211-221.

Kim, D., Paggi, J.M., Park, C., Bennett, C., and Salzberg, S.L. (2019). Graph-based genome alignment and genotyping with HISAT2 and HISAT-genotype. Nat Biotechnol 37, 907-915.

Kim, S., Mollet, J.-C., Dong, J., Zhang, K., Park, S.-Y., and Lord, E.M. (2003). Chemocyanin, a small basic protein from the lily stigma, induces pollen tube chemotropism. Proc Natl Acad Sci USA 100, 16125.

Krämer, U., and Clemens, S. (2005). Functions and homeostasis of zinc, copper, and nickel in plants. In Molecular Biology of Metal Homeostasis and Detoxification, M.J. Tamás and E. Martinoia, eds (Springer Berlin Heidelberg New York), pp. 216-271.

Kropat, J., Tottey, S., Birkenbihl, R.P., Depege, N., Huijser, P., and Merchant, S.S. (2005). A regulator of nutritional copper signaling in Chlamydomonas is an SBP domain protein that recognizes the GTAC core of copper response element. Proc Natl Acad Sci USA 102, 18730-18735. 
Kropat, J., Gallaher, S.D., Urzica, E.I., Nakamoto, S.S., Strenkert, D., Tottey, S., Mason, A.Z., and Merchant, S.S. (2015). Copper economy in Chlamydomonas: prioritized allocation and reallocation of copper to respiration vs. photosynthesis. Proc Natl Acad Sci USA 112, 2644-2651.

Lambers, H. (1982). Cyanide-resistant respiration: A non-phosphorylating electron transport pathway acting as an energy overflow. Physiol Plant 55, 478-485.

Lamesch, P., Berardini, T.Z., Li, D., Swarbreck, D., Wilks, C., Sasidharan, R., Muller, R., Dreher, K., Alexander, D.L., Garcia-Hernandez, M., Karthikeyan, A.S., Lee, C.H., Nelson, W.D., Ploetz, L., Singh, S., Wensel, A., and Huala, E. (2012). The Arabidopsis Information Resource (TAIR): improved gene annotation and new tools. Nucleic Acids Res 40, D1202-1210.

Lampropoulos, A., Sutikovic, Z., Wenzl, C., Maegele, I., Lohmann, J.U., and Forner, J. (2013). GreenGate - A Novel, Versatile, and Efficient Cloning System for Plant Transgenesis. PLoS One 8, e83043.

Langmead, B., and Salzberg, S.L. (2012). Fast gapped-read alignment with Bowtie 2. Nat Methods 9, 357-359.

Langmead, B., Trapnell, C., Pop, M., and Salzberg, S.L. (2009). Ultrafast and memory-efficient alignment of short DNA sequences to the human genome. Genome Biol 10, R25.

Lappe, R.R., Baier, J.W., Boehlein, S.K., Huffman, R., Lin, Q., Wattebled, F., Settles, A.M., Hannah, L.C., Borisjuk, L., Rolletschek, H., Stewart, J.D., Scott, M.P., Hennen-Bierwagen, T.A., and Myers, A.M. (2018). Functions of maize genes encoding pyruvate phosphate dikinase in developing endosperm. Proc Natl Acad Sci USA 115, E24-E33.

Larronde, F., Krisa, S., Decendit, A., Chèze, C., Deffieux, G., and Mérillon, J.M. (1998). Regulation of polyphenol production in Vitis vinifera cell suspension cultures by sugars. Plant Cell Reports 17, 946-950.

Lejay, L., Wirth, J., Pervent, M., Cross, J.M., Tillard, P., and Gojon, A. (2008). Oxidative pentose phosphate pathway-dependent sugar sensing as a mechanism for regulation of root ion transporters by photosynthesis. Plant Physiol 146, 2036-2053.

Lejay, L., Gansel, X., Cerezo, M., Tillard, P., Muller, C., Krapp, A., von Wiren, N., Daniel-Vedele, F., and Gojon, A. (2003). Regulation of root ion transporters by photosynthesis: functional importance and relation with hexokinase. Plant Cell 15, 2218-2232.

Li, L., and Sheen, J. (2016). Dynamic and diverse sugar signaling. Curr Opin Plant Biol 33, 116-125.

Li, X., Zhang, H., Ai, Q., Liang, G., and Yu, D. (2016). Two bHLH Transcription Factors, bHLH34 and bHLH104, Regulate Iron Homeostasis in Arabidopsis thaliana. Plant Physiol 170, 2478-2493.

Liang, G., Zhang, H., Li, X., Ai, Q., and Yu, D. (2017). bHLH transcription factor bHLH115 regulates iron homeostasis in Arabidopsis thaliana. J Exp Bot 68, 1743-1755.

Liu, Y., Duan, X., Zhao, X., Ding, W., Wang, Y., and Xiong, Y. (2021). Diverse nitrogen signals activate convergent ROP2-TOR signaling in Arabidopsis. Dev Cell 56, 1283-1295 e1285.

Love, M.I., Huber, W., and Anders, S. (2014). Moderated estimation of fold change and dispersion for RNA-seq data with DESeq2. Genome Biol 15, 550.

Lunn, J.E., Feil, R., Hendriks, J.H.M., Gibon, Y., Morcuende, R., Osuna, D., Scheible, W.-R., Carillo, P., Hajirezaei, M.-R., and Stitt, M. (2006). Sugar-induced increases in trehalose 6-phosphate are correlated with redox activation of ADPglucose pyrophosphorylase and higher rates of starch synthesis in Arabidopsis thaliana. Biochem J 397, 139-148.

Machanick, P., and Bailey, T.L. (2011). MEME-ChIP: motif analysis of large DNA datasets. Bioinformatics 27, 1696-1697.

Marschner, H., and Marschner, P. (2012). Marschner's mineral nutrition of higher plants. (London ; Waltham, MA: Elsevier/Academic Press).

Martin, M. (2011). Cutadapt removes adapter sequences from high-throughput sequencing reads. EMBnet J 17, 3. 
Moehs, C.P., McElwain, E.F., and Spiker, S. (1988). Chromosomal proteins of Arabidopsis thaliana. Pant Mol Biol 11, 507-515.

Møller, I.M., Bérczi, A., van der Plas, L.H.W., and Lambers, H. (1988). Measurement of the activity and capacity of the alternative pathway in intact plant tissues: Identification of problems and possible solutions. Physiol Plant 72, 642-649.

Nunes, C., Primavesi, L.F., Patel, M.K., Martinez-Barajas, E., Powers, S.J., Sagar, R., Fevereiro, P.S., Davis, B.G., and Paul, M.J. (2013a). Inhibition of SnRK1 by metabolites: Tissue-dependent effects and cooperative inhibition by glucose 1-phosphate in combination with trehalose 6phosphate. Plant Physiol Biochem 63, 89-98.

Nunes, C., O'Hara, L.E., Primavesi, L.F., Delatte, T.L., Schluepmann, H., Somsen, G.W., Silva, A.B., Fevereiro, P.S., Wingler, A., and Paul, M.J. (2013b). The Trehalose 6-Phosphate/SnRK1 Signaling Pathway Primes Growth Recovery following Relief of Sink Limitation. Plant Physiol 162, 1720.

O'Leary, B.M., Asao, S., Millar, A.H., and Atkin, Owen K. (2019). Core principles which explain variation in respiration across biological scales. New Phytol 222, 670-686.

O'Malley, R.C., Huang, S.C., Song, L., Lewsey, M.G., Bartlett, A., Nery, J.R., Galli, M., Gallavotti, A., and Ecker, J.R. (2016). Cistrome and Epicistrome Features Shape the Regulatory DNA Landscape. Cell 165, 1280-1292.

Okonechnikov, K., Conesa, A., and Garcia-Alcalde, F. (2016). Qualimap 2: advanced multi-sample quality control for high-throughput sequencing data. Bioinformatics 32, 292-294.

Pietzenuk, B., Markus, C., Gaubert, H., Bagwan, N., Merotto, A., Bucher, E., and Pecinka, A. (2016). Recurrent evolution of heat-responsiveness in Brassicaceae COPIA elements. Genome Biol 17, 209.

Ponnu, J., Schlereth, A., Zacharaki, V., Dzialo, M.A., Abel, C., Feil, R., Schmid, M., and Wahl, V. (2020). The trehalose 6-phosphate pathway impacts vegetative phase change in Arabidopsis thaliana. Plant J 104, 768-780.

Quinn, J.M., and Merchant, S.S. (1995). Two copper-responsive elements associated with the Chlamydomonas Cyc6 gene function as targets for transcriptional activators. Plant Cell 7, 623628.

R Core Team. (2019). R: A language and environment for statistical computing. R Foundation for Statistical Computing, Vienna, Austria.

Rabino, I., and Mancinelli, A.L. (1986). Light, Temperature, and Anthocyanin Production. Plant Physiol 81, 922-924.

Rae, T.D., Schmidt, P.J., Pufahl, R.A., Culotta, V.C., and O'Halloran, T.V. (1999). Undetectable intracellular free copper: the requirement of a copper chaperone for superoxide dismutase. Science 284, 805-808.

Rahmati Ishka, M., and Vatamaniuk, O.K. (2020). Copper deficiency alters shoot architecture and reduces fertility of both gynoecium and androecium in Arabidopsis thaliana. Plant Direct 4, e00288.

Ravet, K., Danford, F.L., Dihle, A., Pittarello, M., and Pilon, M. (2011). Spatiotemporal analysis of copper homeostasis in Populus trichocarpa reveals an integrated molecular remodeling for a preferential allocation of copper to plastocyanin in the chloroplasts of developing leaves. Plant Physiol 157, 1300-1312.

Redinbo, M.R., Yeates, T.O., and Merchant, S. (1994). Plastocyanin: structural and functional analysis. J Bioenerg Biomembr 26, 49-66.

Reimann, C., Birke, M., Demetriades, A., Filzmoser, P., and O'Connor, P. (2014). Chemistry of Europe's agricultural soils - Part A: Methodology and interpretation of the GEMAS data set. (Hannover: Schweizerbarth). 
Ren, L., and Tang, G. (2012). Identification of sucrose-responsive microRNAs reveals sucrose-regulated copper accumulations in an SPL7-dependent and independent manner in Arabidopsis thaliana. Plant Sci 187, 59-68.

Robinson, N.J., and Winge, D.R. (2010). Copper metallochaperones. Annu Rev Biochem 79, 537-562.

Roman, A., Li, X., Deng, D., Davey, J.W., James, S., Graham, I.A., and Haydon, M.J. (2021). Superoxide is promoted by sucrose and affects amplitude of circadian rhythms in the evening. Proc Natl Acad Sci USA 118.

Romera-Branchat, M., Severing, E., Pocard, C., Ohr, H., Vincent, C., Nee, G., Martinez-Gallegos, R., Jang, S., Andres, F., Madrigal, P., and Coupland, G. (2020). Functional Divergence of the Arabidopsis Florigen-Interacting bZIP Transcription Factors FD and FDP. Cell Rep 32, 107966.

Schluepmann, H., Pellny, T., van Dijken, A., Smeekens, S., and Paul, M. (2003). Trehalose 6-phosphate is indispensable for carbohydrate utilization and growth in Arabidopsis thaliana. Proc Natl Acad Sci USA 100, 6849-6854.

Schubert, M., Petersson, U.A., Haas, B.J., Funk, C., Schroder, W.P., and Kieselbach, T. (2002). Proteome map of the chloroplast lumen of Arabidopsis thaliana. J Biol Chem 277, 8354-8365.

Schulten, A., Bytomski, L., Quintana, J., Bernal, M., and Kramer, U. (2019). Do Arabidopsis Squamosa promoter binding Protein-Like genes act together in plant acclimation to copper or zinc deficiency? Plant Direct 3, e00150.

Schwarz, S., Grande, A.V., Bujdoso, N., Saedler, H., and Huijser, P. (2008). The microRNA regulated SBPbox genes SPL9 and SPL15 control shoot maturation in Arabidopsis. Plant Mol Biol 67, 183-195.

Shen, W., Wei, Y., Dauk, M., Tan, Y., Taylor, D.C., Selvaraj, G., and Zou, J. (2006). Involvement of a Glycerol-3-Phosphate Dehydrogenase in Modulating the NADH/NAD ${ }^{+}$Ratio Provides Evidence of a Mitochondrial Glycerol-3-Phosphate Shuttle in Arabidopsis. Plant Cell 18, 422-441.

Shikanai, T., Müller-Moulé, P., Munekage, Y., Niyogi, K.K., and Pilon, M. (2003). PAA1, a P-type ATPase of Arabidopsis, functions in copper transport in chloroplasts. Plant Cell 15, 1333-1346.

Sinclair, S.A., Larue, C., Bonk, L., Khan, A., Castillo-Michel, H., Stein, R.J., Grolimund, D., Begerow, D., Neumann, U., Haydon, M.J., and Krämer, U. (2017). Etiolated Seedling Development Requires Repression of Photomorphogenesis by a Small Cell-Wall-Derived Dark Signal. Curr Biol 27, 34033418 e3407.

Solfanelli, C., Poggi, A., Loreti, E., Alpi, A., and Perata, P. (2006). Sucrose-specific induction of the anthocyanin biosynthetic pathway in Arabidopsis. Plant Physiol 140, 637-646.

Sommer, F., Kropat, J., Malasarn, D., Grossoehme, N.E., Chen, X., Giedroc, D.P., and Merchant, S.S. (2010). The CRR1 nutritional copper sensor in Chlamydomonas contains two distinct metalresponsive domains. Plant Cell 22, 4098-4113.

Stief, A., Altmann, S., Hoffmann, K., Pant, B.D., Scheible, W.-R., and Bäurle, I. (2014). Arabidopsis miR156 Regulates Tolerance to Recurring Environmental Stress through SPL Transcription Factors. Plant Cell 26, 1792.

Stone, J.M., Liang, X., Nekl, E.R., and Stiers, J.J. (2005). Arabidopsis AtSPL14, a plant-specific SBPdomain transcription factor, participates in plant development and sensitivity to fumonisin B1. Plant J 41, 744-754.

Storey, J.D., Bass, A.J., Dabney, A., and Robinson, D. (2019). qvalue: Q-value estimation for false discovery rate control. $\mathrm{R}$ package version 2.14.1.

Teng, S., Keurentjes, J., Bentsink, L., Koornneef, M., and Smeekens, S. (2005). Sucrose-specific induction of anthocyanin biosynthesis in Arabidopsis requires the MYB75/PAP1 gene. Plant Physiol 139, 1840-1852.

Towbin, H., Staehelin, T., and Gordon, J. (1979). Electrophoretic transfer of proteins from polyacrylamide gels to nitrocellulose sheets: procedure and some applications. Proc Natl Acad Sci USA 76, 4350-4354. 
Unte, U.S., Sorensen, A.-M., Pesaresi, P., Gandikota, M., Leister, D., Saedler, H., and Huijser, P. (2003). $S P L 8$, an SBP-box gene that affects pollen sac development in Arabidopsis. Plant Cell 15, 10091019.

Urano, D., Phan, N., Jones, J.C., Yang, J., Huang, J., Grigston, J., Taylor, J.P., and Jones, A.M. (2012). Endocytosis of the seven-transmembrane RGS1 protein activates G-protein-coupled signalling in Arabidopsis. Nat Cell Biol 14, 1079-1088.

Varkonyi-Gasic, E., Wu, R., Wood, M., Walton, E.F., and Hellens, R.P. (2007). Protocol: a highly sensitive RT-PCR method for detection and quantification of microRNAs. Plant Methods 3, 12.

Wahl, V., Ponnu, J., Schlereth, A., Arrivault, S., Langenecker, T., Franke, A., Feil, R., Lunn, J.E., Stitt, M., and Schmid, M. (2013). Regulation of flowering by trehalose-6-phosphate signaling in Arabidopsis thaliana. Science 339, 704-707.

Wang, H.-Y., Klatte, M., Jakoby, M., Bäumlein, H., Weisshaar, B., and Bauer, P. (2007). Iron deficiencymediated stress regulation of four subgroup Ib BHLH genes in Arabidopsis thaliana. Planta 226, 897-908.

Wang, J.-W., Schwab, R., Czech, B., Mica, E., and Weigel, D. (2008). Dual Effects of miR156-Targeted SPL Genes and CYP78A5/KLUH on Plastochron Length and Organ Size in Arabidopsis thaliana. Plant Cell 20, 1231.

Wang, J., Zhou, L., Shi, H., Chern, M., Yu, H., Yi, H., He, M., Yin, J., Zhu, X., Li, Y., Li, W., Liu, J., Wang, J., Chen, X., Qing, H., Wang, Y., Liu, G., Wang, W., Li, P., Wu, X., Zhu, L., Zhou, J.-M., Ronald, P.C., Li, S., Li, J., and Chen, X. (2018). A single transcription factor promotes both yield and immunity in rice. Science $\mathbf{3 6 1}, 1026$.

Wang, J.W., Czech, B., and Weigel, D. (2009). miR156-regulated SPL transcription factors define an endogenous flowering pathway in Arabidopsis thaliana. Cell 138, 738-749.

Weigel, M., Varotto, C., Pesaresi, P., Finazzi, G., Rappaport, F., Salamini, F., and Leister, D. (2003). Plastocyanin is indispensable for photosynthetic electron flow in Arabidopsis thaliana. J Biol Chem 278, 31286-31289.

Weiss, D. (2000). Regulation of flower pigmentation and growth: Multiple signaling pathways control anthocyanin synthesis in expanding petals. Physiol Plant 110, 152-157.

Woeste, K.E., and Kieber, J.J. (2000). A strong loss-of-function mutation in RAN1 results in constitutive activation of the ethylene response pathway as well as a rosette-lethal phenotype. Plant Cell 12, 443-455.

Wu, G., and Poethig, R.S. (2006). Temporal regulation of shoot development in Arabidopsis thaliana by miR156 and its target SPL3. Development 133, 3539-3547.

Wu, G., Park, M.Y., Conway, S.R., Wang, J.W., Weigel, D., and Poethig, R.S. (2009). The sequential action of miR156 and miR172 regulates developmental timing in Arabidopsis. Cell 138, 750-759.

Xing, S., Salinas, M., Hohmann, S., Berndtgen, R., and Huijser, P. (2010). miR156-targeted and nontargeted SBP-box transcription factors act in concert to secure male fertility in Arabidopsis. Plant Cell 22, 3935-3950.

Xing, S., Salinas, M., Garcia-Molina, A., Hohmann, S., Berndtgen, R., and Huijser, P. (2013). SPL8 and miR156-targeted SPL genes redundantly regulate Arabidopsis gynoecium differential patterning. Plant J 75, 566-577.

Xiong, Y., and Sheen, J. (2012). Rapamycin and glucose-target of rapamycin (TOR) protein signaling in plants. J Biol Chem 287, 2836-2842.

Xiong, Y., McCormack, M., Li, L., Hall, Q., Xiang, C., and Sheen, J. (2013). Glucose-TOR signalling reprograms the transcriptome and activates meristems. Nature 496, 181-186.

Xu, M., Hu, T., Zhao, J., Park, M.Y., Earley, K.W., Wu, G., Yang, L., and Poethig, R.S. (2016). Developmental Functions of miR156-Regulated SQUAMOSA PROMOTER BINDING PROTEIN-LIKE (SPL) Genes in Arabidopsis thaliana. PLoS Genet 12, e1006263. 
Yamaguchi, A., Wu, M.F., Yang, L., Wu, G., Poethig, R.S., and Wagner, D. (2009). The microRNAregulated SBP-Box transcription factor SPL3 is a direct upstream activator of LEAFY, FRUITFULL, and APETALA1. Dev Cell 17, 268-278.

Yamaguchi, N., Winter, C.M., Wu, M.-F., Kwon, C.S., William, D.A., and Wagner, D. (2014a). PROTOCOLS: Chromatin Immunoprecipitation from Arabidopsis Tissues. The Arabidopsis Book 12, e0170-e0170.

Yamaguchi, N., Winter, C.M., Wu, M.F., Kanno, Y., Yamaguchi, A., Seo, M., and Wagner, D. (2014b). Gibberellin acts positively then negatively to control onset of flower formation in Arabidopsis. Science 344, 638-641.

Yamasaki, H., Hayashi, M., Fukazawa, M., Kobayashi, Y., and Shikanai, T. (2009). SQUAMOSA Promoter Binding Protein-Like7 Is a Central Regulator for Copper Homeostasis in Arabidopsis. Plant Cell 21, 347-361.

Yamasaki, H., Abdel-Ghany, S.E., Cohu, C.M., Kobayashi, Y., Shikanai, T., and Pilon, M. (2007). Regulation of copper homeostasis by micro-RNA in Arabidopsis. J Biol Chem 282, 16369-16378.

Yan, J., Chia, J.-C., Sheng, H., Jung, H.-I., Zavodna, T.-O., Zhang, L., Huang, R., Jiao, C., Craft, E.J., Fei, Z., Kochian, L.V., and Vatamaniuk, O.K. (2017). Arabidopsis Pollen Fertility Requires the Transcription Factors CITF1 and SPL7 That Regulate Copper Delivery to Anthers and Jasmonic Acid Synthesis. Plant Cell 29, 3012-3029.

Yang, L., Conway, S.R., and Poethig, R.S. (2011). Vegetative phase change is mediated by a leaf-derived signal that represses the transcription of miR156. Development 138, 245-249.

Yang, L., Xu, M., Koo, Y., He, J., and Poethig, R.S. (2013). Sugar promotes vegetative phase change in Arabidopsis thaliana by repressing the expression of MIR156A and MIR156C. eLife 2, e00260.

Yruela, I. (2013). Transition metals in plant photosynthesis. Metallomics 5, 1090-1109.

Yu, N., Cai, W.-J., Wang, S., Shan, C.-M., Wang, L.-J., and Chen, X.-Y. (2010). Temporal Control of Trichome Distribution by MicroRNA156-Targeted SPL Genes in Arabidopsis thaliana. Plant Cell 22, 2322.

Yu, S., Cao, L., Zhou, C.-M., Zhang, T.-Q., Lian, H., Sun, Y., Wu, J., Huang, J., Wang, G., and Wang, J.-W. (2013). Sugar is an endogenous cue for juvenile-to-adult phase transition in plants. elife 2, e00269.

Zhai, Z., Keereetaweep, J., Liu, H., Feil, R., Lunn, J.E., and Shanklin, J. (2018). Trehalose 6-Phosphate Positively Regulates Fatty Acid Synthesis by Stabilizing WRINKLED1. Plant Cell 30, 2616-2627.

Zhang, H., and Li, L. (2013). SQUAMOSA promoter binding protein-like7 regulated microRNA408 is required for vegetative development in Arabidopsis. Plant J 74, 98-109.

Zhang, H., Zhao, X., Li, J., Cai, H., Deng, X.W., and Li, L. (2014). MicroRNA408 is critical for the HY5-SPL7 gene network that mediates the coordinated response to light and copper. Plant Cell 26, 49334953.

Zhang, Y., Primavesi, L.F., Jhurreea, D., Andralojc, P.J., Mitchell, R.A.C., Powers, S.J., Schluepmann, H., Delatte, T., Wingler, A., and Paul, M.J. (2009). Inhibition of SNF1-Related Protein Kinase1 Activity and Regulation of Metabolic Pathways by Trehalose-6-Phosphate. Plant Physiol 149, 1860-1871.

Zhang, Y., Liu, T., Meyer, C.A., Eeckhoute, J., Johnson, D.S., Bernstein, B.E., Nusbaum, C., Myers, R.M., Brown, M., Li, W., and Liu, X.S. (2008). Model-based Analysis of ChIP-Seq (MACS). Genome Biol 9, R137. 
Table 1. Genes undergoing maximal SPL7-dependent transcriptional regulation and microRNA loci associated with SPL7 binding sites according to ChIP-seq on shoot tissues of seedlings cultivated on copper-deficient medium.

\section{TL $^{\mathrm{a}} \quad$ RTL (WT vs. spl7) ${ }^{\mathrm{b}} \quad$ ChIP-seq peaks $^{\mathrm{c}} \quad$ Identified by DAP-seq $^{\mathrm{d}}$}

\begin{tabular}{|c|c|c|c|c|c|c|c|c|c|c|c|c|c|}
\hline AGI code & $\begin{array}{l}\text { Short } \\
\text { name }\end{array}$ & Annotation & TPM & Low $\mathrm{Cu}$ & $\begin{array}{c}\text { Control } \\
\mathrm{Cu}\end{array}$ & Low $\mathrm{Cu}$ & $\begin{array}{c}\text { Control } \\
\mathrm{Cu}\end{array}$ & SPL1 & SPL5 & SPL9 & SPL13 & SPL14 & $\begin{array}{l}\text { SPL15 } \\
\text { ampl. }\end{array}$ \\
\hline AT4G25100 & FSD1 & Fe superoxide dismutase 1 & 1800 & 4,700 & 1,500 & $4 \mathrm{G}^{*} * \S$ & none & $Y$ & & $Y$ & $Y$ & $\mathrm{Y}$ & $\mathrm{Y}$ \\
\hline AT1G71200 & $\begin{array}{l}\text { BHLH160, } \\
\text { CITF1 }\end{array}$ & $\begin{array}{l}\text { CU-DEFICIENCY INDUCED } \\
\text { TRANSCRIPTION FACTOR } 1\end{array}$ & 3 & 390 & - & $3 \mathrm{P}^{* *}$ & none & $\mathrm{Y}$ & & $\mathrm{Y}$ & $\mathrm{Y}$ & Y & $\mathrm{Y}$ \\
\hline AT5G59520 & ZIP2 & ZRT/IRT-like protein 2 & 0.86 & 32 & - & $2 \mathrm{G}^{* *}$ & none & Y & & Y & Y & Y & Y \\
\hline AT4G28790 & $\begin{array}{l}\text { BHLH23, } \\
\text { CITF2 }\end{array}$ & $\begin{array}{l}\text { CU-DEFICIENCY INDUCED } \\
\text { TRANSCRIPTION FACTOR } 2\end{array}$ & 2.2 & 18 & - & $3 P^{* *}$ & none & $\mathrm{Y}$ & & Y & & & Y \\
\hline AT5G24380 & YSL2 & YELLOW STRIPE like 2 & 30 & 13 & 5.24 & $3 G^{* *}$ & none & $\mathrm{Y}$ & & $\mathrm{Y}$ & & & $\mathrm{Y}$ \\
\hline AT3G23326 & MIR853a & unknown function & N.a. & N.a. & N.a. & $4 \mathrm{P}, 2 \mathrm{P}$ & $4 \mathrm{P}, 2 \mathrm{P}$ & & & & & & \\
\hline AT5G14545 & MIR398B & $\begin{array}{l}\text { targets both CSD and CytC oxidase } \\
\text { family members. }\end{array}$ & N.a. & N.a. & N.a. & $4 G^{\#}$ & none & $\mathrm{Y}$ & & $\mathrm{Y}$ & $\mathrm{Y}$ & $\mathrm{Y}$ & $\mathrm{Y}$ \\
\hline AT5G14565 & MIR398C & $\begin{array}{l}\text { targets both CSD and CytC oxidase } \\
\text { family members }\end{array}$ & N.a. & N.a. & N.a. & $4 \mathrm{P}, 4 \mathrm{G}^{\#}$ & none & $\mathrm{Y}$ & & $\mathrm{Y}$ & $\mathrm{Y}$ & Y & $\mathrm{Y}$ \\
\hline AT2G47015 & MIR408 & $\begin{array}{l}\text { targets a Laccase and Plantacyanin- } \\
\text { like family member }\end{array}$ & N.a. & N.a. & N.a. & $3 S^{\# \#}$ & none & Y & $\mathrm{Y}$ & $\mathrm{Y}$ & $\mathrm{Y}$ & Y & $\mathrm{Y}$ \\
\hline AT4G13554 & MIR857a & targets a Laccase family member & N.a. & N.a. & N.a. & $3 \mathrm{P}^{\mathrm{\# \#}}$ & none & & & & & & \\
\hline AT4G13555 & MIR397B & $\begin{array}{l}\text { targets several Laccase family } \\
\text { members }\end{array}$ & N.a. & N.a. & N.a. & $3 G^{\# \#}$ & none & Y & & $\mathrm{Y}$ & $\mathrm{Y}$ & Y & $\mathrm{Y}$ \\
\hline AT5G26038 & MIR860a & unknown function & N.a. & N.a. & N.a. & $3 G$ & $4 \mathrm{G}$ & & Y & Y & & & $Y$ \\
\hline AT1G19371 & MIR169H & $\begin{array}{l}\text { targets several HAP2 family } \\
\text { members }\end{array}$ & N.a. & N.a. & N.a. & $2 \mathrm{P}$ & none & & Y & Y & & & Y \\
\hline
\end{tabular}

${ }^{a} \mathrm{TL}$ (normalized transcript levels in transcripts per million, TPM, in WT low Cu), ${ }^{\mathbf{b}} \mathrm{RTL}$ relative transcript levels) according to RNAseq data (Supplemental Data Set 3). ${ }^{\circ}$ ChIP-seq peaks: number of replicates identifying peaks, followed by localization: P (promoter), S (overlapping start), G (gene body). ${ }^{\mathrm{d} D A P}$-seq data were taken from O'Malley et al. (2016); ampl.: amplified; Y, locus identified; N.a., no data obtained; -, ratio not significantly different from 1. *one, **two GTACTRC motifs (see Figure 7D, Supplemental Data Set 6); " \#\#two GTACTRC motifs (Supplementary Data Set 4). ${ }^{\circledR}$ at least 2 non-consensus upstream GTAC core motifs (Supplemental Figure 15). 
A
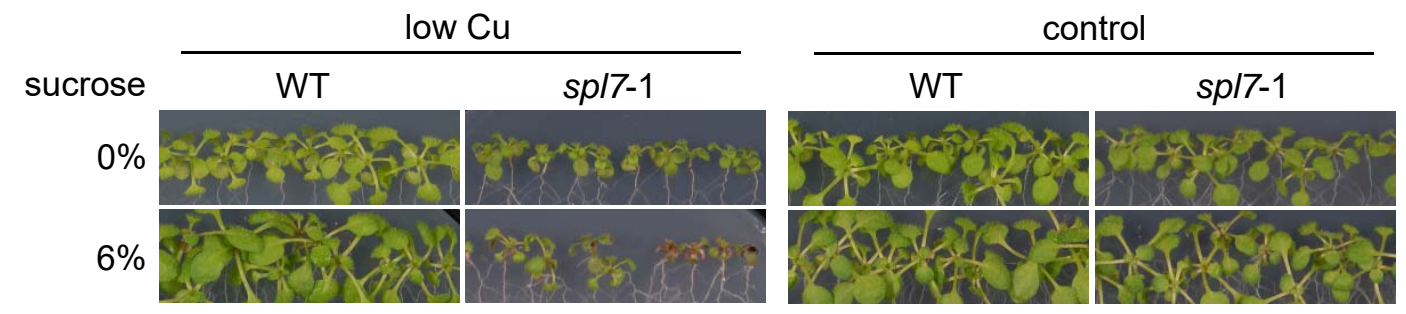

B

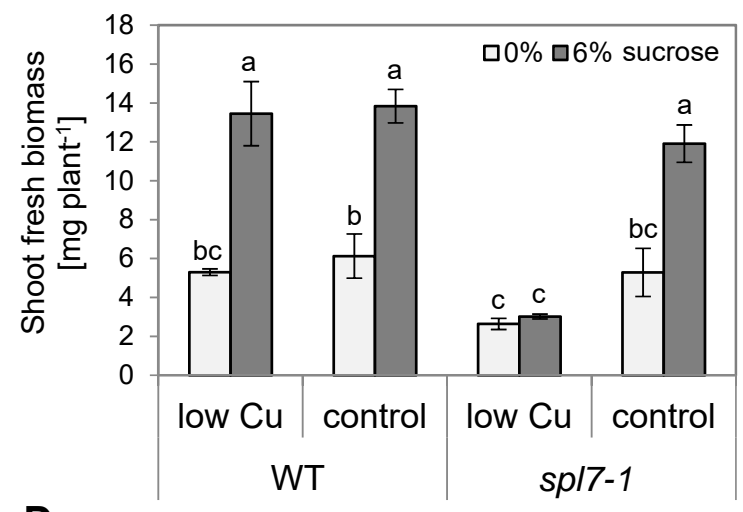

D

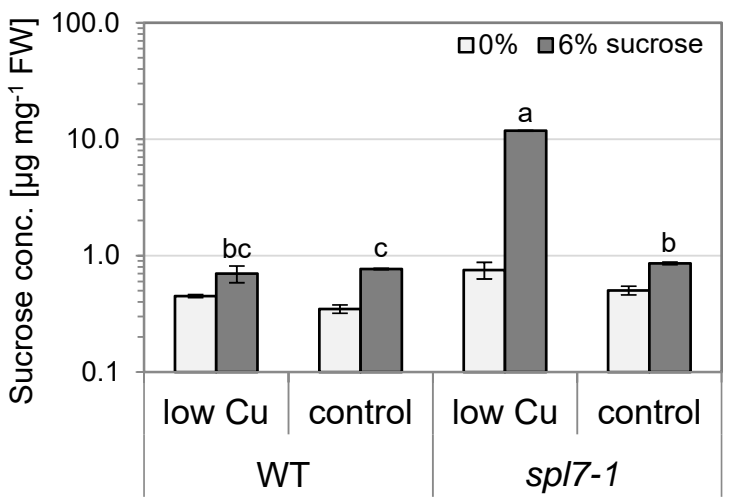

C

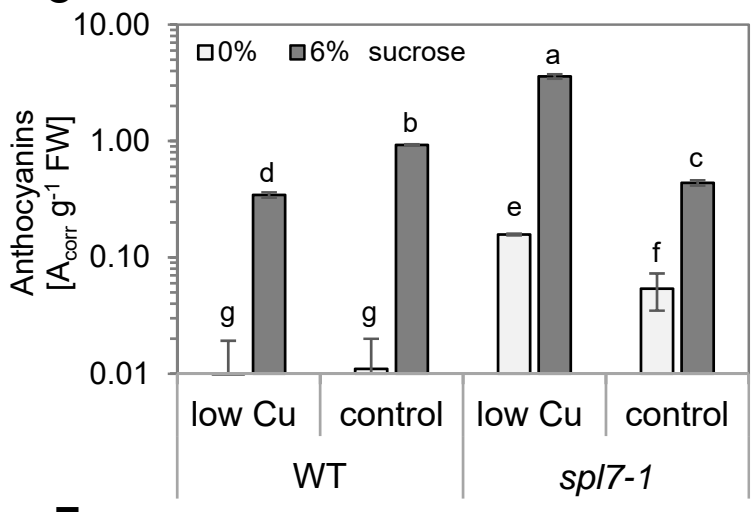

$\mathbf{E}$

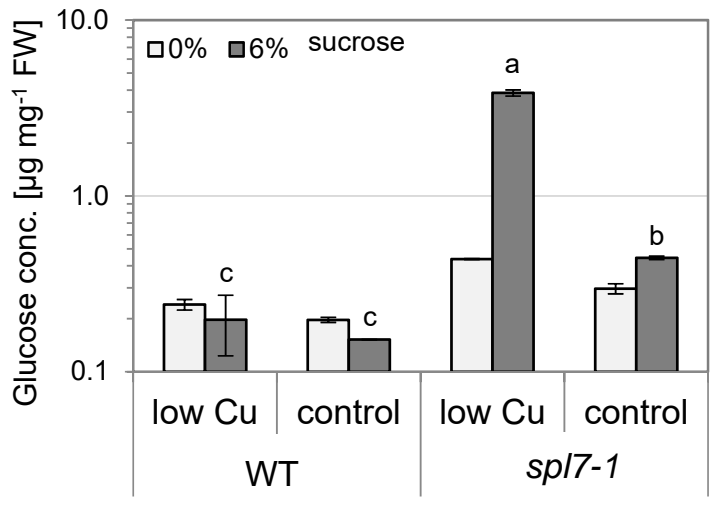

Figure 1. The sp/7-1 mutant accumulates elevated levels of sugars instead of directing them into growth.

(A) Photographs of 21-day-old wild-type (WT) and sp/7-1 mutant seedlings cultivated for $14 \mathrm{~d}$ in vertically oriented glass petri dishes on low-Cu $\left(0.05 \mu \mathrm{M} \mathrm{CuSO}_{4}\right)$ or control $\left(0.5 \mu \mathrm{M} \mathrm{CuSO}{ }_{4}\right)$ EDTA-washed agar-solidified media supplemented with $0 \%$ or $6 \%(\mathrm{w} / \mathrm{v})$ sucrose.

(B) Shoot fresh biomass of seedlings (see A). Bars represent arithmetic means \pm SD $(n=3$ pools of seedlings, with each pool from one replicate plate).

(C) Anthocyanin levels in shoots (see A). Bars represent arithmetic means \pm SD $(n=3$ technical replicates for one pool).

$(D, E)$ Sucrose (D) and glucose (E) concentrations in shoots (see A). Bars represent arithmetic means \pm SD ( $n=2$ and 3 technical replicates for $0 \%$ and $6 \%$ sucrose samples, respectively). Data from an independent experiment (C-E) are shown in Supplemental Figure 3.

Different characters denote statistically significant differences between means based on ANOVA (Tukey's HSD; $p<0.05$, B; $t$-tests with FDR adjustment, $q$-value $<0.05, \mathrm{C}-\mathrm{E}$, wherever $n>2$ ). n.d.: not detectable. 

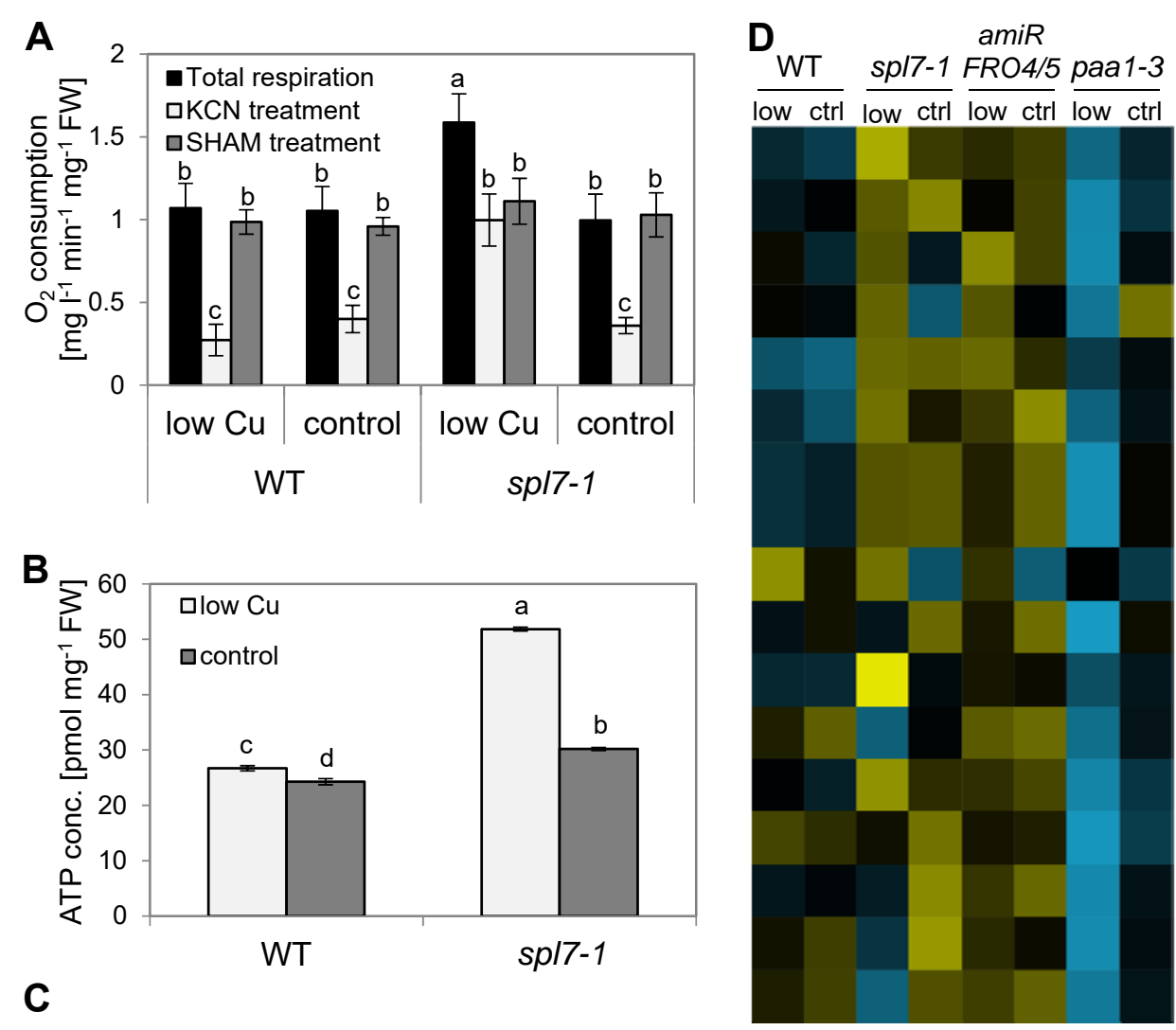

Schulten et al., Figure 2

C
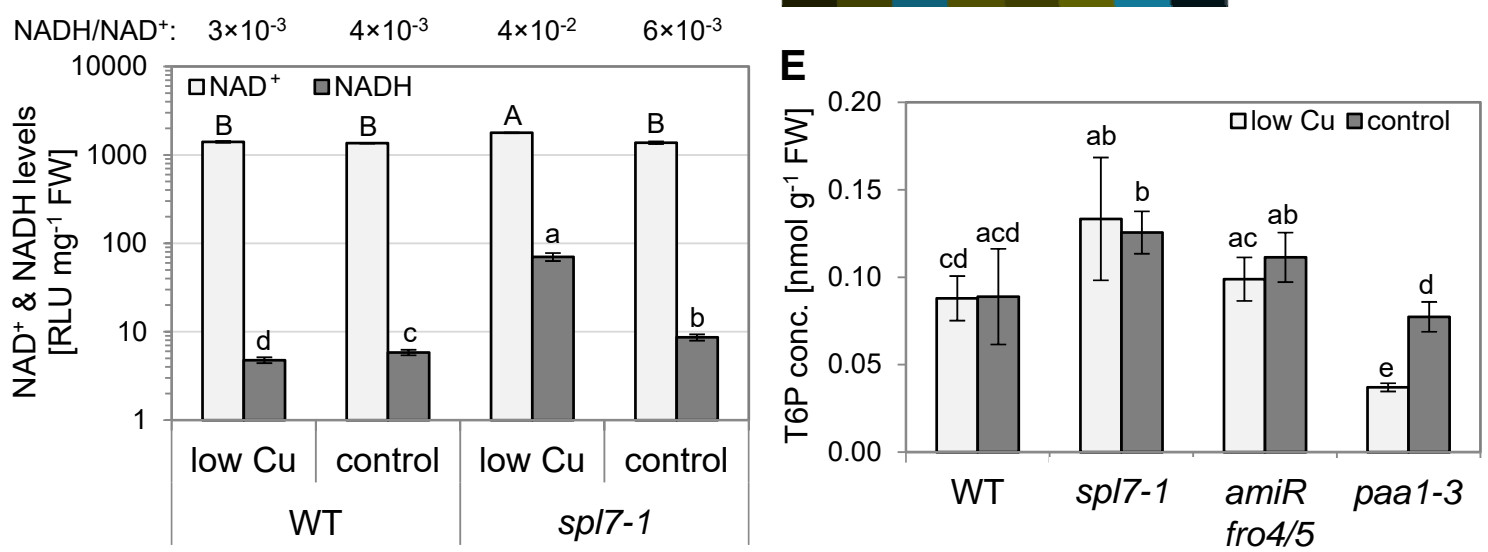

Figure 2. Respiratory activity and quantification of metabolites associated with sugar metabolism and respiration.

(A) Respiration rates measured as $\mathrm{O}_{2}$ consumption in darkness. Data are from leaves of 21-day-old wildtype (WT) and sp/7-1 seedlings cultivated in vertically oriented glass petri dishes on low-Cu (no $\mathrm{CuSO}_{4}$ added) or control $\left(0.5 \mu \mathrm{M} \mathrm{CuSO}_{4}\right)$ EDTA-washed agar-solidified media supplemented with $1 \%(\mathrm{w} / \mathrm{v})$ sucrose. Complex IV inhibitor KCN (1 mM) or AOX inhibitor SHAM (20 mM) were present during a subset of respiration measurements as indicated. Bars represent arithmetic means \pm SD $(n=8$ and 4 replicate seedling batches for total respiration and for inhibitor treatments, respectively).

(B, C) ATP (B), NAD+ and NADH levels (C) in shoots of seedlings cultivated as described for (A). Bars represent arithmetic means $\pm \mathrm{SD}$ ( $n=3$ technical replicates).

(D) Heatmap of metabolites of respiratory and sugar metabolism. Data are from shoots of 21-day-old seedlings (wild-type, sp/7-1, 35S:amiRFRO4/5, paa1-3) cultivated in vertically-oriented glass petri dishes on low $\mathrm{Cu}\left(0.05 \mu \mathrm{M} \mathrm{CuSO}_{4}\right)$ or control $\left(0.5 \mu \mathrm{M} \mathrm{CuSO}_{4}\right)$ EDTA-washed agar-solidified media lacking added sucrose for $14 \mathrm{~d}$. Represented are $z$-scores $(n=4$ replicate pools per genotype, with one pool per replicate petri plate).

(E) T6P concentrations in shoots of seedlings cultivated as described for (D). Bars represent arithmetic means $\pm \operatorname{SD}(n=4$, see (D)). Compare Figure $5 \mathrm{~A}$. 
bioRxiv preprint doi: https://doi.org/10.1101/2021.09.17.460807; this version posted September 2Ø, 2021. The copyright holder for this preprint (which was not certified by peer review) is the author/funder, who has granted bioRxiv a license to display the preprint in perpetuity. It is made available under aCC-BY-NC 4.0 International license.

Schulten et al., Figure 2

Different characters denote statistically significant differences $(p<0.05)$ between means based on ANOVA (Tukey's HSD)(A, B) or $t$-tests with FDR adjustment ( $q$-value < 0.05$)$ for $(C, E)$, with uppercase and lowercase characters corresponding to different statistical test groups. Data for a second $(B, C)$ and two additional independent experiments (D) are shown in Supplemental Figure 6A-D. RLU: relative light units; Suc6P: sucrose-6-phosphate; T6P: trehalose-6-phosphate; Glc6P: glucose-6-phosphate; Man6P: mannose-6-phosphate, GBP: glucose-1,6-bisphosphate Glc1P: glucose-1-phosphate, Gal1P: galactose-1phosphate, UDPGIc: uridine diphosphate glucose, PEP: phosphoenolpyruvate, Gly3P: glycerol-3phosphate, 2-OG: 2-oxoglutarate. 
A

$\operatorname{suc}(3 \mathrm{~h})$

WT

spl7-1

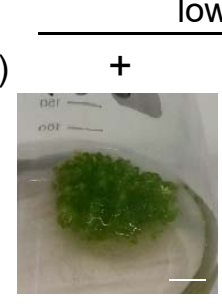

low $\mathrm{Cu}$
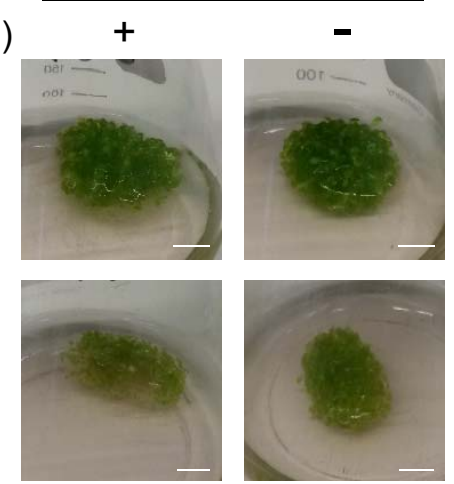

B

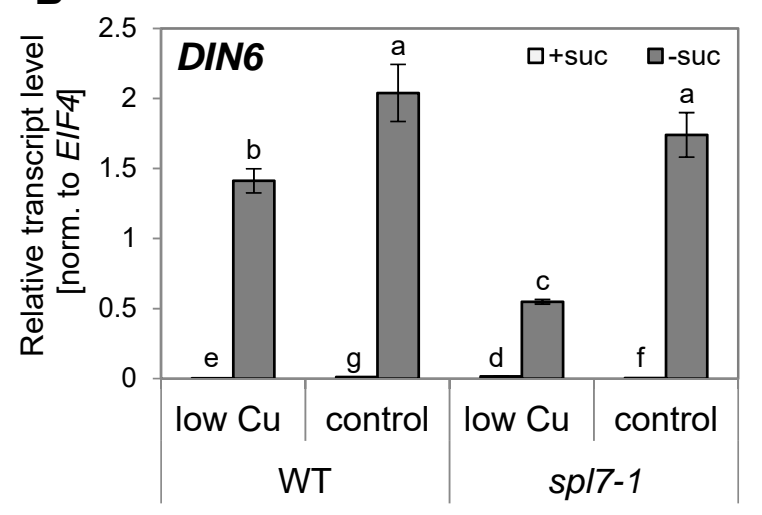

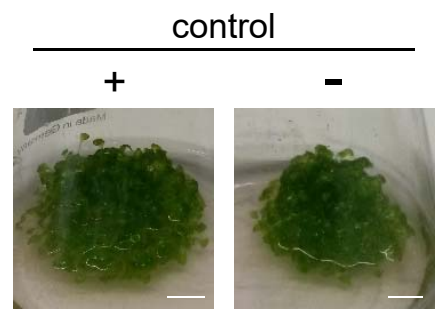
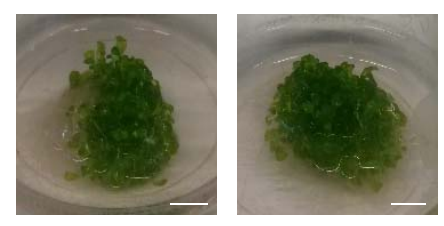

C

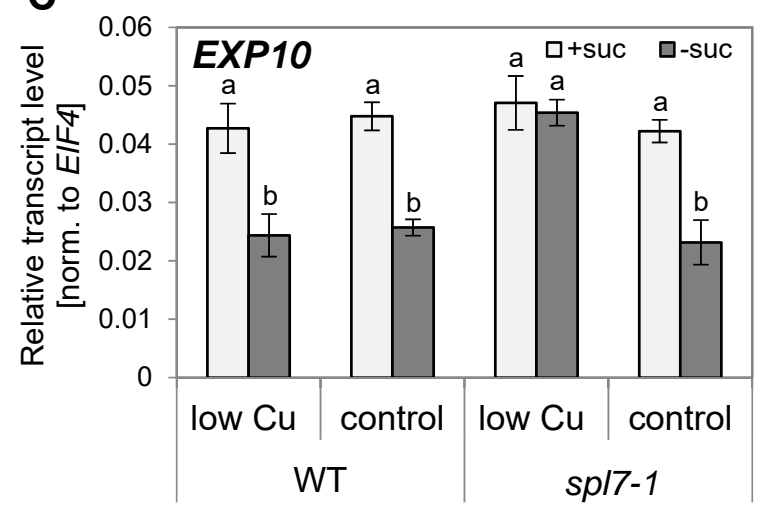

Figure 3. SnRK1 pathway activation in response to sucrose starvation in wild-type and spl7-1 mutant seedlings.

(A) Photographs of 15-day-old seedlings cultivated in liquid culture in low-Cu (no $\mathrm{CuSO}_{4}$ added) or control $\left(1 \mu \mathrm{M} \mathrm{CuSO}_{4}\right)$ conditions with $0.5 \%(\mathrm{w} / \mathrm{v})$ sucrose following a 3-h sucrose starvation treatment ( $0 \%$ sucrose). Scale bar, $1 \mathrm{~cm}$.

(B, C) Relative transcript levels of the SnRK1 pathway marker genes DIN6 (induced by SnRK1 activity) and EXP10 (repressed by SnRK1 activity) in shoots of seedlings cultivated as described for $(A)$, as quantified by RT-qPCR. Bars represent arithmetic means \pm SD $(n=3$ technical replicates, i.e. independent PCR runs, each with three replicate wells per transcript). Data shown are transcript levels relative to EIF4 as a constitutively expressed control gene. Different characters denote statistically significant differences $(p<0.05)$ between means based on $t$-tests with FDR adjustment $(q$-value $<0.05)(B)$ or ANOVA (Tukey's HSD)(C). 

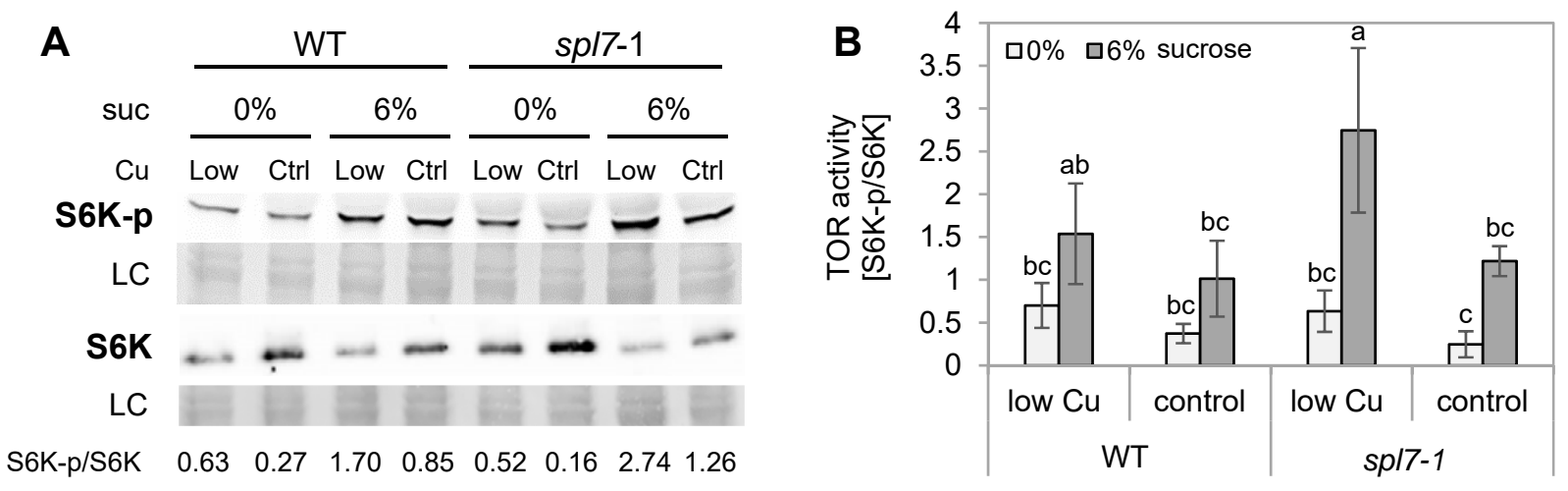

Figure 4. TOR activity in wild-type and spl7-1 mutant seedlings.

(A) Immunodetection of phosphorylated (S6K-p) and total S6K (S6K1 and S6K2) protein as a marker of TOR activity. Data are from shoots of 21-day-old wild-type (WT) and spl7-1 seedlings cultivated in vertically oriented glass petri dishes on low-Cu $\left.(0.05 \mu \mathrm{M} \mathrm{CuSO})_{4}\right)$ or control $(0.5 \mu \mathrm{M}$ $\mathrm{CuSO}_{4}$ ) agar-solidified media supplemented with $0 \%$ or $6 \%(\mathrm{w} / \mathrm{v})$ sucrose for $14 \mathrm{~d}$. Total protein extracts were separated in denaturing polyacrylamide gels and transferred to nitrocellulose membranes. Proteins were visualized on the membrane through Ponceau Red staining as a loading control (LC) prior to immunodetection (S6K-p, S6K apparent sizes $52 \mathrm{kDa}$ ). The ratio of S6K-p/S6K band intensities is shown below each lane. Blots from two additional independent experiments are shown in Supplemental Figure 7.

(B) Ratios of S6K-p/S6K band intensities for immunoblot images shown in (A) and Supplemental Figure 7. Bars represent arithmetic means $\pm S D(n=3$ replicate blots from independent experiments). Different characters denote statistically significant differences $(p<0.05)$ between means based on ANOVA (Tukey's HSD). 


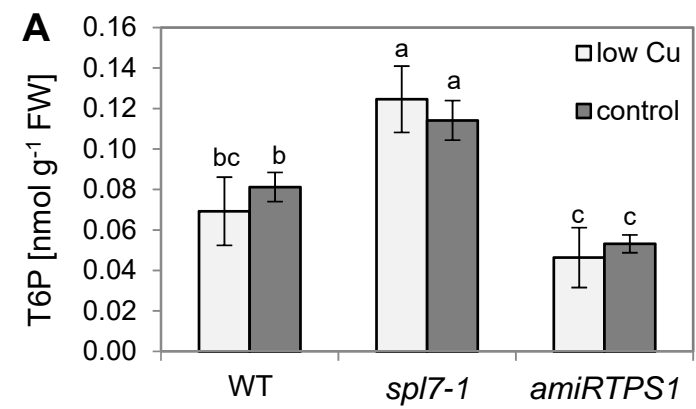

C

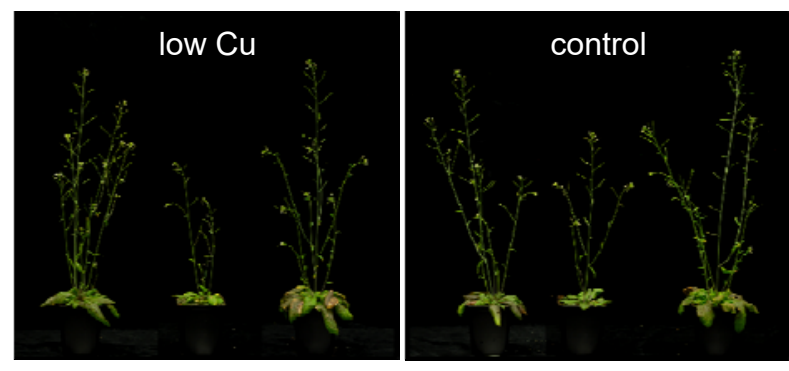

$\mathbf{F}$
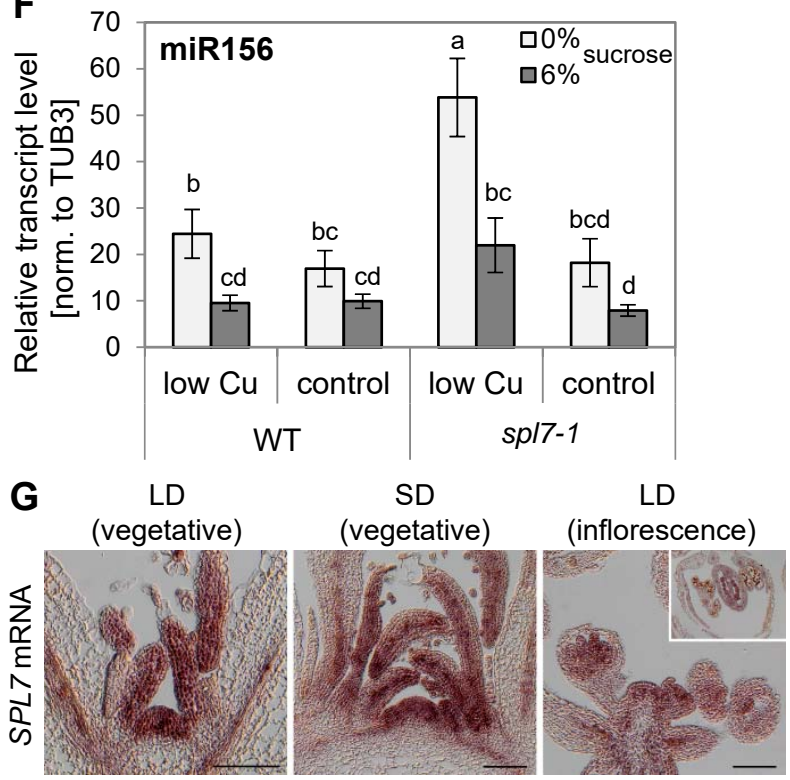

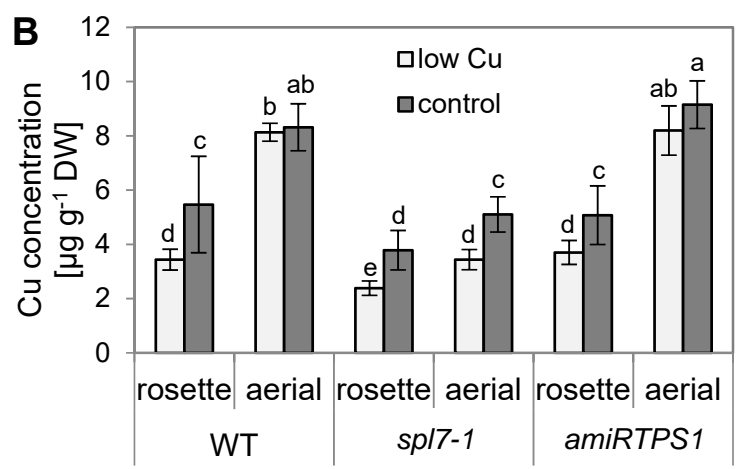

D

E
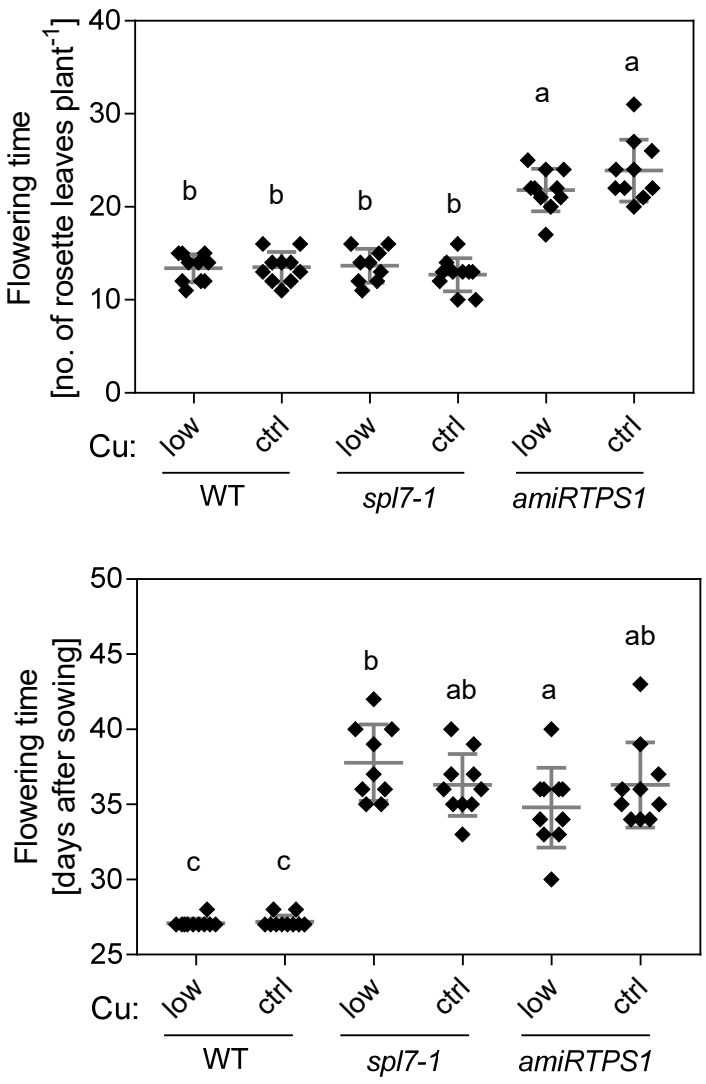

Figure 5. Flowering time of wild-type, spl7-1 and 35S:amiRTPS1 Arabidopsis plants. (A) T6P concentrations. Data are from shoots of 21-day-old seedlings of wild-type (WT), spl7-1 and 35S:amiRTPS1 cultivated in vertically oriented glass petri dishes on low-Cu $(0.05 \mu \mathrm{M}$ $\left.\mathrm{CuSO}_{4}\right)$ or control $\left(0.5 \mu \mathrm{M} \mathrm{CuSO}_{4}\right)$ agar-solidified media without added sucrose for $14 \mathrm{~d}$. Bars represent arithmetic means $\pm \mathrm{SD}(n=4$ replicate pools, with one pool per petri plate). Compare Figure 2E

(B) Cu concentrations in rosette and aerial tissues of plants cultivated in soil in long days. Plants were watered with equal amounts of tap water without (low $\mathrm{Cu}$ ) or with $2 \mathrm{mM} \mathrm{CuSO}_{4}$ (control) once per week and harvested $10 \mathrm{~d}$ after bolting. Bars represent arithmetic means \pm SD $(n=8$ plants per genotype, treatment and tissue).

(C) Photographs of wild-type, sp/7-1 and 35S:amiRTPS1 plants $10 \mathrm{~d}$ after bolting. Plants were cultivated as described for (B).

(D, E) Flowering time given as the number of rosette leaves (D) and age at bolting time (E) of plants cultivated as described for (B). Plots show arithmetic mean (line) \pm SD and all data points (diamonds) ( $n=8$ plants per genotype and treatment). Two independent experiments are shown in Supplemental Figure 8. 
bioRxiv preprint doi: https://doi.org/10.1101/2021.09.17.460807; this version posted September 2Ø, 2021. The copyright holder for this preprint (which was not certified by peer review) is the author/funder, who has granted bioRxiv a license to display the preprint in perpetuity. It is made available under aCC-BY-NC 4.0 International license.

Schulten et al., Figure 5

(F) Relative transcript levels of miR156 in shoots of 21-day-old seedlings. Cultivation was in vertically oriented glass petri dishes on-low $\mathrm{Cu}\left(0.05 \mu \mathrm{M} \mathrm{CuSO}_{4}\right)$ or control $\left(0.5 \mu \mathrm{M} \mathrm{CuSO}{ }_{4}\right)$ agar-solidified media supplemented with $0 \%$ or $6 \%(\mathrm{w} / \mathrm{v})$ sucrose for $14 \mathrm{~d}$, with harvest at ZT 3 . Bars represent arithmetic means \pm SD $(n=3$ technical replicates, i.e. independent PCR runs, each with three replicate wells per transcript) as calculated based on RT-qPCR. Data shown are representative of two independent experiments.

(G) SPL7 mRNA detection in the shoot apex by in situ RNA hybridization. Shown longitudinal sections through apices of wild-type plants cultivated in soil in short (SD) or long-day (LD) conditions. Inset shows a transverse section of a flower. Scale bars, $100 \mu \mathrm{m}$.

Different characters denote statistically significant differences between means ( $t$-tests with FDR adjustment; $q$-value < 0.05)(A, B, D-G). T6P: trehalose-6-phosphate. 


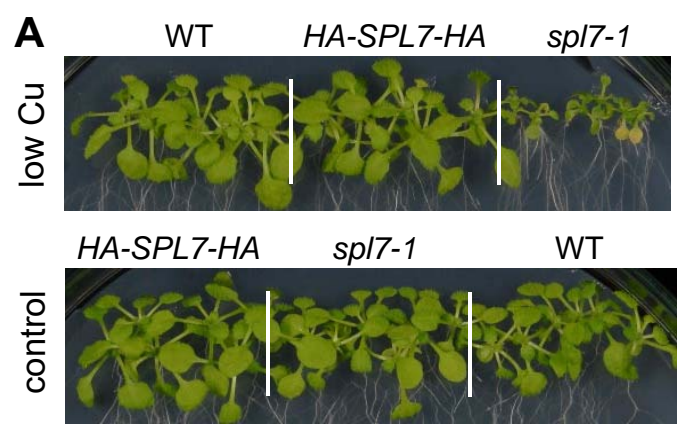

C

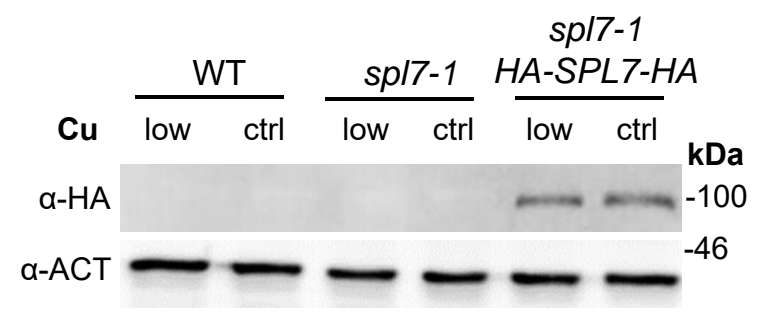

B

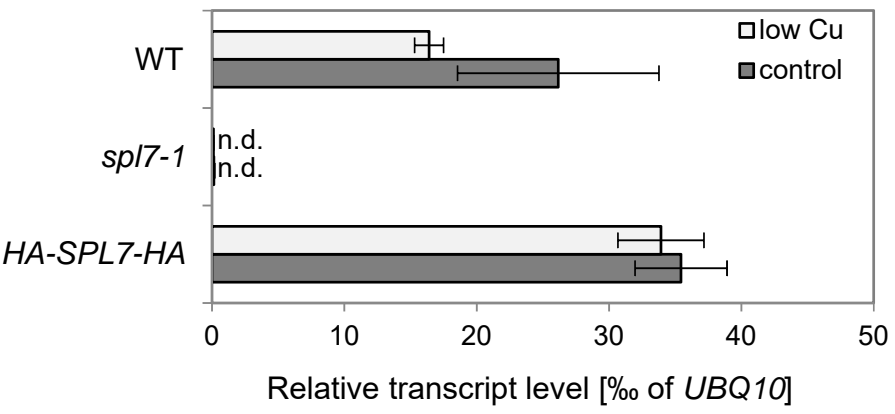

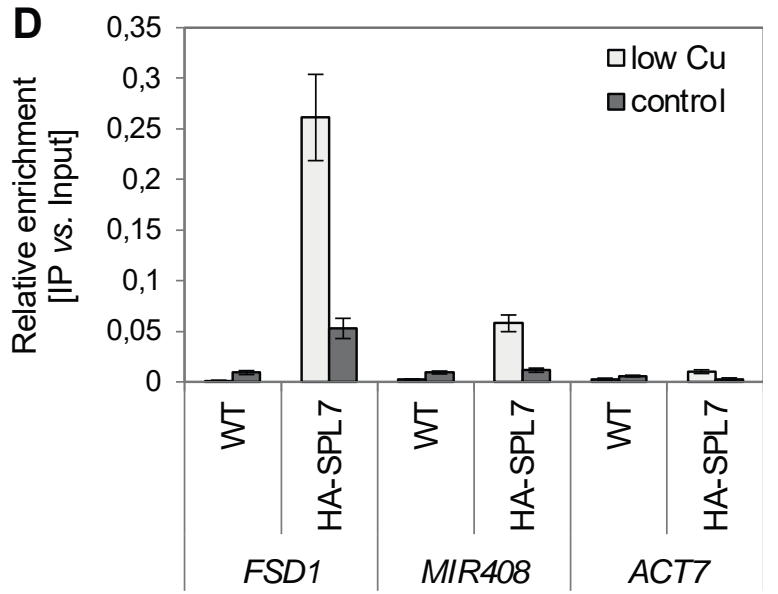

Figure 6. Complementation of the spl7-1 mutant through the $P_{S P L 7}: H A-S P L 7-H A: t_{S P L 7}$ transgene.

(A) Photographs of the wild type (WT), the spl7-1 mutant and the chosen transgenic homozygous spl7-1 $P_{S P L 7}:$ HA-SPL7-HA:t $t_{S P L 7}(H A-S P L 7-H A)$ line. Shown are 21-day-old seedlings cultivated in low-Cu (no $\mathrm{CuSO}_{4}$ added) or control $\left(0.5 \mu \mathrm{M} \mathrm{CuSO}_{4}\right.$ ) media supplemented with $1 \%(\mathrm{w} / \mathrm{v})$ sucrose and solidified with EDTA-washed agar in vertically oriented glass petri dishes.

(B) Relative transcript abundance of SPL7 according to RT-qPCR, in shoots of seedlings cultivated as described for (A). Bars represent arithmetic means $\pm S D(n=3$ technical replicates, i.e. independent PCR runs, each with three replicate wells per transcript). Data from two additional transgenic lines are shown in Supplemental Figure 9.

(C) Immunoblot detection of HA-SPL7-HA protein (expected at $\sim 90 \mathrm{kDa}$ ) in shoots of wild-type, sp/7-1 and HA-SPL7-HA seedlings cultivated as described for (A). PVDF membranes were stripped and reprobed with a-ACTIN (ACT) antibody (shown as a loading control). The full image and results from an independent experiment are shown in Supplemental Figure 10.

(D) Validation of ChIP using ChIP-qPCR of previously implicated direct target genes of SPL7. Bargraph shows relative DNA enrichment of the promoter regions of putative target FSD1, MIR408 as a positive control gene, as well as ACT7 (negative control gene), quantified by ChIP qPCR on immunoprecipitation (IP) and input samples. Chromatin was isolated from shoot tissues of spl7-1 $P_{S P L 7} \because: H A-S P L 7-H A: t_{S P L 7}$ (HA-SPL7) and wild-type seedlings (WT, negative control), cultivated as described for (A). Input samples represent aliquots taken after chromatin shearing and before the addition of $\alpha-\mathrm{HA}$ for the IP. 

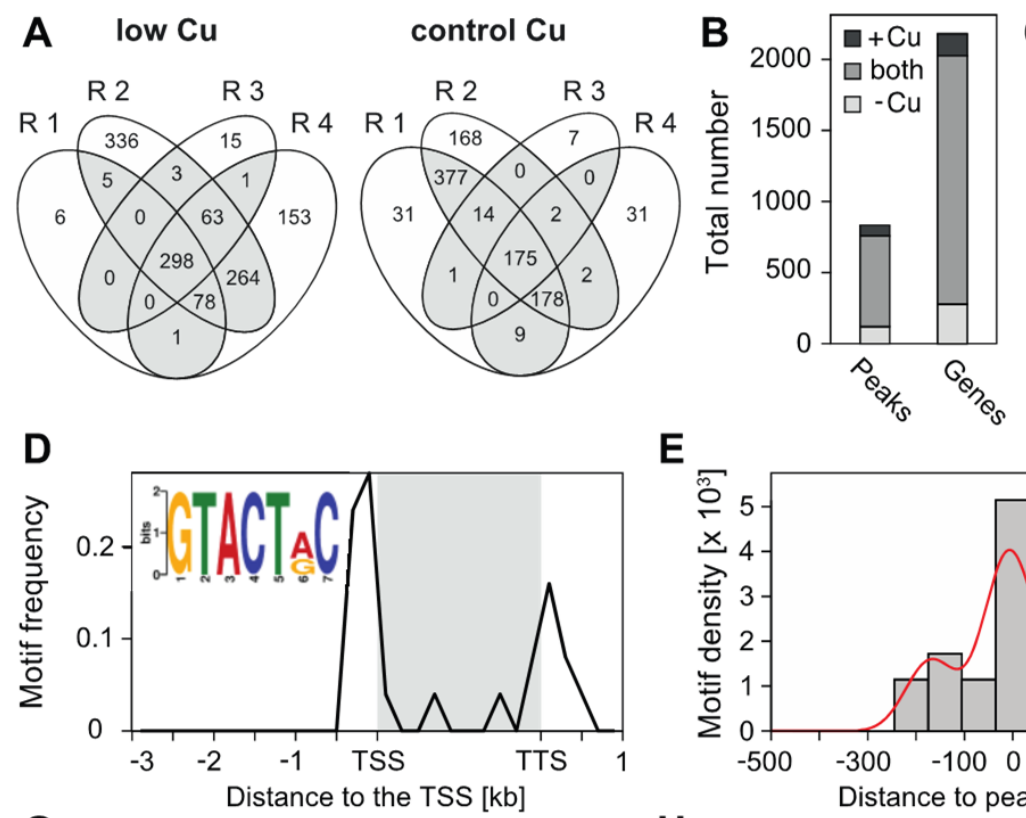

G

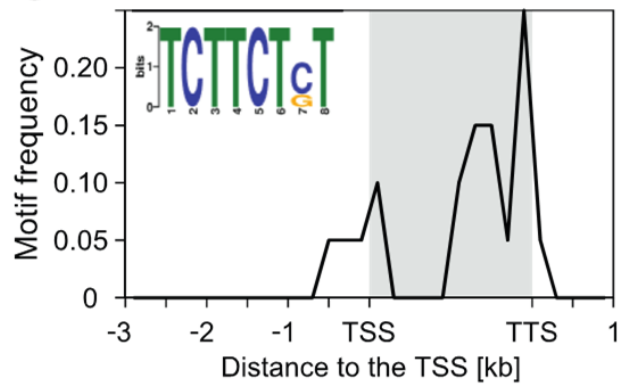

E

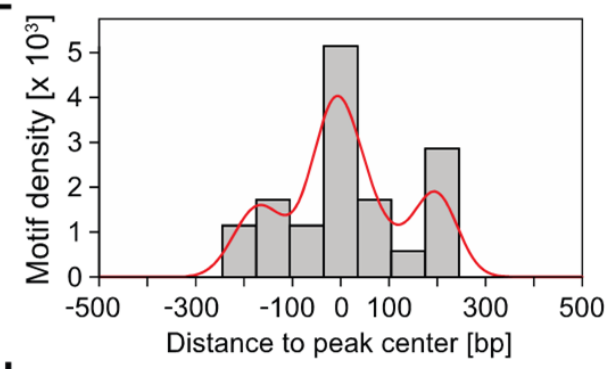

H

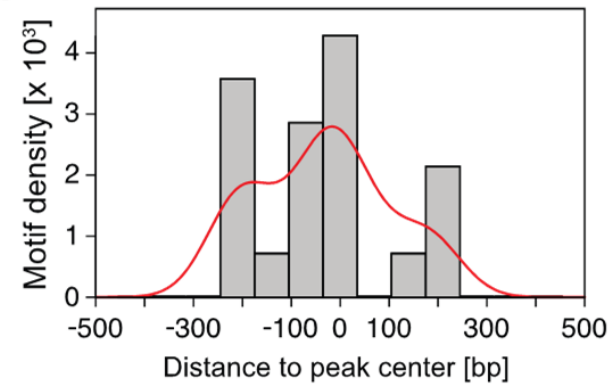

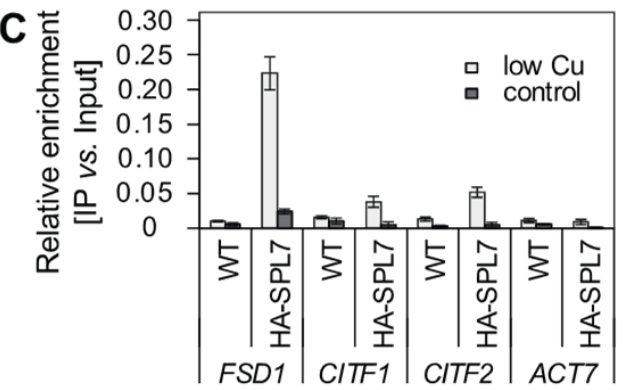

$\mathbf{F}$

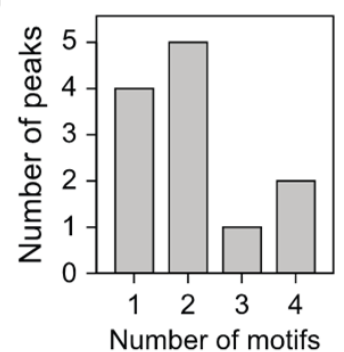

I

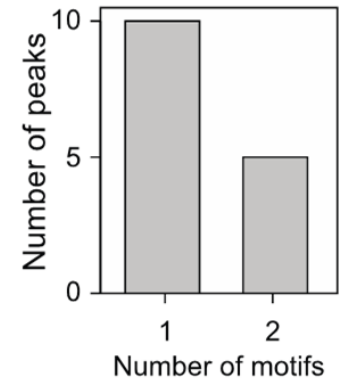

Figure 7. Genome-wide identification of SPL7 binding sites.

(A) Venn diagrams showing the reproducibility of results. Given are the numbers of SPL7-binding segments (peaks) identified genome-wide by sequencing chromatin immunoprecipitates (ChIP-seq) in each of 4 independent experiments (as replicates, R). ChIP-seq was conducted on shoots of 21-d-old seedlings cultivated on control $(0.5 \mu \mathrm{M} \mathrm{Cu})$ and low-Cu (no Cu added) media supplemented with $1 \%(\mathrm{w} / \mathrm{v})$ sucrose and solidified with EDTA-washed agar in vertically oriented glass petri dishes.

(B) Bargraph showing the numbers of genomic SPL7-binding segments identified by ChIP-seq (shown on a grey background in $\mathrm{A}$ ) and associated gene loci.

(C) Validation of ChIP-seq results by ChIP-qPCR. Bargraph shows relative DNA enrichment of the promoter regions of novel candidates FSD1, CITF1, CITF2 (bHLH23), and ACTIN7 (ACT7) as a negative control, quantified by ChIP-qPCR on immunoprecipitation (IP) and input samples. Chromatin was isolated from shoots of spl7-1 $P_{S P L 7}: \because H A-S P L 7-H A: t_{S P L 7}$ (HA-SPL7) and wild-type seedlings (WT, negative control) cultivated as described for $(A)$. Input samples represent aliquots taken after chromatin shearing and before the addition of $\alpha-\mathrm{HA}$ for the IP. See Supplemental Figure 12C, D for two additional independent experiments.

(D-I) The GTACTRG motif (D-F, E-value $=8.20 \times 10^{-3}, 21$ motif sites) and the TCTTCTST motif (G-I, Evalue $=3.40 \times 10^{-2}, 19$ motif sites) identified by MEME motif analysis. Motif frequency positional distribution (200 bp bin size), with conservation logo generated by MEME as an inset (D, G). Density plot summarizing distances of motif from center of peaks from ChIP-seq (75 bp bin size)(E, H). Bargraph showing motif copy numbers within single peaks $(\mathbf{F}, \mathbf{I})$.

The gene body (grey box) of all corresponding genes was normalized to $2,000 \mathrm{bp}(\mathrm{D}, \mathrm{G})$. The red line visualizes the shape of the distribution $(E, H)$. TSS: transcriptional start site, TTS: transcriptional termination site (positions from $A$. thaliana TAIR10 genome annotation). 


\section{Parsed Citations}

Abdel-Ghany, S.E., and Pilon, M. (2008). MicroRNA-mediated systemic down-regulation of copper protein expression in response to low copper availability in Arabidopsis. J Biol Chem 283, 15932-15945.

Google Scholar: Author Only Title Only Author and Title

Abdel-Ghany, S.E., Müller-Moulé, P., Niyogi, K.K., Pilon, M., and Shikanai, T. (2005). Two P-type ATPases are required for copper delivery in Arabidopsis thaliana chloroplasts. Plant Cell 17, 1233-1251.

Google Scholar: Author Only Title Only Author and Title

Assunção, AG.L., Herrero, E., Lin, Y.-F., Huettel, B., Talukdar, S., Smaczniak, C., Immink, R.G.H., van Eldik, M., Fiers, M., Schat, H., and Aarts, M.G.M. (2010). Arabidopsis thaliana transcription factors bZP19 and bZP23 regulate the adaptation to zinc deficiency. Proc Natl Acad Sci USA 107, 10296.

Google Scholar: Author Only Title Only Author and Title

Attallah, C.V., Welchen, E., Martin, AP., Spinelli, S.V., Bonnard, G., Palatnik, J.F., and Gonzalez, D.H. (2011). Plants contain two SCO proteins that are differentially involved in cytochrome c oxidase function and copper and redox homeostasis. J Exp Bot 62, 4281-4294.

Google Scholar: Author Only Title Only Author and Title

Azcón-Bieto, J., Lambers, H., and Day, D.A (1983). Effect of photosynthesis and carbohydrate status on respiratory rates and the involvement of the alternative pathway in leaf respiration. Plant Physiol 72, 598-603.

Google Scholar: Author Only Title Only Author and Title

Baena-Gonzalez, E., and Hanson, J. (2017). Shaping plant development through the SnRK1-TOR metabolic regulators. Curr Opin Plant Biol 35, $152-157$.

Google Scholar: Author Only Title Only Author and Title

Baena-González, E., Rolland, F., Thevelein, J.M., and Sheen, J. (2007). A central integrator of transcription networks in plant stress and energy signalling. Nature 448, 938.

Google Scholar: Author Only Title Only Author and Title

Bahr, J.T., and Bonner, W.D., Jr. (1973). Cyanide-insensitive respiration. II. Control of the alternate pathway. J Biol Chem 248, 34463450.

Google Scholar: Author Only Title Only Author and Title

Bailey, T.L., Boden, M., Buske, F.A, Frith, M., Grant, C.E., Clementi, L., Ren, J., Li, W.W., and Noble, W.S. (2009). MEME SUITE: tools for motif discovery and searching. Nucleic Acids Res 37, W202-208.

Google Scholar: Author Only Title Only Author and Title

Becher, M., Talke, I.N., Krall, L., and Krämer, U. (2004). Cross-species microarray transcript profiling reveals high constitutive expression of metal homeostasis genes in shoots of the zinc hyperaccumulator Arabidopsis halleri. Plant J 37, 251-268.

Google Scholar: Author Only Title Only Author and Title

Benjamini, Y., and Hochberg, Y. (1995). Controlling the False Discovery Rate: APractical and Powerful Approach to Multiple Testing. Journal of the Royal Statistical Society: Series B (Methodological) 57, 289-300.

Google Scholar: Author Only Title Only Author and Title

Berardini, T.Z, Reiser, L., Li, D., Mezheritsky, Y., Muller, R., Strait, E., and Huala, E. (2015). The Arabidopsis information resource: Making and mining the "gold standard" annotated reference plant genome. Genesis 53, 474-485.

Google Scholar: Author Only Title Only Author and Title

Bernal, M., Casero, D., Singh, V., Wilson, G.T., Grande, A, Yang, H., Dodani, S.C., Pellegrini, M., Huijser, P., Connolly, E.L., Merchant, S.S., and Krämer, U. (2012). Transcriptome sequencing identifies SPL7-regulated copper acquisition genes FRO4/FRO5 and the copper dependence of iron homeostasis in Arabidopsis. Plant Cell 24, 738-761.

Google Scholar: Author Only Title Only Author and Title

Birkenbihl, R.P., Jach, G., Saedler, H., and Huijser, P. (2005). Functional dissection of the plant-specific SBP-domain: overlap of the DNAbinding and nuclear localization domains. J Mol Biol 352, 585-596.

Google Scholar: Author Only Title Only Author and Title

Blaby-Haas, C.E., Padilla-Benavides, T., Stube, R., Argüello, J.M., and Merchant, S.S. (2014). Evolution of a plant-specific copper chaperone family for chloroplast copper homeostasis. Proc Natl Acad Sci USA111, E5480-5487.

Google Scholar: Author Only Title Only Author and Title

Bolger, AM., Lohse, M., and Usadel, B. (2014). Trimmomatic: a flexible trimmer for Illumina sequence data. Bioinformatics 30, $2114-2120$.

Google Scholar: Author Only Title Only Author and Title

Cardon, G., Hohmann, S., Klein, J., Nettesheim, K., Saedler, H., and Huijser, P. (1999). Molecular characterisation of the Arabidopsis SBP-box genes. Gene 237, 91-104.

Google Scholar: Author Only Title Only Author and Title

Caspar, T., Huber, S.C., and Somerville, C. (1985). Atterations in Growth, Photosynthesis, and Respiration in a Starchless Mutant of Arabidopsis thaliana (L.) Deficient in Chloroplast Phosphoglucomutase Activity. Plant Physiol 79, 11-17. 
Chao, L.M., Liu, Y.Q., Chen, D.Y., Xue, X.Y., Mao, Y.B., and Chen, X.Y. (2017). Arabidopsis Transcription Factors SPL1 and SPL12

Confer Plant Thermotolerance at Reproductive Stage. Mol Plant 10, 735-748.

Google Scholar: Author Only Title Only Author and Title

Cheng, C.Y., Krishnakumar, V., Chan, AP., Thibaud-Nissen, F., Schobel, S., and Town, C.D. (2017). Araport11: a complete reannotation of the Arabidopsis thaliana reference genome. Plant J 89, 789-804.

Google Scholar: Author Only Title Only Author and Title

Cho, Y.H., Yoo, S.D., and Sheen, J. (2006). Regulatory functions of nuclear hexokinase1 complex in glucose signaling. Cell 127, 579589.

Google Scholar: Author Only Title Only Author and Title

Clemens, S. (2001). Molecular mechanisms of plant metal tolerance and homeostasis. Planta 212, 475-486.

Google Scholar: Author Only Title Only Author and Title

Clough, S.J., and Bent, AF. (1998). Floral dip: a simplified method for Agrobacterium-mediated transformation of Arabidopsis thaliana. Plant J 16, 735-743.

Google Scholar: Author Only Title Only Author and Title

Colangelo, E.P., and Guerinot, M.L. (2004). The Essential Basic Helix-Loop-Helix Protein FIT1 Is Required for the Iron Deficiency Response. Plant Cell 16, 3400.

Google Scholar: Author Only Title Only Author and Title

Cui, L.-G., Shan, J.-X., Shi, M., Gao, J.-P., and Lin, H.-X. (2014). The miR156-SPL9-DFR pathway coordinates the relationship between development and abiotic stress tolerance in plants. Plant $\mathrm{J}$ 80, 1108-1117.

Google Scholar: Author Only Title Only Author and Title

Dahan, J., Tcherkez, G., Macherel, D., Benamar, A, Belcram, K., Quadrado, M., Arnal, N., and Mireau, H. (2014). Disruption of the CYTOCHROME C OXIDASE DEFICIENT1 gene leads to cytochrome c oxidase depletion and reorchestrated respiratory metabolism in Arabidopsis. Plant Physiol 166, 1788-1802.

Google Scholar: Author Only Title Only Author and Title

Deprost, D., Yao, L., Sormani, R., Moreau, M., Leterreux, G., Nicolaï, M., Bedu, M., Robaglia, C., and Meyer, C. (2007). The Arabidopsis TOR kinase links plant growth, yield, stress resistance and mRNA translation. EMBO Rep 8, 864-870.

Google Scholar: Author Only Title Only Author and Title

Dobrenel, T., Mancera-Martínez, E., Forzani, C., Azzopardi, M., Davanture, M., Moreau, M., Schepetilnikov, M., Chicher, J., Langella, O., Zvy, M., Robaglia, C., Ryabova, L.A, Hanson, J., and Meyer, C. (2016). The Arabidopsis TOR Kinase Specifically Regulates the Expression of Nuclear Genes Coding for Plastidic Ribosomal Proteins and the Phosphorylation of the Cytosolic Ribosomal Protein S6. Front Plant Sci 7, 1611-1611.

Google Scholar: Author Only Title Only Author and Title

Dong, J., Kim, S.T., and Lord, E.M. (2005). Plantacyanin Plays a Role in Reproduction in Arabidopsis. Plant Physiol $138,778$.

Google Scholar: Author Only Title Only Author and Title

Dong, Y., Silbermann, M., Speiser, A, Forieri, I., Linster, E., Poschet, G., Alboje Samami, A, Wanatabe, M., Sticht, C., Teleman, AA, Deragon, J.M., Saito, K., Hell, R., and Wirtz, M. (2017). Sulfur availability regulates plant growth via glucose-TOR signaling. Nat Commun 8, 1174.

Google Scholar: Author Only Title Only Author and Title

Figueroa, C.M., and Lunn, J.E. (2016). A Tale of Two Sugars: Trehalose 6-Phosphate and Sucrose. Plant Physiol $172,7-27$. Google Scholar: Author Only Title Only Author and Title

Figueroa, C.M., Feil, R., Ishihara, H., Watanabe, M., Kölling, K., Krause, U., Höhne, M., Encke, B., Plaxton, W.C., Zeeman, S.C., Li, Z, Schulze, W.X., Hoefgen, R., Stitt, M., and Lunn, J.E. (2016). Trehalose 6-phosphate coordinates organic and amino acid metabolism with carbon availability. Plant $\mathrm{J} 85,410-423$.

Google Scholar: Author Only Title Only Author and Title

Foster, AW., Osman, D., and Robinson, N.J. (2014). Metal Preferences and Metallation. J Biol Chem 289, $28095-28103$.

Google Scholar: Author Only Title Only Author and Title

Fraústo da Silva, J.J.R., and Williams, R.J.P. (2001). The Biological Chemistry of the Elements. (Oxford, UK: Oxford University Press). Google Scholar: Author Only Title Only Author and Title

Garcia-Molina, A, Xing, S., and Huijser, P. (2014a). Aconserved KIN17 curved DNA-binding domain protein assembles with SQUAMOSA PROMOTER-BINDING PROTEIN-LIKE7 to adapt Arabidopsis growth and development to limiting copper availability. Plant Physiol 164, 828-840.

Google Scholar: Author Only Title Only Author and Title

Garcia-Molina, A, Xing, S., and Huijser, P. (2014b). Functional characterisation of Arabidopsis SPL7 conserved protein domains suggests novel regulatory mechanisms in the Cu deficiency response. BMC Plant Biol 14, 231.

Google Scholar: Author Only Title Only Author and Title 
Garcia, L., Welchen, E., Gey, U., Arce, AL., Steinebrunner, I., and Gonzalez, D.H. (2016). The cytochrome c oxidase biogenesis factor AtCOX17 modulates stress responses in Arabidopsis. Plant Cell Environ 39, 628-644.

Google Scholar: Author Only Title Only Author and Title

Gendrel, A-V., Lippman, Z, Yordan, C., Colot, V., and Martienssen, R.A (2002). Dependence of Heterochromatic Histone H3

Methylation Patterns on the Arabidopsis Gene DDM1. Science 297, 1871-1873.

Google Scholar: Author Only Title Only Author and Title

Gibon, Y., Bläsing, O.E., Palacios-Rojas, N., Pankovic, D., Hendriks, J.H., Fisahn, J., Hohne, M., Gunther, M., and Stitt, M. (2004).

Adjustment of diurnal starch turnover to short days: depletion of sugar during the night leads to a temporary inhibition of carbohydrate utilization, accumulation of sugars and post-translational activation of ADP-glucose pyrophosphorylase in the following light period.

Plant J 39, 847-862.

Google Scholar: Author Only Title Only Author and Title

He, J., Xu, M., Willmann, M.R., McCormick, K., Hu, T., Yang, L., Starker, C.G., Voytas, D.F., Meyers, B.C., and Poethig, R.S. (2018). Threshold-dependent repression of SPL gene expression by miR156/miR157 controls vegetative phase change in Arabidopsis thaliana. PLOS Genet 14, e1007337.

Google Scholar: Author Only Title Only Author and Title

Heim, M.A, Jakoby, M., Werber, M., Martin, C., Weisshaar, B., and Bailey, P.C. (2003). The basic helix-loop-helix transcription factor family in plants: a genome-wide study of protein structure and functional diversity. Mol Biol Evol 20, 735-747.

Google Scholar: Author Only Title Only Author and Title

Heineke, D., Riens, B., Grosse, H., Hoferichter, P., Peter, U., Flügge, U.I., and Heldt, H.W. (1991). Redox Transfer across the Inner Chloroplast Envelope Membrane. Plant Physiol 95, 1131-1137.

Google Scholar: Author Only Title Only Author and Title

Hemschemeier, A, Casero, D., Liu, B., Benning, C., Pellegrini, M., Happe, T., and Merchant, S.S. (2013). Copper response regulator1dependent and -independent responses of the Chlamydomonas reinhardtii transcriptome to dark anoxia. Plant Cell 25, 3186-3211.

Google Scholar: Author Only Title Only Author and Title

Hsieh, L.-C., Lin, S.-I., Shih, AC.-C., Chen, J.-W., Lin, W.-Y., Tseng, C.-Y., Li, W.-H., and Chiou, T.-J. (2009). Uncovering Small RNA Mediated Responses to Phosphate Deficiency in Arabidopsis by Deep Sequencing. Plant Physiol 151, 2120.

Google Scholar: Author Only Title Only Author and Title

Hyun, Y., Richter, R., Vincent, C., Martinez-Gallegos, R., Porri, A, and Coupland, G. (2016). Multi-layered Regulation of SPL15 and Cooperation with SOC1 Integrate Endogenous Flowering Pathways at the Arabidopsis Shoot Meristem Dev Cell 37, 254-266.

Google Scholar: Author Only Title Only Author and Title

Journet, E.-P., Neuburger, M., and Douce, R. (1981). Role of Glutamate-oxaloacetate Transaminase and Malate Dehydrogenase in the Regeneration of NAD+ for Glycine Oxidation by Spinach leaf Mitochondria. Plant Physiol 67, 467-469.

Google Scholar: Author Only Title Only Author and Title

Kadenbach, B., Huttemann, M., Arnold, S., Lee, I., and Bender, E. (2000). Mitochondrial energy metabolism is regulated via nuclearcoded subunits of cytochrome c oxidase. Free Radic Biol Med 29, 211-221.

Google Scholar: Author Only Title Only Author and Title

Kim, D., Paggi, J.M., Park, C., Bennett, C., and Salzberg, S.L. (2019). Graph-based genome alignment and genotyping with HISAT2 and HISAT-genotype. Nat Biotechnol 37, 907-915.

Google Scholar: Author Only Title Only Author and Title

Kim, S., Mollet, J.-C., Dong, J., Zhang, K., Park, S.-Y., and Lord, E.M. (2003). Chemocyanin, a small basic protein from the lily stigma, induces pollen tube chemotropism. Proc Natl Acad Sci USA 100, 16125.

Google Scholar: Author Only Title Only Author and Title

Krämer, U., and Clemens, S. (2005). Functions and homeostasis of zinc, copper, and nickel in plants. In Molecular Biology of Metal Homeostasis and Detoxification, M.J. Tamás and E. Martinoia, eds (Springer Berlin Heidelberg New York), pp. 216-271.

Google Scholar: Author Only Title Only Author and Title

Kropat, J., Tottey, S., Birkenbihl, R.P., Depege, N., Huijser, P., and Merchant, S.S. (2005). A regulator of nutritional copper signaling in Chlamydomonas is an SBP domain protein that recognizes the GTAC core of copper response element. Proc Natl Acad Sci USA 102, 18730-18735.

Google Scholar: Author Only Title Only Author and Title

Kropat, J., Gallaher, S.D., Urzica, E.I., Nakamoto, S.S., Strenkert, D., Tottey, S., Mason, AZ, and Merchant, S.S. (2015). Copper economy in Chlamydomonas: prioritized allocation and reallocation of copper to respiration vs. photosynthesis. Proc Natl Acad Sci USA112, 2644-2651.

Google Scholar: Author Only Title Only Author and Title

Lambers, H. (1982). Cyanide-resistant respiration: Anon-phosphorylating electron transport pathway acting as an energy overflow. Physiol Plant 55, 478-485.

Google Scholar: Author Only Title Only Author and Title 

available under aCC-BY-NC 4.0 International license.

Lamesch, P., Berardini, T.Z, Li, D., Swarbreck, D., Wilks, C., Sasidharan, R., Muller, R., Dreher, K., Alexander, D.L., Garcia-Hernandez, M., Karthikeyan, AS., Lee, C.H., Nelson, W.D., Ploetz, L., Singh, S., Wensel, A, and Huala, E. (2012). The Arabidopsis Information Resource (TAR): improved gene annotation and new tools. Nucleic Acids Res 40, D1202-1210.

Google Scholar: Author Only Title Only Author and Title

Lampropoulos, A, Sutikovic, Z, Wenzl, C., Maegele, I., Lohmann, J.U., and Forner, J. (2013). GreenGate - ANovel, Versatile, and Efficient Cloning System for Plant Transgenesis. PLoS One 8, e83043.

Google Scholar: Author Only Title Only Author and Title

Langmead, B., and Salzberg, S.L. (2012). Fast gapped-read alignment with Bowtie 2. Nat Methods 9, $357-359$.

Google Scholar: Author Only Title Only Author and Title

Langmead, B., Trapnell, C., Pop, M., and Salzberg, S.L. (2009). Ultrafast and memory-efficient alignment of short DNA sequences to the human genome. Genome Biol 10, R25.

Google Scholar: Author Only Title Only Author and Title

Lappe, R.R., Baier, J.W., Boehlein, S.K., Huffman, R., Lin, Q., Wattebled, F., Settles, AM., Hannah, L.C., Borisjuk, L., Rolletschek, H., Stewart, J.D., Scott, M.P., Hennen-Bierwagen, T.A, and Myers, AM. (2018). Functions of maize genes encoding pyruvate phosphate dikinase in developing endosperm. Proc Natl Acad Sci USA115, E24-E33.

Google Scholar: Author Only Title Only Author and Title

Larronde, F., Krisa, S., Decendit, A, Chèze, C., Deffieux, G., and Mérillon, J.M. (1998). Regulation of polyphenol production in Vitis vinifera cell suspension cultures by sugars. Plant Cell Reports 17, 946-950.

Google Scholar: Author Only Title Only Author and Title

Lejay, L., Wirth, J., Pervent, M., Cross, J.M., Tillard, P., and Gojon, A (2008). Oxidative pentose phosphate pathway-dependent sugar sensing as a mechanism for regulation of root ion transporters by photosynthesis. Plant Physiol 146, $2036-2053$.

Google Scholar: Author Only Title Only Author and Title

Lejay, L., Gansel, X., Cerezo, M., Tillard, P., Muller, C., Krapp, A, von Wiren, N., Daniel-Vedele, F., and Gojon, A (2003). Regulation of root ion transporters by photosynthesis: functional importance and relation with hexokinase. Plant Cell 15, $2218-2232$.

Google Scholar: Author Only Title Only Author and Title

Li, L., and Sheen, J. (2016). Dynamic and diverse sugar signaling. Curr Opin Plant Biol 33, 116-125.

Google Scholar: Author Only Title Only Author and Title

Li, X., Zhang, H., Ai, Q., Liang, G., and Yu, D. (2016). Two bHLH Transcription Factors, bHLH34 and bHLH104, Regulate Iron Homeostasis in Arabidopsis thaliana. Plant Physiol 170, 2478-2493.

Google Scholar: Author Only Title Only Author and Title

Liang, G., Zhang, H., Li, X., Ai, Q., and Yu, D. (2017). bHLH transcription factor bHLH115 regulates iron homeostasis in Arabidopsis thaliana. J Exp Bot 68, 1743-1755.

Google Scholar: Author Only Title Only Author and Title

Liu, Y., Duan, X., Zhao, X., Ding, W., Wang, Y., and Xiong, Y. (2021). Diverse nitrogen signals activate convergent ROP2-TOR signaling in Arabidopsis. Dev Cell 56, 1283-1295 e1285.

Google Scholar: Author Only Title Only Author and Title

Love, M.I., Huber, W., and Anders, S. (2014). Moderated estimation of fold change and dispersion for RNAseq data with DESeq2.

Genome Biol 15, 550.

Google Scholar: Author Only Title Only Author and Title

Lunn, J.E., Feil, R., Hendriks, J.H.M., Gibon, Y., Morcuende, R., Osuna, D., Scheible, W.-R., Carillo, P., Hajirezaei, M.-R., and Stitt, M. (2006). Sugar-induced increases in trehalose 6-phosphate are correlated with redox activation of ADPglucose pyrophosphorylase and higher rates of starch synthesis in Arabidopsis thaliana. Biochem J 397, 139-148.

Google Scholar: Author Only Title Only Author and Title

Machanick, P., and Bailey, T.L. (2011). MEME-ChIP: motif analysis of large DNA datasets. Bioinformatics 27, $1696-1697$.

Google Scholar: Author Only Title Only Author and Title

Marschner, H., and Marschner, P. (2012). Marschner's mineral nutrition of higher plants. (London ; Waltham, MA: Elsevier/Academic Press).

Google Scholar: Author Only Title Only Author and Title

Martin, M. (2011). Cutadapt removes adapter sequences from high-throughput sequencing reads. EMBnet $\mathrm{J} 17,3$.

Google Scholar: Author Only Title Only Author and Title

Moehs, C.P., McElwain, E.F., and Spiker, S. (1988). Chromosomal proteins of Arabidopsis thaliana. Pant Mol Biol 11, 507-515.

Google Scholar: Author Only Title Only Author and Title

Møller, I.M., Bérczi, A, van der Plas, L.H.W., and Lambers, H. (1988). Measurement of the activity and capacity of the alternative pathway in intact plant tissues: Identification of problems and possible solutions. Physiol Plant 72, $642-649$.

Google Scholar: Author Only Title Only Author and Title 
bioRxiv preprint doi: https://doi.org/10.1101/2021.09.17.460807; this version posted September 20, 2021. The copyright holder for this preprint (which was not certified by peer review) is the author/funder, who has granted bioRxiv a license to display the preprint in perpetuity. It is made available under aCC-BY-NC 4.0 International license.

Nunes, C., Primavesi, L.F., Patel, M.K., Martinez-Barajas, E., Powers, S.J., Sagar, R., Fevereiro, P.S., Davis, B.G., and Paul, M.J. (2013a). Inhibition of SnRK1 by metabolites: Tissue-dependent effects and cooperative inhibition by glucose 1-phosphate in combination with trehalose 6-phosphate. Plant Physiol Biochem 63, 89-98.

Google Scholar: Author Only Title Only Author and Title

Nunes, C., O'Hara, L.E., Primavesi, L.F., Delatte, T.L., Schluepmann, H., Somsen, G.W., Silva, AB., Fevereiro, P.S., Wingler, A, and Paul, M.J. (2013b). The Trehalose 6-Phosphate/SnRK1 Signaling Pathway Primes Growth Recovery following Relief of Sink Limitation. Plant Physiol 162, 1720.

Google Scholar: Author Only Title Only Author and Title

O'Leary, B.M., Asao, S., Millar, AH., and Atkin, Owen K. (2019). Core principles which explain variation in respiration across biological scales. New Phytol 222, 670-686.

Google Scholar: Author Only Title Only Author and Title

O'Malley, R.C., Huang, S.C., Song, L., Lewsey, M.G., Bartlett, A, Nery, J.R., Galli, M., Gallavotti, A, and Ecker, J.R. (2016). Cistrome and Epicistrome Features Shape the Regulatory DNALandscape. Cell 165, 1280-1292.

Google Scholar: Author Only Title Only Author and Title

Okonechnikov, K., Conesa, A, and Garcia-Alcalde, F. (2016). Qualimap 2: advanced multi-sample quality control for high-throughput sequencing data. Bioinformatics 32, 292-294.

Google Scholar: Author Only Title Only Author and Title

Pietzenuk, B., Markus, C., Gaubert, H., Bagwan, N., Merotto, A, Bucher, E., and Pecinka, A (2016). Recurrent evolution of heatresponsiveness in Brassicaceae COPIAelements. Genome Biol 17, 209.

Google Scholar: Author Only Title Only Author and Title

Ponnu, J., Schlereth, A, Zacharaki, V., Dzialo, M.A, Abel, C., Feil, R., Schmid, M., and Wahl, V. (2020). The trehalose 6-phosphate pathway impacts vegetative phase change in Arabidopsis thaliana. Plant J 104, 768-780.

Google Scholar: Author Only Title Only Author and Title

Quinn, J.M., and Merchant, S.S. (1995). Two copper-responsive elements associated with the Chlamydomonas Cyc6 gene function as targets for transcriptional activators. Plant Cell 7, 623-628.

Google Scholar: Author Only Title Only Author and Title

R Core Team (2019). R: A language and environment for statistical computing. R Foundation for Statistical Computing, Vienna, Austria. Google Scholar: Author Only Title Only Author and Title

Rabino, I., and Mancinelli, AL. (1986). Light, Temperature, and Anthocyanin Production. Plant Physiol 81, $922-924$.

Google Scholar: Author Only Title Only Author and Title

Rae, T.D., Schmidt, P.J., Pufahl, R.A, Culotta, V.C., and O'Halloran, T.V. (1999). Undetectable intracellular free copper: the requirement of a copper chaperone for superoxide dismutase. Science $284, \mathbf{8 0 5 - 8 0 8 . ~}$

Google Scholar: Author Only Title Only Author and Title

Rahmati Ishka, M., and Vatamaniuk, O.K. (2020). Copper deficiency alters shoot architecture and reduces fertility of both gynoecium and androecium in Arabidopsis thaliana. Plant Direct 4, e00288.

Google Scholar: Author Only Title Only Author and Title

Ravet, K., Danford, F.L., Dihle, A, Pittarello, M., and Pilon, M. (2011). Spatiotemporal analysis of copper homeostasis in Populus trichocarpa reveals an integrated molecular remodeling for a preferential allocation of copper to plastocyanin in the chloroplasts of developing leaves. Plant Physiol 157, 1300-1312.

Google Scholar: Author Only Title Only Author and Title

Redinbo, M.R., Yeates, T.O., and Merchant, S. (1994). Plastocyanin: structural and functional analysis. J Bioenerg Biomembr 26, $49-66$. Google Scholar: Author Only Title Only Author and Title

Reimann, C., Birke, M., Demetriades, A, Filzmoser, P., and O'Connor, P. (2014). Chemistry of Europe's agricultural soils - Part A: Methodology and interpretation of the GEMAS data set. (Hannover: Schweizerbarth).

Google Scholar: Author Only Title Only Author and Title

Ren, L., and Tang, G. (2012). Identification of sucrose-responsive microRNAs reveals sucrose-regulated copper accumulations in an SPL7-dependent and independent manner in Arabidopsis thaliana. Plant Sci 187, 59-68.

Google Scholar: Author Only Title Only Author and Title

Robinson, N.J., and Winge, D.R. (2010). Copper metallochaperones. Annu Rev Biochem 79, 537-562.

Google Scholar: Author Only Title Only Author and Title

Roman, A, Li, X., Deng, D., Davey, J.W., James, S., Graham, I.A, and Haydon, M.J. (2021). Superoxide is promoted by sucrose and affects amplitude of circadian rhythms in the evening. Proc Natl Acad Sci USA118.

Google Scholar: Author Only Title Only Author and Title

Romera-Branchat, M., Severing, E., Pocard, C., Ohr, H., Vincent, C., Nee, G., Martinez-Gallegos, R., Jang, S., Andres, F., Madrigal, P., and Coupland, G. (2020). Functional Divergence of the Arabidopsis Florigen-Interacting bZP Transcription Factors FD and FDP. Cell 
Rep 32, 107966. available under aCC-BY-NC 4.0 International license.

Google Scholar: Author Only Title Only Author and Title

Schluepmann, H., Pellny, T., van Dijken, A, Smeekens, S., and Paul, M. (2003). Trehalose 6-phosphate is indispensable for carbohydrate utilization and growth in Arabidopsis thaliana. Proc Natl Acad Sci USA 100, 6849-6854.

Google Scholar: Author Only Title Only Author and Title

Schubert, M., Petersson, U.A, Haas, B.J., Funk, C., Schroder, W.P., and Kieselbach, T. (2002). Proteome map of the chloroplast lumen of Arabidopsis thaliana. J Biol Chem 277, 8354-8365.

Google Scholar: Author Only Title Only Author and Title

Schulten, A, Bytomski, L., Quintana, J., Bernal, M., and Kramer, U. (2019). Do Arabidopsis Squamosa promoter binding Protein-Like genes act together in plant acclimation to copper or zinc deficiency? Plant Direct 3, e00150.

Google Scholar: Author Only Title Only Author and Title

Schwarz, S., Grande, AV., Bujdoso, N., Saedler, H., and Huijser, P. (2008). The microRNA regulated SBP-box genes SPL9 and SPL15 control shoot maturation in Arabidopsis. Plant Mol Biol 67, 183-195.

Google Scholar: Author Only Title Only Author and Title

Shen, W., Wei, Y., Dauk, M., Tan, Y., Taylor, D.C., Selvaraj, G., and Zou, J. (2006). Involvement of a Glycerol-3-Phosphate Dehydrogenase in Modulating the NADH/NAD+ Ratio Provides Evidence of a Mitochondrial Glycerol-3-Phosphate Shuttle in Arabidopsis. Plant Cell 18, 422-441.

Google Scholar: Author Only Title Only Author and Title

Shikanai, T., Müller-Moulé, P., Munekage, Y., Niyogi, K.K., and Pilon, M. (2003). PAA1, a P-type ATPase of Arabidopsis, functions in copper transport in chloroplasts. Plant Cell 15, 1333-1346.

Google Scholar: Author Only Title Only Author and Title

Sinclair, S.A, Larue, C., Bonk, L., Khan, A, Castillo-Michel, H., Stein, R.J., Grolimund, D., Begerow, D., Neumann, U., Haydon, M.J., and Krämer, U. (2017). Etiolated Seedling Development Requires Repression of Photomorphogenesis by a Small Cell-Wall-Derived Dark Signal. Curr Biol 27, 3403-3418 e3407.

Google Scholar: Author Only Title Only Author and Title

Solfanelli, C., Poggi, A, Loreti, E., Alpi, A, and Perata, P. (2006). Sucrose-specific induction of the anthocyanin biosynthetic pathway in Arabidopsis. Plant Physiol 140, 637-646.

Google Scholar: Author Only Title Only Author and Title

Sommer, F., Kropat, J., Malasarn, D., Grossoehme, N.E., Chen, X., Giedroc, D.P., and Merchant, S.S. (2010). The CRR1 nutritional copper sensor in Chlamydomonas contains two distinct metal-responsive domains. Plant Cell 22, 4098-4113.

Google Scholar: Author Only Title Only Author and Title

Stief, A, Altmann, S., Hoffmann, K., Pant, B.D., Scheible, W.-R., and Bäurle, I. (2014). Arabidopsis miR156 Regulates Tolerance to Recurring Environmental Stress through SPL Transcription Factors. Plant Cell 26, 1792.

Google Scholar: Author Only Title Only Author and Title

Stone, J.M., Liang, X., Nekl, E.R., and Stiers, J.J. (2005). Arabidopsis AtSPL14, a plant-specific SBP-domain transcription factor, participates in plant development and sensitivity to fumonisin B1. Plant J 41, 744-754.

Google Scholar: Author Only Title Only Author and Title

Storey, J.D., Bass, AJ., Dabney, A, and Robinson, D. (2019). qvalue: Q-value estimation for false discovery rate control. R package version 2.14.1.

Google Scholar: Author Only Title Only Author and Title

Teng, S., Keurentjes, J., Bentsink, L., Koornneef, M., and Smeekens, S. (2005). Sucrose-specific induction of anthocyanin biosynthesis in Arabidopsis requires the MYB75/PAP1 gene. Plant Physiol 139, 1840-1852.

Google Scholar: Author Only Title Only Author and Title

Towbin, H., Staehelin, T., and Gordon, J. (1979). Electrophoretic transfer of proteins from polyacrylamide gels to nitrocellulose sheets: procedure and some applications. Proc Natl Acad Sci USA76, 4350-4354.

Google Scholar: Author Only Title Only Author and Title

Unte, U.S., Sorensen, A-M., Pesaresi, P., Gandikota, M., Leister, D., Saedler, H., and Huijser, P. (2003). SPL8, an SBP-box gene that affects pollen sac development in Arabidopsis. Plant Cell 15, 1009-1019.

Google Scholar: Author Only Title Only Author and Title

Urano, D., Phan, N., Jones, J.C., Yang, J., Huang, J., Grigston, J., Taylor, J.P., and Jones, AM. (2012). Endocytosis of the seventransmembrane RGS1 protein activates G-protein-coupled signalling in Arabidopsis. Nat Cell Biol 14, 1079-1088.

Google Scholar: Author Only Title Only Author and Title

Varkonyi-Gasic, E., Wu, R., Wood, M., Walton, E.F., and Hellens, R.P. (2007). Protocol: a highly sensitive RT-PCR method for detection and quantification of microRNAs. Plant Methods 3, 12.

Google Scholar: Author Only Title Only Author and Title

Wahl, V., Ponnu, J., Schlereth, A, Arrivault, S., Langenecker, T., Franke, A, Feil, R., Lunn, J.E., Stitt, M., and Schmid, M. (2013). 
bioRxiv preprint doi: https://doi.org/10.1101/2021.09.17.460807; this version posted September 20, 2021. The copyright holder for this preprint (which was not certified by peer review) is the author/funder, who has granted bioRxiv a license to display the preprint in perpetuity. It is made available under aCC-BY-NC 4.0 International license.

Regulation of flowering by trehalose-6-phosphate signaling in Arabidopsis thaliana. Science 339, $704-707$.

Google Scholar: Author Only Title Only Author and Title

Wang, H.-Y., Klatte, M., Jakoby, M., Bäumlein, H., Weisshaar, B., and Bauer, P. (2007). Iron deficiency-mediated stress regulation of four subgroup Ib BHLH genes in Arabidopsis thaliana. Planta 226, 897-908.

Google Scholar: Author Only Title Only Author and Title

Wang, J.-W., Schwab, R., Czech, B., Mica, E., and Weigel, D. (2008). Dual Effects of miR156-Targeted SPL Genes and CYP78A5/KLUH on Plastochron Length and Organ Size in Arabidopsis thaliana. Plant Cell 20, 1231.

Google Scholar: Author Only Title Only Author and Title

Wang, J., Zhou, L., Shi, H., Chern, M., Yu, H., Yi, H., He, M., Yin, J., Zhu, X., Li, Y., Li, W., Liu, J., Wang, J., Chen, X., Qing, H., Wang, Y., Liu, G., Wang, W., Li, P., Wu, X., Zhu, L., Zhou, J.-M., Ronald, P.C., Li, S., Li, J., and Chen, X. (2018). Asingle transcription factor promotes both yield and immunity in rice. Science $361,1026$.

Google Scholar: Author Only Title Only Author and Title

Wang, J.W., Czech, B., and Weigel, D. (2009). miR156-regulated SPL transcription factors define an endogenous flowering pathway in Arabidopsis thaliana. Cell 138, 738-749.

Google Scholar: Author Only Title Only Author and Title

Weigel, M., Varotto, C., Pesaresi, P., Finazzi, G., Rappaport, F., Salamini, F., and Leister, D. (2003). Plastocyanin is indispensable for photosynthetic electron flow in Arabidopsis thaliana. J Biol Chem 278, 31286-31289.

Google Scholar: Author Only Title Only Author and Title

Weiss, D. (2000). Regulation of flower pigmentation and growth: Multiple signaling pathways control anthocyanin synthesis in expanding petals. Physiol Plant 110, 152-157.

Google Scholar: Author Only Title Only Author and Title

Woeste, K.E., and Kieber, J.J. (2000). A strong loss-of-function mutation in RAN1 results in constitutive activation of the ethylene response pathway as well as a rosette-lethal phenotype. Plant Cell 12, 443-455.

Google Scholar: Author Only Title Only Author and Title

Wu, G., and Poethig, R.S. (2006). Temporal regulation of shoot development in Arabidopsis thaliana by miR156 and its target SPL3. Development 133, 3539-3547.

Google Scholar: Author Only Title Only Author and Title

Wu, G., Park, M.Y., Conway, S.R., Wang, J.W., Weigel, D., and Poethig, R.S. (2009). The sequential action of miR156 and miR172 regulates developmental timing in Arabidopsis. Cell 138, 750-759.

Google Scholar: Author Only Title Only Author and Title

Xing, S., Salinas, M., Hohmann, S., Berndtgen, R., and Huijser, P. (2010). miR156-targeted and nontargeted SBP-box transcription factors act in concert to secure male fertility in Arabidopsis. Plant Cell 22, 3935-3950.

Google Scholar: Author Only Title Only Author and Title

Xing, S., Salinas, M., Garcia-Molina, A, Hohmann, S., Berndtgen, R., and Huijser, P. (2013). SPL8 and miR156-targeted SPL genes redundantly regulate Arabidopsis gynoecium differential patterning. Plant J 75, 566-577.

Google Scholar: Author Only Title Only Author and Title

Xiong, Y., and Sheen, J. (2012). Rapamycin and glucose-target of rapamycin (TOR) protein signaling in plants. J Biol Chem 287, 28362842.

Google Scholar: Author Only Title Only Author and Title

Xiong, Y., McCormack, M., Li, L., Hall, Q., Xiang, C., and Sheen, J. (2013). Glucose-TOR signalling reprograms the transcriptome and activates meristems. Nature 496, 181-186.

Google Scholar: Author Only Title Only Author and Title

Xu, M., Hu, T., Zhao, J., Park, M.Y., Earley, K.W., Wu, G., Yang, L., and Poethig, R.S. (2016). Developmental Functions of miR156Regulated SQUAMOSAPROMOTER BINDING PROTEIN-LIKE (SPL) Genes in Arabidopsis thaliana. PLoS Genet 12, e1006263.

Google Scholar: Author Only Title Only Author and Title

Yamaguchi, A, Wu, M.F., Yang, L., Wu, G., Poethig, R.S., and Wagner, D. (2009). The microRNAregulated SBP-Box transcription factor SPL3 is a direct upstream activator of LEAFY, FRUITFULL, and APETALA1. Dev Cell 17, 268-278.

Google Scholar: Author Only Title Only Author and Title

Yamaguchi, N., Winter, C.M., Wu, M.-F., Kwon, C.S., William, D.A, and Wagner, D. (2014a). PROTOCOLS: Chromatin Immunoprecipitation from Arabidopsis Tissues. The Arabidopsis Book 12, e0170-e0170.

Google Scholar: Author Only Title Only Author and Title

Yamaguchi, N., Winter, C.M., Wu, M.F., Kanno, Y., Yamaguchi, A, Seo, M., and Wagner, D. (2014b). Gibberellin acts positively then negatively to control onset of flower formation in Arabidopsis. Science 344, 638-641.

Google Scholar: Author Only Title Only Author and Title

Yamasaki, H., Hayashi, M., Fukazawa, M., Kobayashi, Y., and Shikanai, T. (2009). SQUAMOSAPromoter Binding Protein-Like7 Is a 
Google Scholar: Author Only Title Only Author and Title

Yamasaki, H., Abdel-Ghany, S.E., Cohu, C.M., Kobayashi, Y., Shikanai, T., and Pilon, M. (2007). Regulation of copper homeostasis by micro-RNA in Arabidopsis. J Biol Chem 282, 16369-16378.

Google Scholar: Author Only Title Only Author and Title

Yan, J., Chia, J.-C., Sheng, H., Jung, H.-I., Zavodna, T.-O., Zhang, L., Huang, R., Jiao, C., Craft, E.J., Fei, Z, Kochian, L.V., and Vatamaniuk, O.K. (2017). Arabidopsis Pollen Fertility Requires the Transcription Factors CITF1 and SPL7 That Regulate Copper Delivery to Anthers and Jasmonic Acid Synthesis. Plant Cell 29, 3012-3029.

Google Scholar: Author Only Title Only Author and Title

Yang, L., Conway, S.R., and Poethig, R.S. (2011). Vegetative phase change is mediated by a leaf-derived signal that represses the transcription of miR156. Development 138, 245-249.

Google Scholar: Author Only Title Only Author and Title

Yang, L., Xu, M., Koo, Y., He, J., and Poethig, R.S. (2013). Sugar promotes vegetative phase change in Arabidopsis thaliana by repressing the expression of MIR156A and MIR156C. eLife 2, e00260.

Google Scholar: Author Only Title Only Author and Title

Yruela, I. (2013). Transition metals in plant photosynthesis. Metallomics 5, 1090-1109.

Google Scholar: Author Only Title Only Author and Title

Yu, N., Cai, W.-J., Wang, S., Shan, C.-M., Wang, L.-J., and Chen, X.-Y. (2010). Temporal Control of Trichome Distribution by MicroRNA156-Targeted SPL Genes in Arabidopsis thaliana. Plant Cell 22, 2322.

Google Scholar: Author Only Title Only Author and Title

Yu, S., Cao, L., Zhou, C.-M., Zhang, T.-Q., Lian, H., Sun, Y., Wu, J., Huang, J., Wang, G., and Wang, J.-W. (2013). Sugar is an endogenous cue for juvenile-to-adult phase transition in plants. eLife 2, e00269.

Google Scholar: Author Only Title Only Author and Title

Zhai, Z, Keereetaweep, J., Liu, H., Feil, R., Lunn, J.E., and Shanklin, J. (2018). Trehalose 6-Phosphate Positively Regulates Fatty Acid Synthesis by Stabilizing WRINKLED1. Plant Cell 30, 2616-2627.

Google Scholar: Author Only Title Only Author and Title

Zhang, H., and Li, L. (2013). SQUAMOSA promoter binding protein-like7 regulated microRNA408 is required for vegetative development in Arabidopsis. Plant J 74, 98-109.

Google Scholar: Author Only Title Only Author and Title

Zhang, H., Zhao, X., Li, J., Cai, H., Deng, X.W., and Li, L. (2014). MicroRNA408 is critical for the HY5-SPL7 gene network that mediates the coordinated response to light and copper. Plant Cell 26, 4933-4953.

Google Scholar: Author Only Title Only Author and Title

Zhang, Y., Primavesi, L.F., Jhurreea, D., Andralojc, P.J., Mitchell, R.AC., Powers, S.J., Schluepmann, H., Delatte, T., Wingler, A, and Paul, M.J. (2009). Inhibition of SNF1-Related Protein Kinase1 Activity and Regulation of Metabolic Pathways by Trehalose-6-Phosphate. Plant Physiol 149, 1860-1871.

Google Scholar: Author Only Title Only Author and Title

Zhang, Y., Liu, T., Meyer, C.A, Eeckhoute, J., Johnson, D.S., Bernstein, B.E., Nusbaum, C., Myers, R.M., Brown, M., Li, W., and Liu, X.S. (2008). Model-based Analysis of ChIP-Seq (MACS). Genome Biol 9, R137.

Google Scholar: Author Only Title Only Author and Title 